
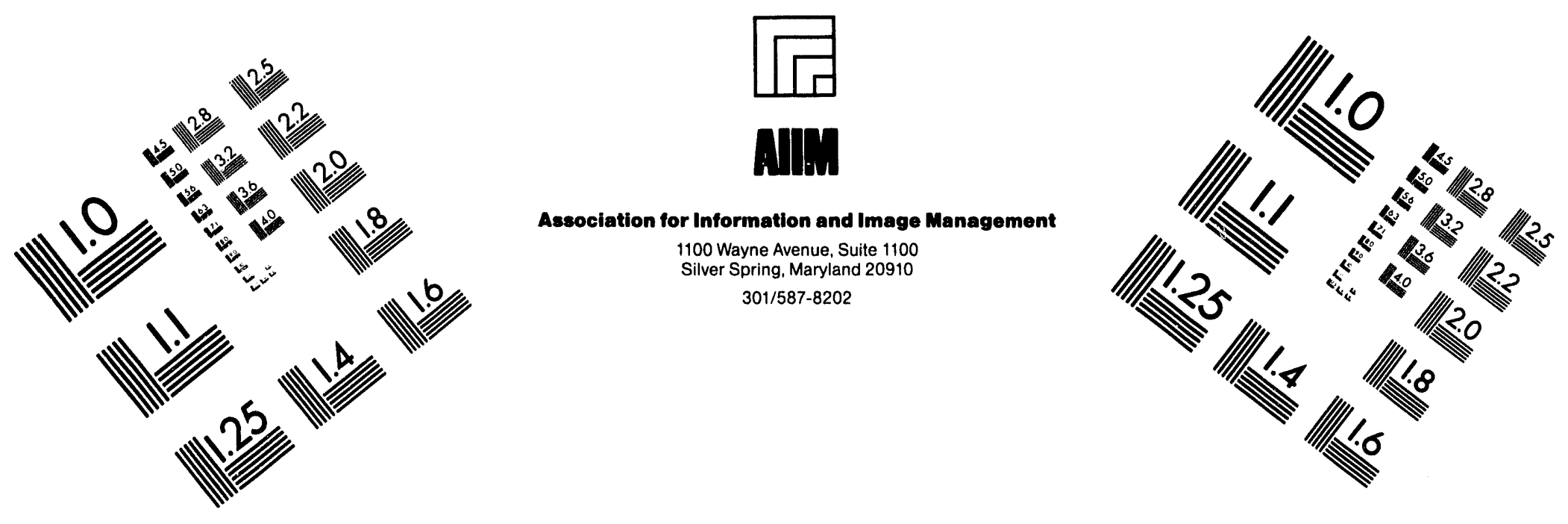

\title{
Centimeter
}

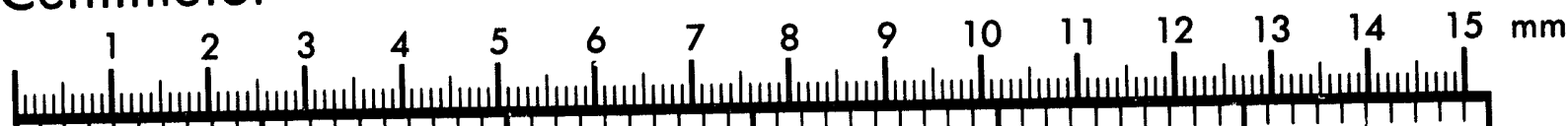

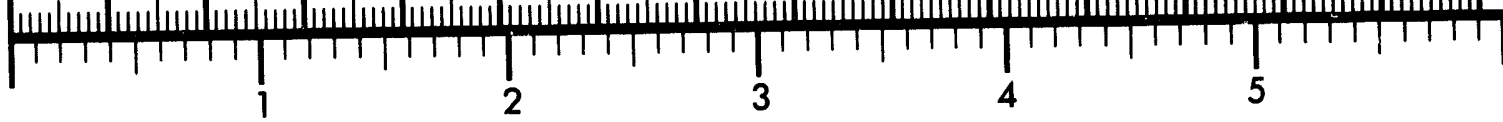
Inches
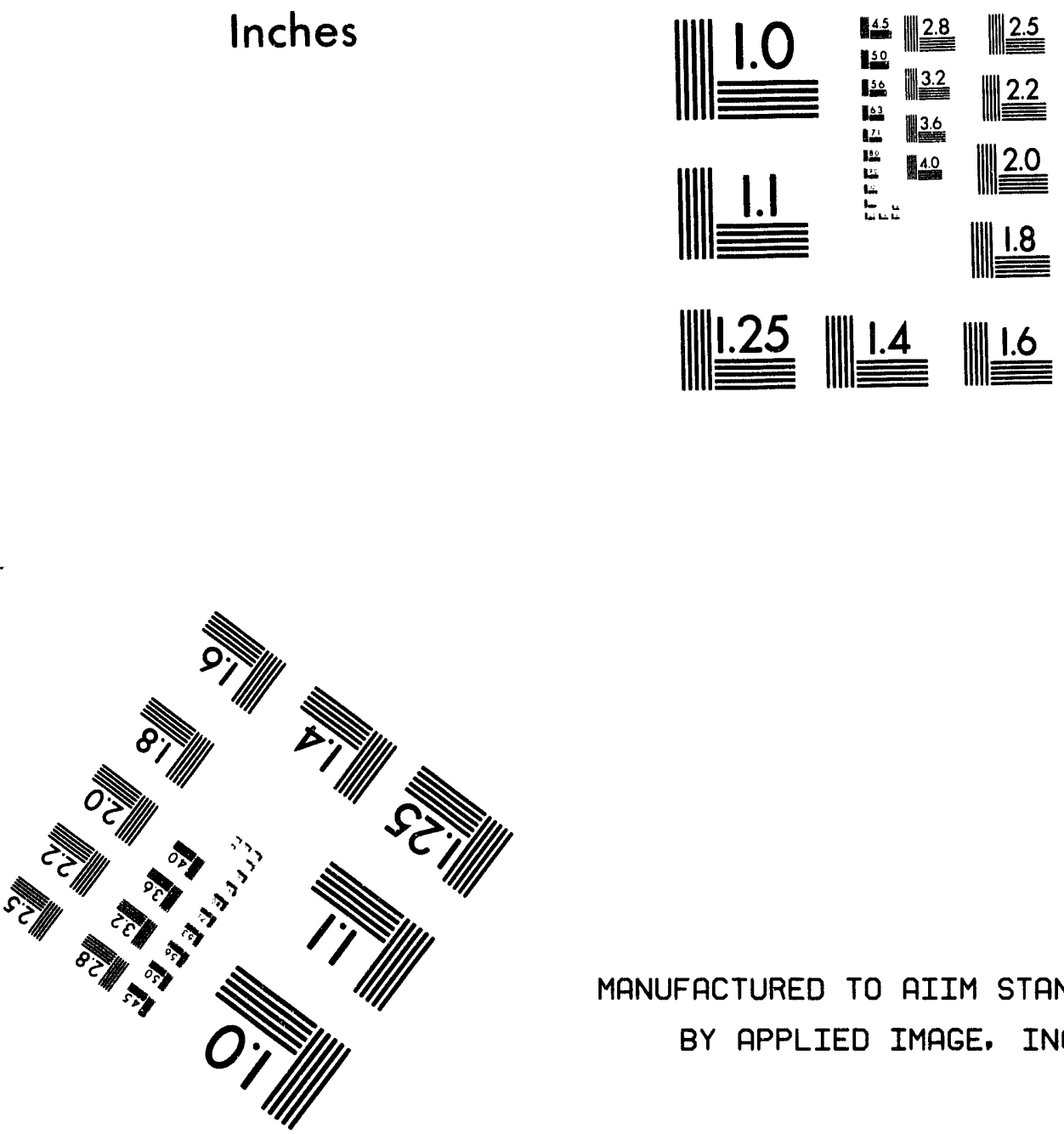

MANUFACTURED TO AIIM STANDARDS

BY APPLIED IMAGE, INC.

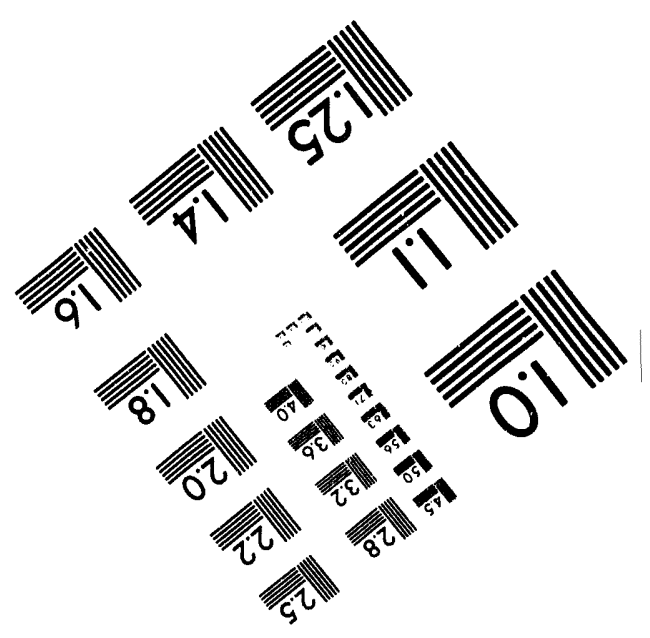



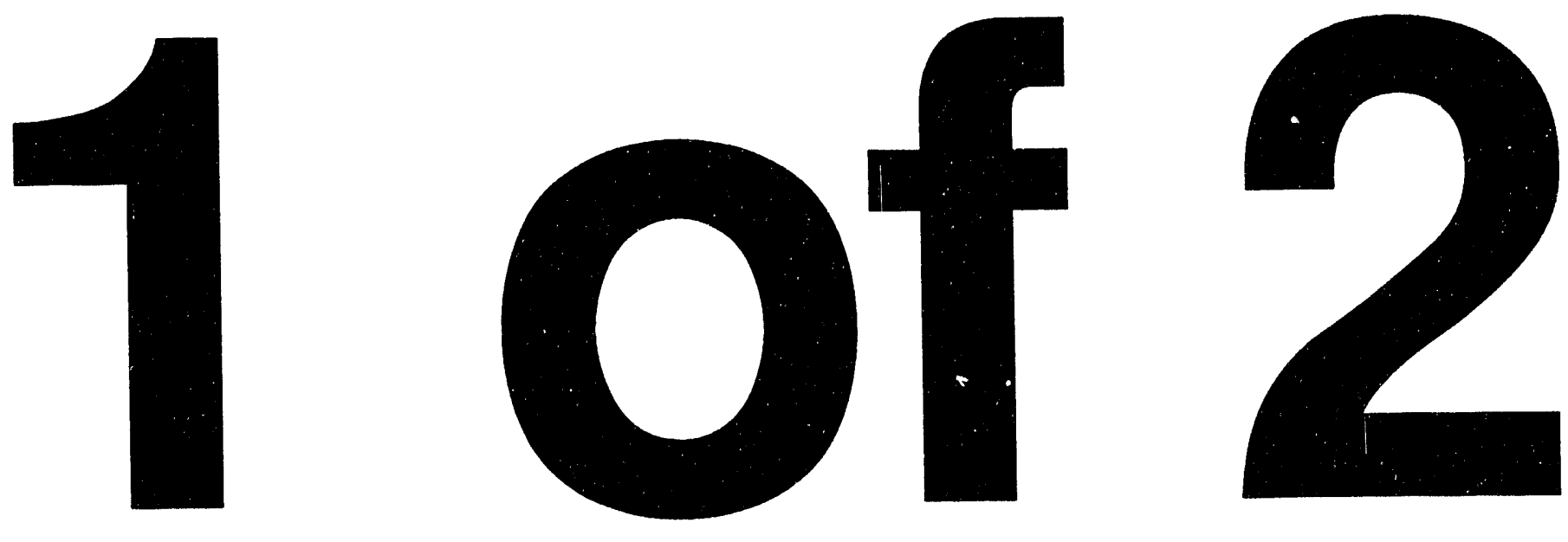


\section{SIMPLEV: A SIMPLE ELECTRIC VEHICLE SIMULATION PROGRAM VERSION 1.0}

G. H. Cole

June 1991

EG\&G Idaho, Inc.

Idaho Falls, Idaho 83415

Prepared for the

u. 8. Department of Energy

Field office, Idaho

Under contract NO. DE-AC07-76ID01570

TOMnSUTIOH OF THIS DOCUMERT IS UNLIMITEN 


\section{Abstract}

An electric vehicle simulation code which can be used with any IBM compatible personal computer was written. This general purpose simulation program is useful for performing parametric studies of electric vehicle performance on user input driving cycles. The program is run interactively and guides the user through all of the necessary inputs. Driveline components and the traction battery are described and defined by ASCII files which may be customized by the user. Scaling of these components is also possible. Detailed simulation results are plotted on the $P C$ monitor and may also be printed on a printer attached to the PC. This report serves as a users' manual and documents the mathematical relationships used in the simulation. 
Abstract .......................... $i$. .

Acronyms .................... . ix

Introduction .................... 1

Using SIMPLEV .....................5 5

Hardware Requirements ................5

Starting SIMPLEV ..................7

Running SIMPLEV ................. 7

Introduction Screen ............. 7

Vehicle Menu ................ 11

Motor Menu . . . . . . . . . . . . . . . 11

Inverter/Controller Menu . . . . . . . . . . 11

Transmission Menu .............. 15

Continuously Variable Transmissions . . . . . . . 20

Driving Cycle Menu .............. 20

Federal Urban Driving Schedule . . . . . . . . 23

Constant Speeds ............. 23

SAE J227 Driving Cycles . . . . . . . . . 23

Federal Highway Driving Cycle........... 23

Simplified Federal Urban Driving Schedule . . . . . 24

Maximum Effort Accelerations ......... 24

Road Conditions ................ 24

Battery Menu . . . . . . . . . . . . . 26

Change Vehicle Parameters Menu . . . . . . . . . 26

Auxiliary Power Unit and Auxiliary Loads . . . . . . . 26

Saving Calculated Results ............ 31

Screen Graphics Menu . . . . . . . . . . . . . 34

Calculated Battery Data Display . . . . . . . . 34

Calculated Vehicle Speed and Component Information . . 34

Calculated Vehicle Coastdown Curves . . . . . . . . 38

Coastdown Graphical Display Menu . . . . . . . . 38

Coastdown Optinns ................ 38 
SIMPLEV output ...................... 43

Page 1 - Input Data ................. 43

Vehicle Characteristics ............ 43

Oriveline Component Information ......... 43

Controller/Inverter ............ 43

Motor .................... 47

Transmission ................... 47

Battery Information ............. 47

other Information ............... 47

Graphical output ................... 47

Simulation Results .............. 48

Calculated Coastdown Times ............ 48

Steady State Road Loads . . . . . . . . . . . . 49

Detailed Results . . . . . . . . . . . . . 49

Cycle and Road Conditions .......... . 49

Maximum Battery Power . . . . . . . . . . 49

Average Battery Current and Power . . . . . . . 49

Ampere-hours Removed . . . . . . . . . . 50

Effective Battery Capacity .......... 50

Net Battery Energy . . . . . . . . . . . 50

Gross Battery Energy . . . . . . . . . . 50

Energy Supplied By APU and Regenerative Braking . . . 50

Percent of Energy Recovered . . . . . . . . . . 50

Component Efficiencies ............ 50

Energy Economy .............. . . 50

Maximum Battery Power Density . . . . . . . 50

Average Speed ............... 51

Total Distance Traveled ........... 51

Test Time ................... 51

Cycle Number of Termination ......... 51

DOD at Termination ............... 51

Battery Voltage and Currant at Termination ..... 51

FUDS Cycle Information ........... 51

Average Component Power Losses . . . . . . . . . 52

Steady State Powertrain Efficiencies . . . . . . 52 
Simulation Diagnostics ........... 52

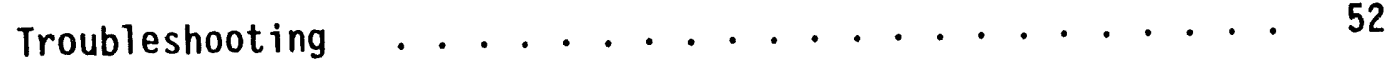

Compiler Error Messages ............. 54

Out of Memory ................. 54

Out of String Space ................. 54

Device Timeout ............. . . 55

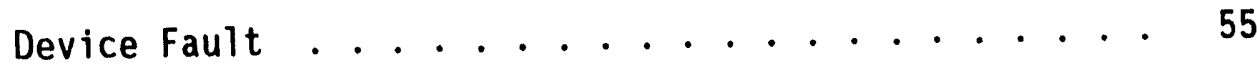

Printer Out of Paper .................... 55

File Not Found .................... 55

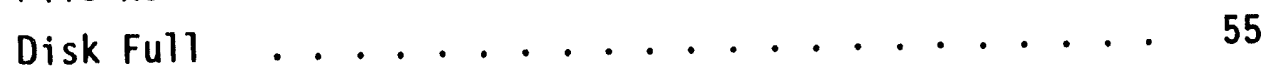

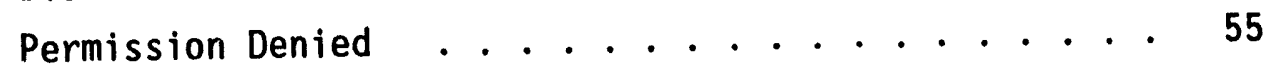

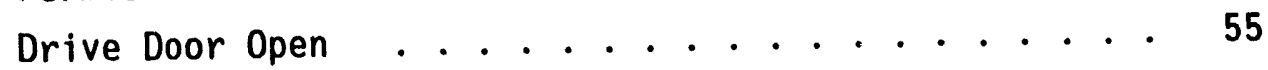

Path Not Found .................... 55

Program Description ................... 57

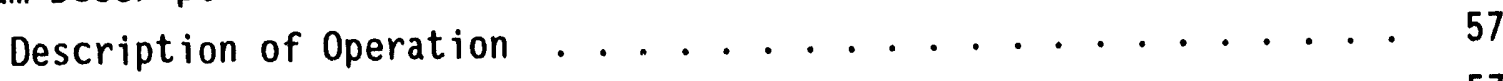

Vehicle/Powertrain Configuration ......... 57

Road Load Power ... . . . . . . . . . . 57

Driveshaft/Transmission Power .......... 60

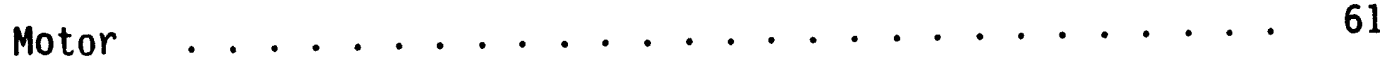

Maximum Motor Torque .......... . . 62

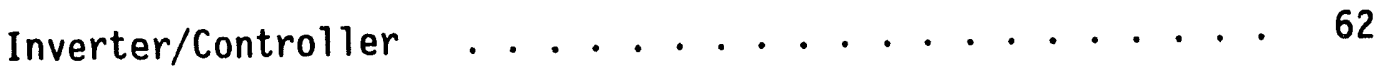

Battery ........................... 62

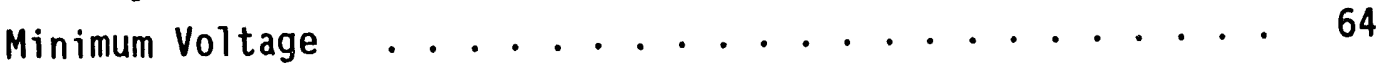

Maximum Current .................. 64

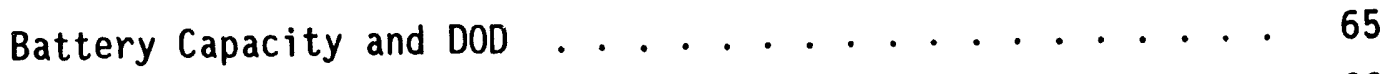

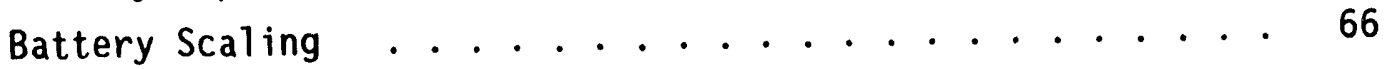

Energy ........................... 67

Average Battery Power ............ 68

Average Component Efficiencies .......... 68

Battery Efficiency . . . . . . . . . . . 69

Average Component Losses ............ . . 69

Coastdown Calculations ................ 70

Input Parameters and Component Definition ...... 70

Vehicle Definition ............ 70 
Vehicle file ...................... 71

Line $1 \ldots \ldots \ldots 71$

Line $2 \ldots \ldots \ldots \ldots \ldots$

Line $3 \ldots \ldots \ldots 71$

Line $4 \ldots \ldots \ldots 71$

Line $5 \ldots \ldots \ldots \ldots$

Line 6 through $9 \ldots \ldots 73$

Line $10 \ldots \ldots . \ldots . \ldots 73$

Line $11 \ldots \ldots \ldots 73$

Line $12 \ldots \ldots \ldots 73$

Line $13 \ldots \ldots \ldots 73$

Transmissions .................... 73

One- or Two-Speed Geared Transmissions ...... 74

Scaling of One- or Two-Speed Transmissions ..... 76

Continuously Variable Transmissions (CVT) . . . . 76

Motors .................. . . 78

Scaling Motor Efficiencies . . . . . . . . 78

Inverters/Controllers ............ 80

Scaling Inverter/Controller Efficiencies ..... 82

Battery Files .............. 82

Driving Schedule files ............. . 84

References ................... 86

\section{APPENDIX}

Appendix A. Sample SIMPLEV Outputs Using ' $D$ ' and ' $G$ ' Option at Introduction

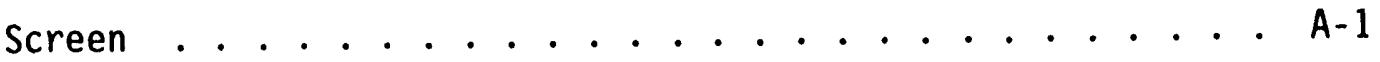

Appendix B. SIMPLEV Vehicle File Listings ........... B-1

Appendix C. SIMPLEV Transmission Files ............. C-1

Appendix D. SIMPLEV Motor Files .............. . D-1

Appendix E. SIMPLEV Inverter/Controller files ..........E-1

Appendix F. SIMPLEV Battery Files .............. F-1 


\section{FIGURES}

1. Printed SIMPLEV heading showing date and time of program execution . 8

2. The introduction screen display after executing SIMPLEV.EXE . . . . 9

3. SIMPLEV vehicle selection menu . . . . . . . . . . . . 12

4. SIMPLEV motor selection menu . . . . . . . . . . . . . . 13

5. SIMPLEV inverter/controller menu .............. 14

6. Scaling motor and inverter .............. 16

7. Changing voltage and current limits ............. 17

8. SIMPLEV transmission selection menu . . . . . . . . . . . . 18

9. Scaling the selected transmission . . . . . . . . . . . . 19

10. Entering information for a CVT . . . . . . . . . . . . . . 21

11. Driving cycle menu . . . . . . . . . . . . . . . . 22

12. Road conditions data entry prompts . . . . . . . . . . . 25

13. Battery selection menu . . . . . . . . . . . . . . . 27

14. Scaling and choosing battery initial conditions and number of modules 28

15. Change vehicle parameters menu . . . . . . . . . . . . . 29

16. APU and auxiliary loads selection prompts ........... . 30

17. Saving data to an ACSII file . . . . . . . . . . . . . . 32

18. Choosing data to be written to an ASCII file .......... 33

19. SIMPLEV screen graphical display menu . . . . . . . . . . . 35

20. Graphical display for menu selection 1 . . . . . . . . . . 36

21. Graphical display for menu selection 2 . . . . . . . . . . 37

22. Screen graphics and simulated vehicle coastdown options . . . . 39

23. Coastdown graphical display for menu selection l . . . . . . . . 40

24. Coastdown graphical display for menu selection 2 . . . . . . . . 41

25. Coastdown graphical display for menu selection 3 . . . . . . . 42

26. Page 1 of printed output . . . . . . . . . . . . . . . 44

27. Page 2 of printed output . . . . . . . . . . . . . . . 45

28. Page 3 of printed output ................... . 46

29. Electric vehicle block diagram assumed for SIMPLEV . . . . . . 58

30. IDSEP vehicle file . . . . . . . . . . . . . . . 72

31. IDSEP transmission file .................. . 75

32. Continuously variable transmission operating strategy . . . . . . 77

33. IDSEP motor file which represents the efficiency of the entire drivetrain . . . . . . . . . . . . . . 79 
34. Example of inverter/controller file . . . . . . . . . . 81

35. Example of battery file .................. 83

36. Example of driving schidule file .............. 85

TABLES

1. Files furnished with SIMPLEV Version 1.0 . . . . . . . . . . 6 


\section{ACRONYMS}

SFUDS

DOE

IDSEP

SIMPLEV

$P C$

I/0

CVT

FUDS

SAE

Ah

APU

DOD
Simplified Federal Urban Driving Schedule

Department of Energy

Improved Dual Shaft Electric Propulsion

simple electric vehicle

personal computer

input/output

continuously variable transmission

Federal Urban Driving Schedule

Society of Automotive Engineers

Ampere-hours

Auxiliary power unit

Depth-of-Discharge 


\section{SIMPLEV: A SIMPLE ELECTRIC VEHICLE SIMULATION PROGRAM}

\section{VERSION 1.0}

\section{INTRODUCTION}

The simple electric vehicle (SIMPLEV) simulation code originated with the work performed while developing the Simplified Federal Urban Driving Schedule (SFUDS) battery test cycle in conjunction with the Department of Energy (DOE) Battery Test Working Task Force. Originally two simulations for the Improved Dual Shaft Electric Propulsion (IDSEP) vehicle were written by the task force. VTOP determined the velocity of the IDSEP vehicle for a given power input to the driveline, and PTOV determined the battery power required to propel the IDSEP vehicle over a given velocity profile. The vehicle powertrain in these programs was described by a single efficiency versus motor torque and speed matrix. After the work on the SFUDS was completed, a more detailed personal computer (PC) based electric vehicle simulation tool was developed, modified, improved, and combined these two programs into the basic SIMPLEV code. As time progressed, various other refinements were made to this code. The result of this effort and the subject of this report is SIMPLEV Version 1.0 .

SIMPLEV is a menu driven, general purpose simulation program intended for use as a tool for performing parametric studies of electric vehicles. The source code of the compiled program program is written in BASIC and will run on any IBM DOS compatible PC. The program is run interactively and guides the user through all of the necessary input steps. SIMPLEV can be easily run by users whose background contains only an elementary knowledge of computer simulation programs. All parameters are input by the user either from the menus or as ASCII data files. To start the program, type SIMPLEV from the directory where SIMPLEV resides, and it will prompt you through various choices of vehicles, driveline components, batteries, driving cycles, and road 
conditions (grade, wind speed, and direction). If desired, the user may scale the menu-selected powertrain components. The user choses graphical display outputs and data capturing.

The methodology used in this simulation is straightforward. SIMPLEV first determines the power required to propel the vehicle from the speed at one point in time to the next from the road load calculated from user input information. The power at each driveline component interface is then determined from a double linear interpolation of the efficiency from component matrices, which results in the electrical power at the battery terminals required to drive the vehicle. Any electrical auxiliary power and auxiliary power unit input power is then algebraically added to the electrical power required for traction. This total power from the battery is then converted into voltage and current using the open circuit voltage and resistance characteristics of the battery. If the operating limit of a component (maximum motor torque, maximum controller/inverter current, or minimum voltage) is unattainable, SIMPLEV then iterates a solution that produces the maximum speed possible while still satisfying the operating limitations of all components. Thus under these conditions, the "best effort" attempt of the driving cycle is simulated.

While executing a driving cycle SIMPLEV continues to "drive" until one of the following conditions are met:

- The run is terminated by the user ( $\langle\mathrm{F} 9\rangle$ or $\langle\mathrm{F} 10\rangle$ key)

- The maximum number of cycles or approximate distance input by the user have been completed

- The battery capacity is depleted (i.e. 100\% depth-of-discharge)

- The vehicle fails to meet the minimum required speed of the driving cycle. 
The notation < > refers to the non-alphanumeric keys on the PC keyboard. During the input session of SIMPLEV, numbered responses to menu selections and yes/no questions are not followed by <Enter>, while numeric or string inputs must be followed by <Enter>.

The minimum speed condition is defined as the inability of the vehicle to remain within $\pm 3.2 \mathrm{~km} / \mathrm{h}(2 \mathrm{mph})$ within $\pm 1 \mathrm{~s}$ of the desired speed. The exception to this is during the 187-305 s portion of the FUDS cycle, where the limits are as defined by the SAE test procedure (SAE J227a). Maximum effort accelerations are automatically terminated after $120 \mathrm{~s}$ (data points) are calculated without regard to vehicle speed.

Upon normal program completion, the driving cycle is stopped and various quantities are calculated and printed, and any requested data are saved in an ASCII text file. Prematurely terminating the program with the <F9> key immediately ends the program execution and returns the system to the DOS command level.

This manual is written in two sections. The section entitled "Using SIMPLEV" is written to guide the user through the menus of the program with an explanation of the selected options. The user with only an elementary knowledge of computer programs and engineering principles will be able to effectively use SIMPLE' after mastering this section. The section entitled "Program Description" is a detailed explanation of the mathematical methodology, equations used, and the ASCII input data files. This section is written for the user desiring to define their own vehicles and components and to understand SIMPLEV's underlying engineering principles and assumptions. 


\section{USING SIMPLEV}

The files listed in Table 1 are furnished with SIMPLEV Version 1.0. These files consist of the executable simulation code (SIMPLEV.EXE) and a variety of files containing vehicle and powertrain component descriptions. The component data files used by SIMPLEV are selectable as appropriate from the program menus. The data contained in these files were either obtained from detailed component dynamometer or battery test data, inferred from vehicle test data, converted from the ELVEC bulk data file, or in some cases, are a best engineering judgement of the behavior characteristics of the component. Most of these data files have been extensively used and are believed to represent the named vehicle and component behavior reasonably accurately; however, you should verify the validity of the component descriptions before drawing any conclusions based upon simulations using this data. Notations regarding the source of the data appears with the input file listings contained in the appendices. You are free to modify any of these data files or construct data files using any PC software that can edit or produce ASCII files.

\section{HaRdware Requirements}

SIMPLEV requires approximately $200 \mathrm{kB}$ of RAM memory to 10 ad and run. Approximately $400 \mathrm{kB}$ of disk storage is required to store the executable code (SIMPLEV.EXE) and the input data files in Table 1. Additional disk storage is required if you wish to save the calculated results to ASCII format files. The amount of disk space required for these files varies; however, these files can become very large on a single simulation run.

SIMPLEV may be executed from either a hard, floppy, or virtual disk drive on any IBM DOS compatible PC with an IBM or Epson printer attached to the parallel device output port. The printer control codes used by SIMPLEV are generally compatible with IBM and Epson printers but may produce erratic results on other printers. If you anticipate needing a hardcopy of the graphical displays, the printer must have the ability of printing screen 
Tabie 1. Files furnished with SIMPLEV Version 1.0

Executable program file:

SIMPLEV.EXE

\begin{tabular}{|c|c|c|c|c|c|c|c|}
\hline \multicolumn{2}{|c|}{$\begin{array}{l}\text { Vehicle } \\
\text { Input Files }\end{array}$} & \multicolumn{2}{|c|}{$\begin{array}{l}\text { Motor } \\
\text { Input Files }\end{array}$} & \multicolumn{2}{|c|}{$\begin{array}{l}\text { Inverter/ } \\
\text { controller } \\
\text { Input Files }\end{array}$} & \multicolumn{2}{|c|}{$\begin{array}{l}\text { Transmission } \\
\text { Input Files }\end{array}$} \\
\hline Name & Ext. & Name & Ext. & Name & Ext. & Name & Ext. \\
\hline $\begin{array}{l}\text { BEDVAN } \\
\text { DSEP } \\
\text { ETV-1 } \\
\text { ETX-I } \\
\text { ETX-II } \\
\text { EVCORT } \\
\text { G-VAN } \\
\text { IDSEP } \\
\text { IMPACT } \\
\text { MEV-75 } \\
\text { SOLQVAN } \\
\text { TB-1 } \\
\text { TEVAN }\end{array}$ & $\begin{array}{l}\text { VEH } \\
\text { VEH } \\
\text { VEH } \\
\text { VEH } \\
\text { VEH } \\
\text { VEH } \\
\text { VEH } \\
\text { VEH } \\
\text { VEH } \\
\text { VEEH } \\
\text { VEH } \\
\text { VEH } \\
\text { VEH }\end{array}$ & $\begin{array}{l}\text { ETV-1 } \\
\text { ETX-I } \\
\text { ETX-II } \\
\text { IDSEP } \\
\text { MEV-100 } \\
\text { MEV-50 } \\
\text { MEV-75 } \\
\text { TB-1 }\end{array}$ & $\begin{array}{l}\text { MOT } \\
\text { MOT } \\
\text { MOT } \\
\text { MOT } \\
\text { MOT } \\
\text { MOT } \\
\text { MOT } \\
\text { MOT }\end{array}$ & $\begin{array}{l}\text { ETV-1 } \\
\text { ETX-I } \\
\text { ETX-II } \\
\text { IDSEP } \\
\text { MEV-100 } \\
\text { MEV-50 } \\
\text { MEV-75 } \\
\text { TB-1 }\end{array}$ & $\begin{array}{l}\text { INV } \\
\text { INV } \\
\text { INV } \\
\text { INV } \\
\text { INV } \\
\text { INV } \\
\text { INV } \\
\text { INV }\end{array}$ & $\begin{array}{l}\text { ETV-1 } \\
\text { ETX-I } \\
\text { ETX-II } \\
\text { IDSEP } \\
\text { MEV-75 } \\
\text { TB-1 }\end{array}$ & $\begin{array}{l}\text { TX } \\
\text { TX } \\
T X \\
T X \\
T X \\
T X \\
T X\end{array}$ \\
\hline \multicolumn{2}{|c|}{$\begin{array}{l}\text { Battery } \\
\text { Input Files }\end{array}$} & \multicolumn{2}{|c|}{$\begin{array}{l}\text { Driving Cycle } \\
\text { Input Files }\end{array}$} & & & & \\
\hline Name & Ext. & Name & Ext. & & & & \\
\hline $\begin{array}{l}3 E T-205 \\
6 E T X-100 \\
6 V 180 \\
\text { ALC02200 } \\
\text { B-11-1 } \\
\text { B-11-2 } \\
\text { CSPL } \\
\text { ED150P } \\
\text { EV5T } \\
\text { NIF170 }\end{array}$ & $\begin{array}{l}\text { BTY } \\
\text { BTY } \\
\text { BTY } \\
\text { BTY } \\
\text { BTY } \\
\text { BTY } \\
\text { BTY } \\
\text { BTY } \\
\text { BTY } \\
\text { BTY }\end{array}$ & $\begin{array}{l}20 M P H \\
30 M P H \\
35 M P H \\
40 M P H \\
45 M P H \\
55 M P H \\
60 M P H \\
\text { A-CYCLE } \\
\text { B-CYCLE } \\
\text { C-CYCLE } \\
\text { D-CYCLE } \\
\text { FUDS } \\
\text { SFUDS79 } \\
\text { HIWAY }\end{array}$ & $\begin{array}{l}C Y C \\
C Y C \\
C Y C \\
C Y C \\
C Y C \\
C Y C \\
C Y C \\
C Y C \\
C Y C \\
C Y C \\
C Y C \\
C Y C \\
C Y C \\
C Y C\end{array}$ & & & & \\
\hline
\end{tabular}


graphics characters. All characters sent to the printer are standard ASCII characters that print either text and IBM screen graphics characters or control the printer (i.e. input/output (ASCII codes 0 through 256). Due to the 1 arge number of file I/O operations, the input session during SIMPLEV execution will run generally faster from a hard or virtual drive. If SIMPLEV's output is to be written to a file, the execution speed will also be affected by the speed of the disk $1 / 0$.

\section{StaRting SIMPLEV}

To start the program, type SIMPLEV <Enter> from the DOS command environment in the drive and directory in which SIMPLEV.EXE resides. Any of the menu selectable data files that are anticipated to be used (i.e., files with extensions .VEH. .MOT, .INV, .TX, .CYC, and .BTY) must also reside in this drive and directory, although files from other directories may be manually entered. The DOS GRAPHICS command must be executed before running SIMPLEV if you wish to print hardcopies of the graphs. The DOS GRAPHICS command need only be executed once each time the PC is booted.

In order to become familiar with executing SIMPLEV, you should first run the simulation while simultaneously reading the remainder of this section.

\section{RUNnINg SIMPLEV}

\section{Introduction Screen}

After executing the program (i.e., typing SIMPLEV <Enter>) a header for this run will be printed on the printer (Figure 1) and an introduction screen will be displayed (Figure 2). 
DATE: $05-01-1991$

TIME: $12: 00: 00$

Page 1

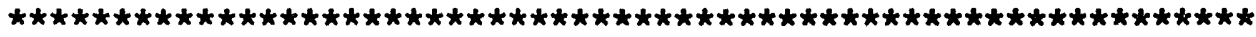

* SIMPLEV - SIMPLE EV SIMULATION PROGRAM VERSION 1.0 * Idaho National Engineering Laboratory

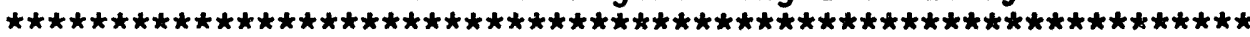

Figure 1. Printed SIMPLEV heading showing date and time of program execution. 


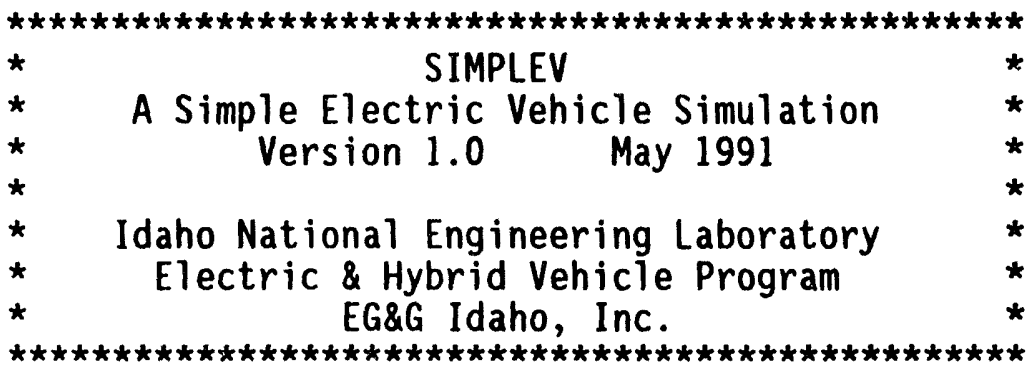

Work supported by the U. S. Department of Energy Assistant Secretary for office of Propulsion Systems under DOE Contract No. DE-AC07-76ID01570.

' $D$ ' or ' $G$ ' runs IDSEP test case.

$\langle\mathrm{Fl}\rangle$ - accesses DOS

$\langle F 7\rangle$ - toggles graphs

$\langle F 8\rangle$ - toggles program execution speed

$\langle F 9\rangle$ - ends this program without printing results

$\langle F 10\rangle$ - ends this program and prints results

Hit space bar to continue....

Figure 2. The introduction screen display after executing SIMPLEV.EXE. 
The introduction screen shows the uses of some of the function keys. Other function keys are inactive once SIMPLEV is executed. The uses of the function keys are as follows:

<F1> shells SIMPLEV to the DOS command level during the simulation. To return to the simulation, type "EXIT" <Enter> from the DOS command level. This key should be used with discretion since in most cases the information on the screen when $\langle F 1\rangle$ is pressed will not be redisplayed upon returning to SIMPLEV.

<F7> toggles the printing of the display graphical output. This key is active only if you initially choose to print graphs during the input session.

<F8> toggles between four execution speeds during the simulation. This function is useful to slow the program execution when it is too rapid to effectively observe the results.

<F9> immediately ends program execution and returns to the DOS command level.

<F10> immediately ends program execution, calculates results up to the point that the key was pressed, and returns to the DOS command level.

Selected test cases may be run at the introduction screen. This feature is useful to ascertain if SIMPLEV is operating properly. Entering a "D" will cause the remainder of the inputs to be bypassed and the program will run using preselected inputs. This output may then be compared to the output in Appendix $A$ to verify that SIMPLEV is operating properiy on your equipment. Entering a "G" will run the same test case and print a sample graph on the attached printer.

To continue with the simulation and begin the input session, enter <SPACE> (space bar), as indicated. 


\section{Vehicle Menu}

After entering $\angle S P A C E>$ at the introduction display, the vehicle menu (Figure 3 ) is displayed. Select one of the options listed. For alpha characters, you may use either upper or lower case characters. If you chose an input not on the menu, the PC will beep and you may then select again.

If you wish to simulate a vehicle that is not on the menu (i.e., a user written vehicle data file) enter "U." You will then be prompted for the file name containing the vehicle data. If the file desired is not in the drive/directory from which the program resides, the full drive:path specification is required.

Another option available at this time is to access the DOS command level by entering "S." This feature is useful for interrupting SIMPLEV to perform other computer functions, such as locating the path and name of a data file. Because SIMPLEV will remain in memory, only a limited amount of the computer's memory remains for running other programs. To return to this menu, enter EXIT <CR $>$ at the DOS command level prompt.

\section{Motor Menu}

After selecting a valid menu choice or entering the name of a valid vehicle data file, the vehicle data file is read and the motor selection menu appears on the display, as shown in Figure 4. Select one of the options listed. For alpha characters, either upper or lower case characters may be used. If you chose an input not on the menu, the PC will beep and you may then select again. You can also select a motor that is not on the menu or access DOS, as described above.

\section{Inverter/Controller Menu}

After selecting a valid menu choice or entering the name of a valid motor data file, the inverter/controller selection menu appears on the display, as shown in Figure 5. Select one of the options listed. For alpha characters, you may use either upper or lower case characters. If you chose 
VEHICLE MENU

Enter number of vehicle for initial parameters:

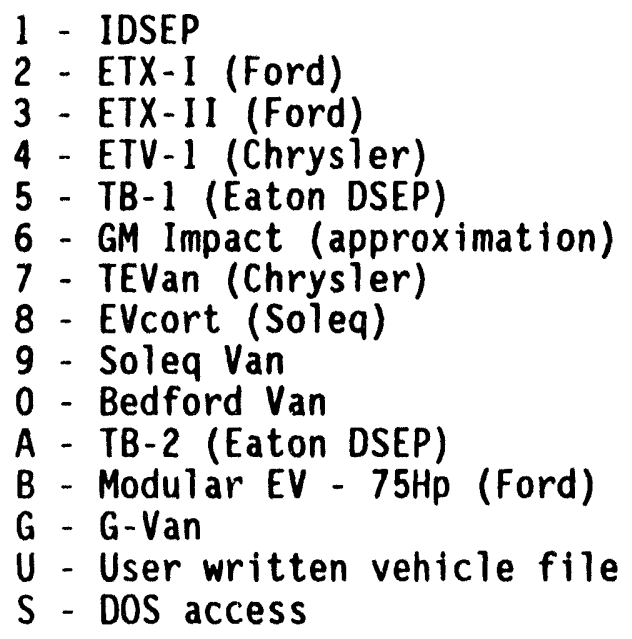

Figure 3. SIMPLEV vehicle selection menu. 


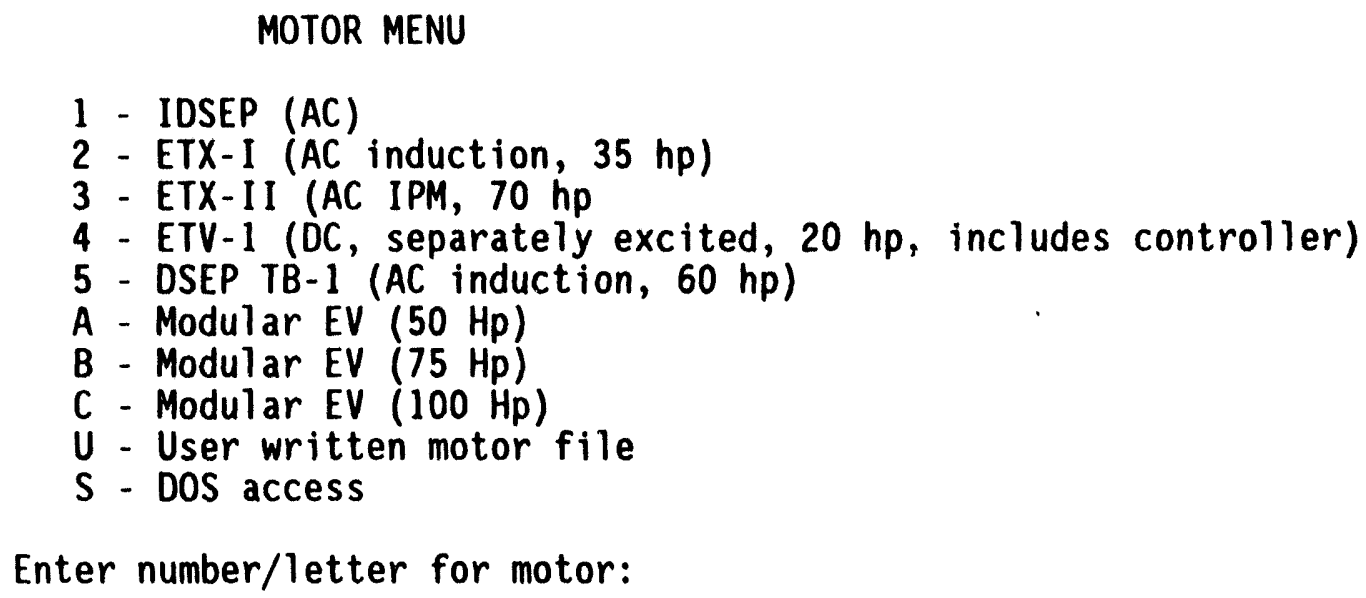

Figure 4. SIMPLEV motor selection menu. 


\section{INVERTER/CONTROLLER MENU}

1 - IDSEP

2 - ETX-I (AC transistor)

3 - ETX-II (AC transistor)

4 - ETV-1 (DC, data included in motor file)

5 - TB-1 (AC transistor)

A - Modular EV (50 Hp)

B - Modular EV (75 Hp)

C - Modular EV (100 Hp)

$U$ - User written inverter/controller file

$S$ - DOS access

Enter number/letter of inverter/controller:

Figure 5. SIMPLEV inverter/controller menu. 
an input not on the menu, the PC will beep and you may then select again. The options of selecting a motor that is not on the menu or accessing DOS are also available as described above.

After selecting the inverter/controller, you can scale selected motor and/or inverter/controller (see Figure 6). The details of the scaling methodology are discussed in the Program Description Section. If you choose to scale either or both of these components, enter " $Y$ " at the appropriate prompt and you will be asked to supply the appropriate information via the keyboard. Once the appropriate information is entered, the motor data file and the inverter/controller data files are read and you can adjust the operating limits of the selected inverter/controller, as shown in figure 7. If you wish to change either or both the minimum voltage and maximum current, answer " $\gamma$ " to the appropriate question. You may then enter the desired operating limits for the inverter/controller via the keyboard at the appropriate prompts. The transmission selection menu then follows.

\section{Transmission Menu}

The transmission selection menu is shown in Figure 8 . Select one of the options listed. For alpha characters, you may use either upper or lower case characters. If you chose an input not on the menu, the PC will beep and you may then select again. The options of selecting a transmission not on the menu or accessing DOS are also available, as described above.

After entering a valid transmission choice [other than a (continuously variable transmission (CVT)], you are then prompted if you want to scale the selected transmission. The details of the scaling methodology are discussed in the Program Description Section. If you choose to scale the transmission (Figure 9), enter " $Y$ " at the appropriate prompt and you will be asked to supply the appropriate information via the keyboard. Once you enter the appropriate information, the transmission data file is read and the driving cycle selection menu is displayed. 
IDSEP Drivetrain:

Do you want to scale this motor $(Y / N)$ ? y

IDSEP Powertrain:

Peak torque is $70.01 \mathrm{~b}-\mathrm{ft}$. o $0 \mathrm{rpm}$.

Peak power is $60.9 \mathrm{hp} 8000 \mathrm{rpm}$.

Enter scaling factor for motor speed: 1

Enter scaling factor for motor torque: 1.?

IDSEP "Dummy" Inverter:

Do you want to scale the inverter/controller $(\mathrm{Y} / \mathrm{N})$ ? y Enter inverter/controller motor speed scaling factor: 1 Enter inverter/controller motor torque scaling factor: 1.2 Enter scaling factor for maximum current: 1

Figure 6. Scaling motor and inverter. 
Limits are 120.0 volts minimum and 400 amps maximum.

Do you want to change them $(Y / N)$ ? $y$

Enter minimum voltage: 135

Enter maximum current limit: 425

Figure 7. Changing voltage and current limits. 


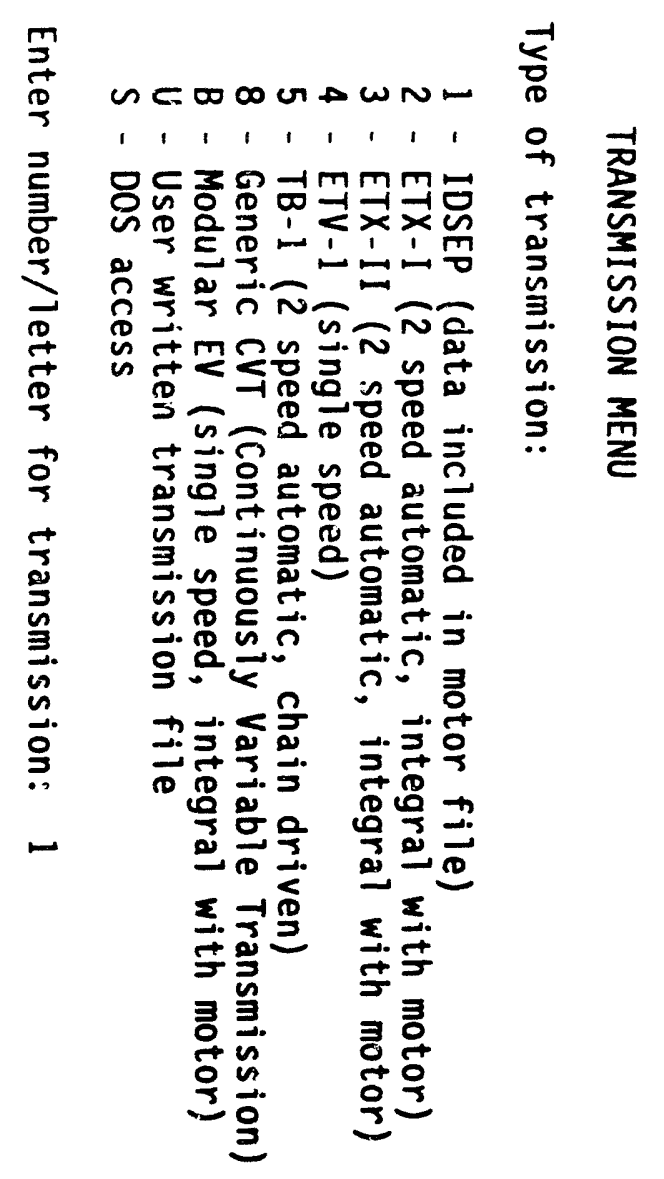


IDSEP "Dummy" Transaxle:

Do you want to scale transmission data $(Y / N)$ ? y

Enter scaling factor for transmission output speed: 1

Enter scaling factor for transmission output torque: 1.2

Figure 9. Scaling the selected transmission. 
Continousiy Variable Transmissions. An additional available option is a simple representation of a CVT. If you choose this option, information is prompted for as shown in Figure 10. The meaning of these parameters and how they are used in SIMPLEV are discussed in the "Program Description Section."

\section{Driving Cycle Menu}

The driving cycle selection menu is shown in Figure 11. Select one of the options listed. For alpha characters, you may use either upper or lower case characters. If you choose an input not on the menu, the PC will beep and you may then select again. You can also select a driving schedule not on the menu or access DOS, as described above. The format of the driving schedule files is contained in the "Program Description Section" which will enable you to write and use other driving schedules.

After selecting a valid driving cycle, you then prompted for a maximum number of cycles (or display screens for the constant speed choices). This feature is useful if data for the entire vehicle range is not desired. Maximum effort accelerations are only performed for $120 \mathrm{~s}$ and the program run is terminated.

The standard driving cycles (i.e. Federal Urban Driving Schedule (FUDS), SAE J227a "A", "B", "C", and "D" cycles) listed in the driving cycle data files were obtained from the Society of Automotive Engineers (SAE) J227a Electric Vehicle Test Procedure. Because the measured range of an electric vehicle on any driving cycle depends on the point at which the test is terminated, it is important that you understand the methodology employed within SIMPLEV relating to vehicle performance on a driving cycle and the point at which the program is terminated and range determined. If a maximum number of driving cycles (or screens) chosen is not within the driving range of the vehicle, SIMPLEV automatically terminates each program run depending upon the cycle chosen.

In general, the selected vehicle and component configuration is simulated on the cycle in a "best effort" fashion. With the exception of the maximum effort acceleration simulation, minimum vehicle performance on a 


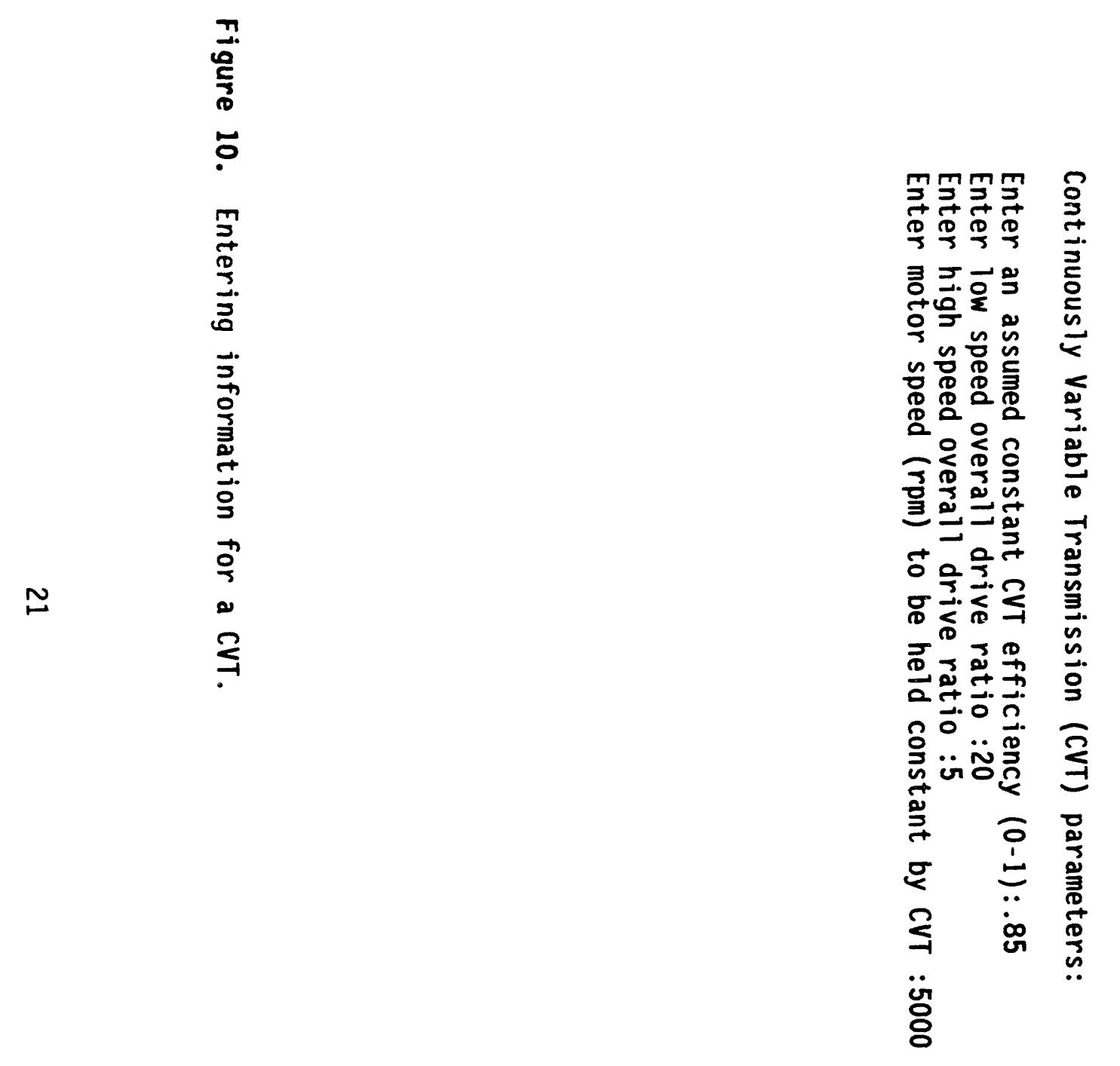


DRIVING CYCLE MENU

1 - FUDS (SAE J227 5/8/86 draft test procedure)

2 - SAE J227a A-Cycle

3- SAE J227a B-Cycle

4 - SAE J227a C-Cycle

5 - SAE J227a D-Cycle

6 - $20 \mathrm{mph}$ constant speed

7 - 30 mph constant speed

8 - $45 \mathrm{mph}$ constant speed

9 - 55 mph constant speed

0 - SFUDS (from Rpt. No. DOE/ID-10146)

A - Maximum effort acceleration

B - 60 mph constant speed

C - $40 \mathrm{mph}$ constant speed

D - $35 \mathrm{mph}$ constant speed

E - Federal Highway Driving Cycle

0 - Other constant speed (no initial acceleration)

$U$ - User written driving cycle

$S$ - Dos access

Enter number of driving cycle:1

Figure 11. Driving cycle menu. 
driving cycle is defined as the vehicle's inability to attain a speed of $\pm 2 \mathrm{mph}$ within $\pm 1 \mathrm{~s}$ of the target speed. The following paragraphs describe the minimum vehicle performance requirements of each of the standard driving cycles.

Federal Urban Driving Schedule--SIMPLEV simulates FUDS according to the test procedure in accordance with the draft SAE J227a procedure (May 8, 1986). The point at which the vehicle cannot meet the \pm 2 mph speed within \pm 1 s of the target speed either the cycle is terminated or marked on the graphical display by a vertical line, depending upon where in the test cycle this occurs. As a reminder, the word "FLAG" appears on the display to show that this has happened. In accordance with the draft SAE procedure, if this occurs between 164 and $305 \mathrm{~s}$ of the cycle, the vehicle is allowed to continue until either the \pm 2 mph speed within \pm 1 s cannot be met during any other portion of the cycle or the vehicle's best effort cannot attain $72 \mathrm{~km} / \mathrm{h}$ within $30 \mathrm{~s}$ after $187 \mathrm{~s}$ and hold that speed until the $305 \mathrm{~s}$ mark of the cycle.

Constant Speeds--A selection of constant speed driving cycles is available that accelerate the vehicle from rest to the specified speed and maintain that speed (selections $6,7,8,9, B, C$, or $D$ in Figure 11). Selection 0 allows you to input any desired constant speed. This selection starts and propels the vehicle at any desired speed without accelerating from rest. If you chose this option, the time step will be requested. A large time step reduces the number of total iterations and therefore decreases the time to complete the simulation. The minimum performance requirement for constant speed driving cycles is $\pm 2 \mathrm{mph}$ within \pm 1 s of the target speed.

SAE J227 Driving Cycles--Selections 2, 3, 4, and 5 (Figure 11) are defined in the SAE procedure (SAE 1986). The minimum performance requirements for these driving cycles is $\pm 2 \mathrm{mph}$ within \pm 1 s of the target speed.

Federal Highway Driving Cycle--Selection E (Figure 11) is the Federal Highway Driving Cycle. The minimum performance requirements for this driving cycle is $\pm 2 \mathrm{mph}$ within \pm 1 s of the target speed. 
Simplified Federal Urban Driving Schedule--The SFUDS driving cycle is the speed versus time profile for the IDSEP vehicle, which produced the SFUDS battery discharge profile. This driving profile may be found in $\underline{A}$ Simplified Version of the Federal Urban Driving Schedule for Electric Vehicle Battery Testing (DOE 1988). Due to differences in the simulations used to produce the SFUDS driving schedule, the power profile resulting from SIMPLEV will not be equivalent to the power profile described in this report. The minimum performance requirements for this driving cycle is $\pm 2 \mathrm{mph}$ within $\pm 1 \mathrm{~s}$ of the target speed.

Maximum Effort Accelerations--Selection 0 (Figure 11) contains no built-in minimum performance criteria. The vehicle is simulated in a maximum acceleration mode limited by either the maximum motor torque, minimum battery voltage, or maximum inverter current.

Road Conditions. After entering a valid driving cycle, a series of prompts requesting information regarding road conditions (see Figure 12) will be displayed. Pressing <Enter> to any of these prompts results in the built-in default values being used. These default values are as follows:

Percent grade $=0 \%$
Vehicle direction $=$
Wind speed $=0 \mathrm{mph}$
Wind Direction $=0^{\circ}$
Air density $=.0022$
Aerodynamic drag coe
\[ \begin{array}{r}a=.00194 \\ b=1.657026 .\end{array} \]

If you chose a nonzero value for either wind speed or wind direction, values for correcting the vehicle aerodynamic drag coefficient, are requested. These correction factors for the vehicle aerodynamic drag coefficient are explained in detail in the "Program Description." 


\section{ROAD CONDITIONS}

Enter percent grade, $\tan (\kappa): .01$

Enter wind speed in mph: 10

Enter air density in slugs/ft^3 (default=.002266):

Enter vehicle direction in degrees (North=0): 30

Enter wind direction in degrees (i.e. 0 = from North): 15

Enter coefficients for wind speed and yaw angle correction to Cd. ( $<C R>$ for defaults):

$$
\delta c t / C d 0=a \cdot \beta^{\wedge} b(|\beta| 17.5 \mathrm{deg} .)
$$

Enter a:

Enter b:

Figure 12. Road conditions data entry prompts. 
The battery selection menu is shown in Figure 13. Select one of the options listed. For alpha characters, you may use either upper or lower case characters. If you chose an input not on the menu, the PC will beep and you may then select again. You may also select a battery not on the menu or access DOS, as described previously. The format of the battery data files is contained in the "Program Description" which will enable the user to use his own battery definitions.

After selecting a valid battery choice, a series of options is available (see Figure 14): battery scaling, initial ampere-hours removed, and number of modules in series desired. The selection number of modules is not an option for the sodium sulfur batteries. If the calculated open circuit voltage for the number of modules is below the minimum inverter voltage, a message is displayed, and you are prompted to enter another entry for the number of modules. The battery scaling methodology is described in detail in the "Program Description."

\section{Change Vehicle Parameters Menu}

After entering all the required battery information, you can change some of the vehicle parameters, as shown in Figure 15. This menu displays the vehicle parameters, which were read or calculated from the data files. If the gross vehicle weight is exceeded, a cautionary message is also displayed. You may change any of the displayed parameters by entering the number or letter of the parameter at the left. After entering the number, you are prompted to enter a new value for this parameter. After entering a new value, the menu is re-displayed with the new value. This process may be repeated as many times as necessary. If no further changes are desired, enter 0.

\section{Auxiliary Power Unit and Auxiliary Loads}

You are then prompted with a series of options regarding auxiliary power units (series hybrid configuration) and auxiliary loads (Figure 16). The auxiliary power unit (series hybrid) represents a constant power input to the 


\section{BATTERY MENU}

Enter battery:

1 - ALCO-2200 Pb-acid, $115 \mathrm{Ah}, 6$ volts

2 - EV5T Pb-acid, $137 \mathrm{Ah}, 6$ volts

3- PTI B-11 NaS, 155 Ah, 187 volts

4 - PII B-11 NaS, $310 \mathrm{Ah}$, two 187 volt packs in parallel

5 - 6ETX-100 (HED 85) Pb-acid, $100 \mathrm{Ah}, 12$ volts

6 - CSPL NaS, 300 Ah, 198 volts (developed for ETX-II)

7 - CEVS 3ET-205, 205 Ah, 6 volts

9 - Sonnensche in 6V180, Pb-acid, $140 \mathrm{Ah}, 6$ volts

A - NIF-170, Ni/Fe, $170 \mathrm{Ah}, 6$ volts

B - ED150P, Pb-acid, $150 \mathrm{Ah}, 12$ volts

$U$ - User written battery file

$S$ - DOS access

Figure 13. Battery selection menu. 
NIF-170 selected. Do you want to scale this battery $(Y / N)$ ? $Y$

This battery has a capacity of 170 Ah at the 2.0 hour rate.

Enter a new capacity at the same rate: 150

Do you want to partially discharge the battery first $(Y / N)$ ? $Y$

Enter constant current for battery pre-discharge, A: 75

Estimated capacity at $75 \mathrm{~A}$ is $148.6 \mathrm{Ah}$.

Enter ampere-hrs to be discharged from battery: 10

Enter number of NIF170 modules for simulation: 28

Figure 14. Scaling and choosing battery initial conditions and number of modules. 
CHANGE VEHICLE PARAMETERS

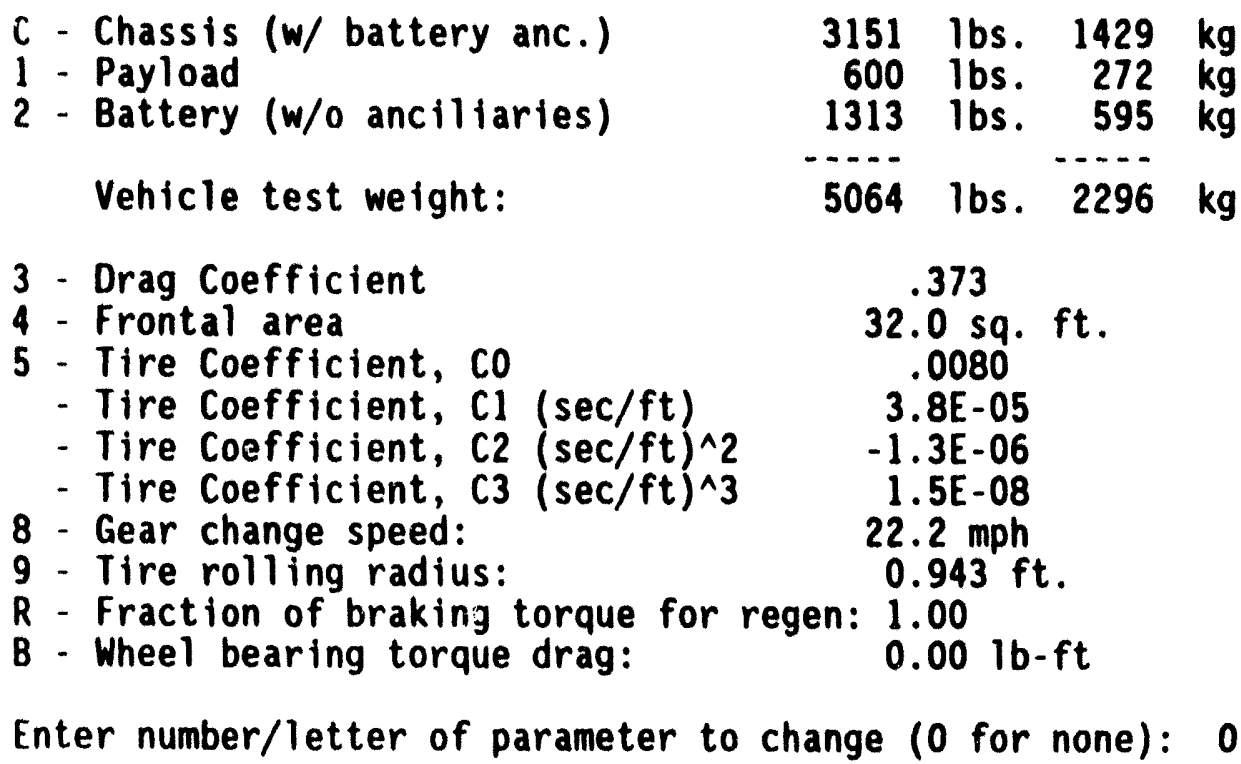

Figure 15. Change vehicle parameters menu. 
AUXILIARY POWER UNIT AND AUXILIARY LOADS

Do you wish an auxiliary power unit (APU) option $(Y / N)$ ?y

Enter DOD (0-1) to start APU: .8

Enter DOD $(0-1)$ to turn off APU: .5

Enter APU power output, watts: 10000

Enter accessory power load in watts: 500

Figure 16. APU and auxiliary loads selection prompts. 
battery at the battery terminals, which may be used for either vehicle propulsion, auxiliary loads, or both. Auxiliary loads are not used to propel the vehicle, such as headlights and loads not included in the efficiency data files, and represent constant power loads directly from the battery terminals.

If you choose an auxiliary power unit, you are prompted for the battery depth-of-discharges, between which the APU will feed power to the battery terminals, and tiee power output of the APU. If you choose not to include an $A P U$, then the only information required is the auxiliary electrical load.

At this point, all of the necessary data describing the vehicle, powertrain, and battery has been entered. However, before SIMPLEV will run, there are several other options available.

\section{Saving Calculated Results}

SIMPLEV performs a large number of calculations at each time step while running. Most of these calculations, which may be of interest for analyses, may be written to ASCII data files. Because of the large amount of data, these files become very large, however, SIMPLEV also provides for some screening so that only data of interest is saved.

You may write data to one or two data files. The first option allows specific data (i.e., time, vehicle speed, and battery power) to be written to a file named by you (see Figure 17). This data may be captured for the time segment of each cycle chosen for a chosen number of cycles.

The prompts for the second data file that data may be written to is shown in Figure 18. You may choose from a menu of data....enter the time segment of data for each cycle to save and how many cycles you wish to capture this data.

As a reminder, the file name and number of cycles chosen appears on the printout. 
Write the resulting battery power and speeds to a file $(Y / N)$ ? y Enter name of file: SAVEl.DAT

Enter time segment of data to be saved in SAVE1.DAT:

Enter start time $(0-1372$ seconds $): 150$

Enter end time $(150-1372$ seconds $): 300$

Store data for first how many cycles? 1

Write your choice of other data to a file $(Y / N)$ ? y

Enter name of file: SAVE2.DAT

Figure 17. Saving data to an ASCII file. 
Choose data to be written to SAVE2.DAT

1 - Time, Speed, Battery Amps, Battery Volts, Battery Power

2 - Time, Speed, Motor RPM, Component Efficiencies

3 - Time, Speed, Road Load Power, Motor Power, Battery Power

4 - Time, Speed, Motor RPM, Transmission Efficiency, Gear Ratio

5 - Time, Speed, Motor RPM, Motor Torque, Battery Amps, Component Efficiencies, Motor Power, Road Load Torque

6 - Time, Speed, Distance, Energy, DOD, Battery Amps, Amp-hrs.

7 - Time, Target Speed, Final Speed, Distance, DOD, Battery Amps, Battery Volts, Amp-hrs.

Enter number of your choice: 1

Enter cycle time segment of data to be saved:

Enter start time $(0-1372$ seconds): 150

Enter end time $(150-1372$ seconds $): 300$

Store data for first how many cycles? 1

Figure 18. Choosing data to be written to an ASCII file. 


\section{Screen Graphics Menu}

A feature of SIMPLEV is that the user may view certain calculated data in graphical form while the program is running. One of the two forms of the calculated results available are chosen from the menu in Figure 19. Figures 20 and 21 show representative examples of the graphical displays corresponding with menu selections 1 and 2 respectively. Selection 1 shows graphically battery power, battery voltage, and battery current versus time. Selection 2 shows vehicle component efficiencies, motor power, and vehicle speed. If you choose selection 3, no graphical data is displayed, allowing SIMPLEV to run two to three times faster than options 1 or 2 . After choosing either options 1 or 2, you may choose to print this graphical display to the attached printer by entering a " $Y$ " at the prompt. Enter " $N$ " if this is not desired. You may select interactively which screens are to be printed by pushing the $\langle F 7\rangle$ key while SIMPLEV is running. An indicator appears at the bottom left corner of each screen (either a " $Y$ " or a " $N$ " to indicate the current option to this prompt). Another way of printing the screen graphics display is to use the <Print Screen> key on the PC keyboard. Note: the DOS Graphics command must be executed before running SIMPLEV if you choose to print out these graphs.

Calculated Battery Data Display. This display (see Figure 20) provides information concerning the calculated battery behavior at each time step of the chosen driving cycle. Beside each parameter plotted, the calculated value at each time step is also displayed. In addition to the vehicle, battery, and driving cycle identifiers at the top of the screen (i.e., vehicle and battery), some other data are displayed numerically and updated at each time step.

Calculated Vehicle Speed and Component Information. This display (see Figure 21) provides information concerning the vehicle and component behavior at each time step of the chosen driving cycle. Beside each parameter plotted, the calculated value at each time step is also displayed. In addition to some identifying information at the top of the screen (i.e., vehicle and battery), calculated data are displayed numerically and updated at each time step. 


\section{SCREEN GRAPHICS MENU}

Select screen graphics presentation:

1 - Battery power, battery volts and battery current

2 - Speed, motor power and component efficiencies

3 - None (approx. 2 times faster)

Enter choice: 1

Print this graph when done? $(Y / N): Y$

Calculate coastdown speed vs. time under these conditions $(Y / N): y$

Figure 19. SIMPLEV screen graphical display menu. 


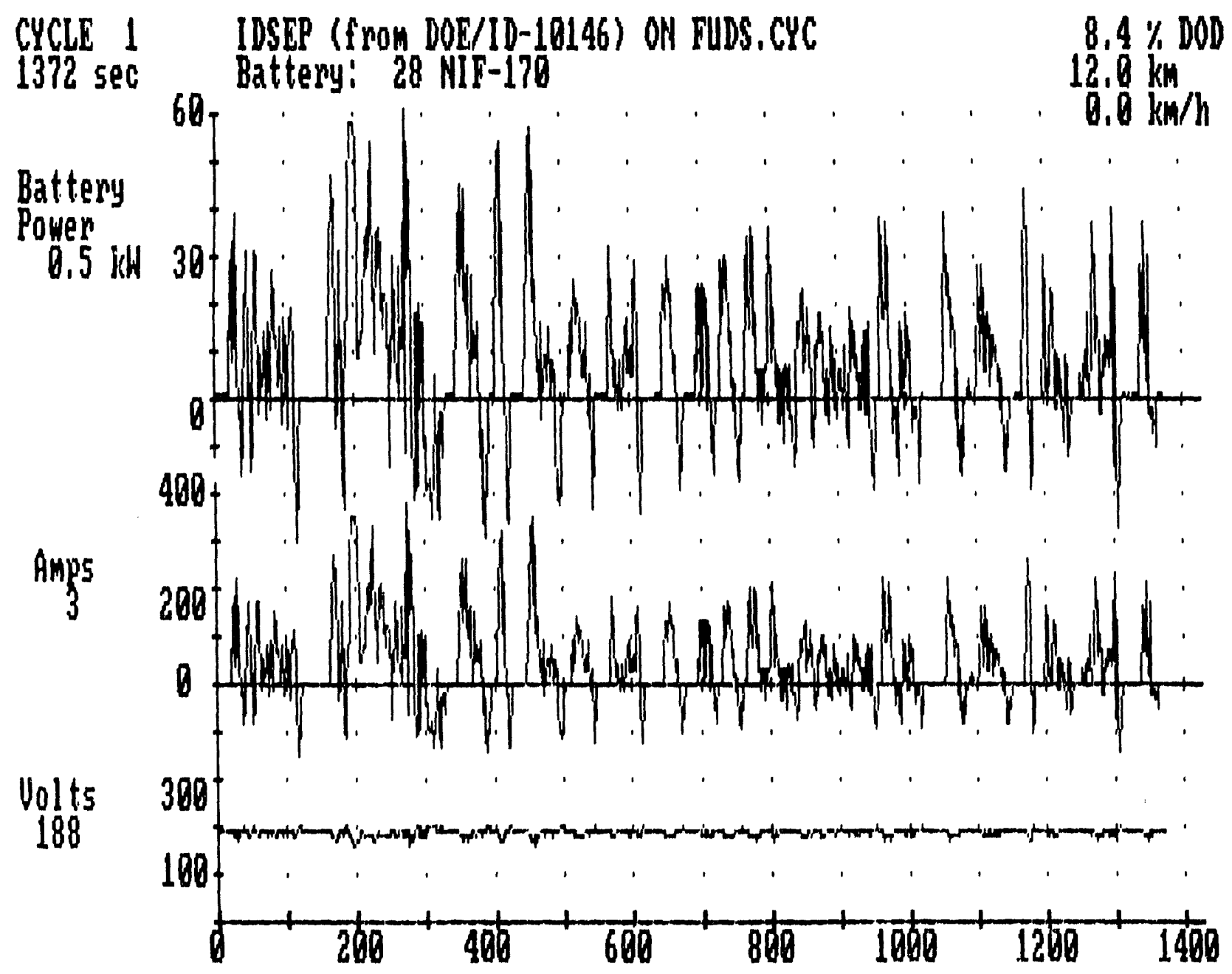

Figure 20. Graphical display for menu selection 1. 


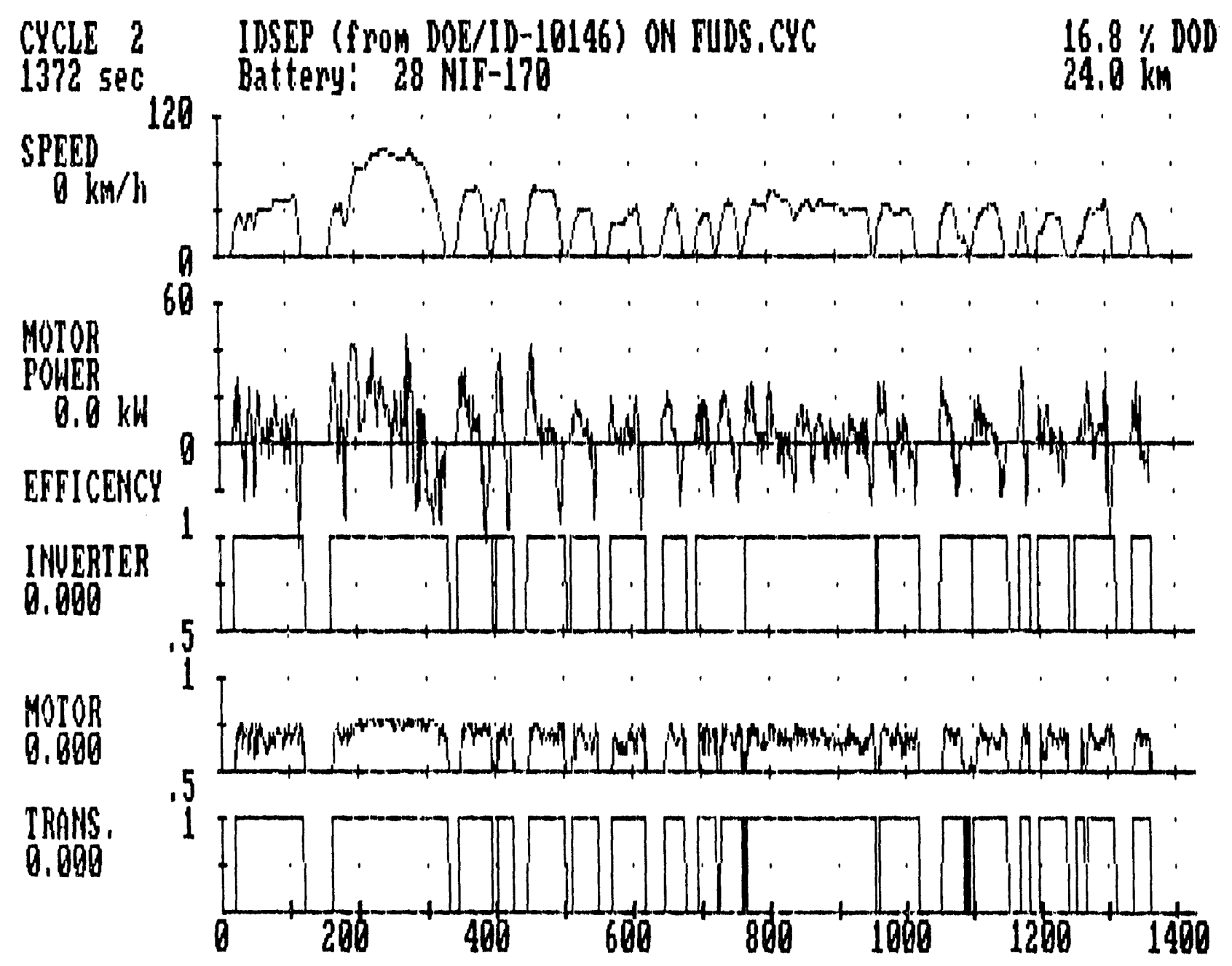

Figure 21. Graphical display for menu selection 2. 


\section{Calculated Vehicle Coastdown Curves}

After selecting the graphical display and printing options, SIMPLEV provides you the opportunity of calculating, displaying, printing, and saving the vehicle coastdown calculations for the previously chosen vehicle parameters and road conditions (grade and wind speed and direction). This option is shown in Figure 22. First you are given a choice of whether or not you would like to perform this function. Enter "Y" for "yes" or "N" for "no" after this prompt. If you choose the response "N", SIMPLEV immediately begins calculating the vehicle and component performance for the selected driving cycle and road conditions. If you respond with a "Y," additional information must be entered, as shown in Figure 22.

Coastdown Graphical Display Menu. Figure 22 shows the coastdown graphical display menu. Select 1, 2 or 3 . Figures 23 through 25 show the resultant displays of these selections respectively. After selecting a graphical display, you are asked whether or not you would like to have this graph printed (as described above).

Coastdown Options. After responding to the above prompt, the series of questions shown in Figure 22 is displayed and must be answered. First you are asked for the time step or increment to compute the coastdown data. A value greater than 0 for this parameter should be entered. One second or less usually gives adequate data resolution. Next you are asked about writing the coastdown data to a file. If answered " $Y$," the file name and time increment for saving data is prompted for before beginning the coastdown calculations. Additionally as a reminder, the file name entered as well as the data time increment is printed on the printer. If the response is " $N$," the coastdown calculations begin immediately.

At the conclusion of the coastdown, you are given the opportunity to rerun the coastdown. You may rerun the coastdown with the same or different options. If you desire no more coastdown runs, answer " $N$ " to this question and SIMPLEV will begin calculating the vehicle and component performance for the selected driving cycle and road conditions. 
COASTDOWN GRAPHICAL DISPLAY

Which coastdown graph would you like?

1 - Speed Vs. time

2 - Aerodynamic, rolling and total road load power vs. speed

3 - Total road load power vs. speed

Enter number: 1

Printout coastdown curve when done $(Y / N)$ ?: $Y$

COASTDOWN OPTIONS

Enter time step for coastdown calculation, sec.: 2

Write coastdown speed and losses vs time to a file $(Y / N)$ ? $Y$

Enter name of file: SAVE3.DAT

Enter time increment for writing coastdown results.

$(t \geq$ and an even multiple of $2.0 \mathrm{sec}): 2$

Figure 22. Screen graphics and simulated vehicle coastdown options. 


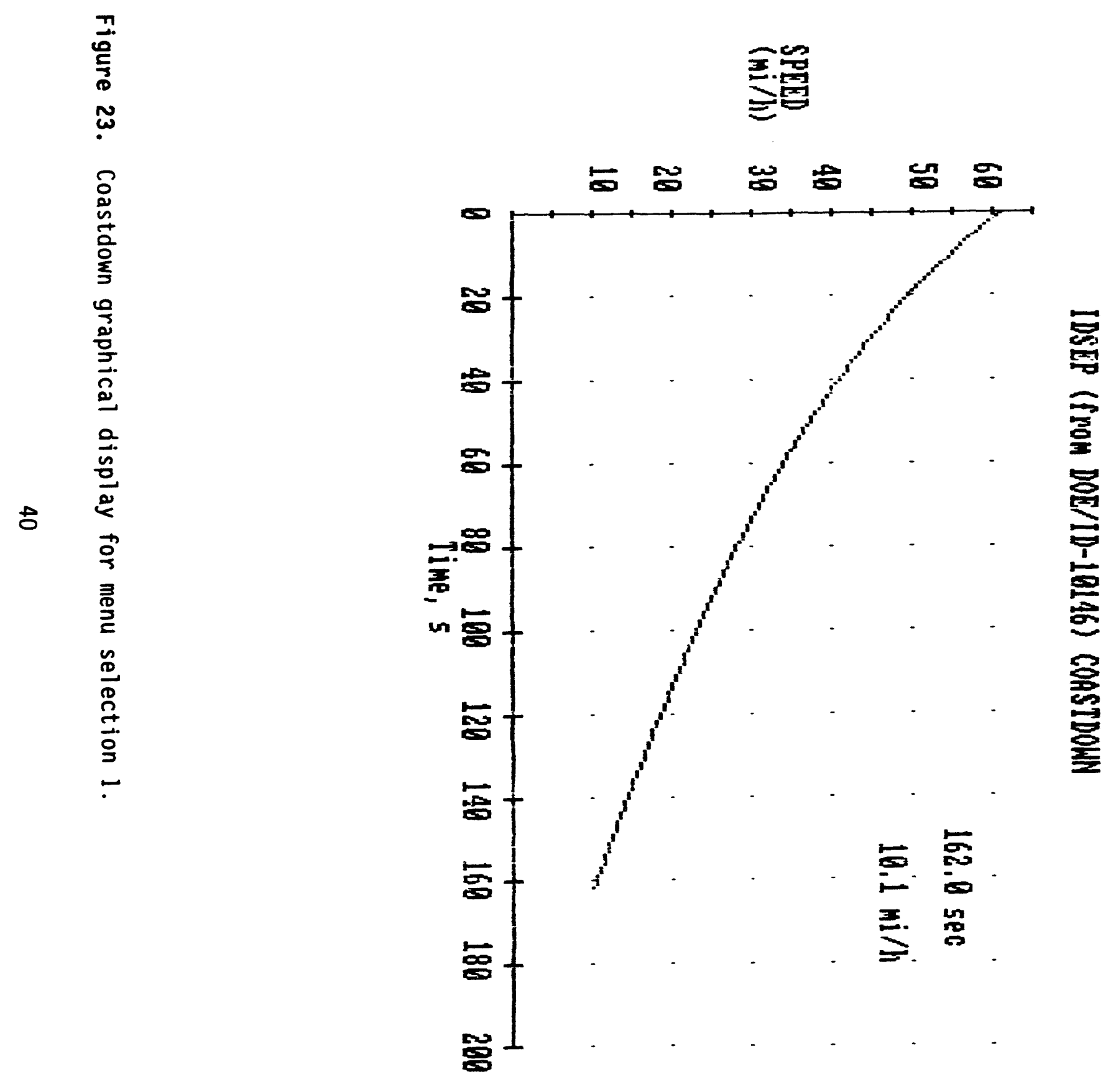




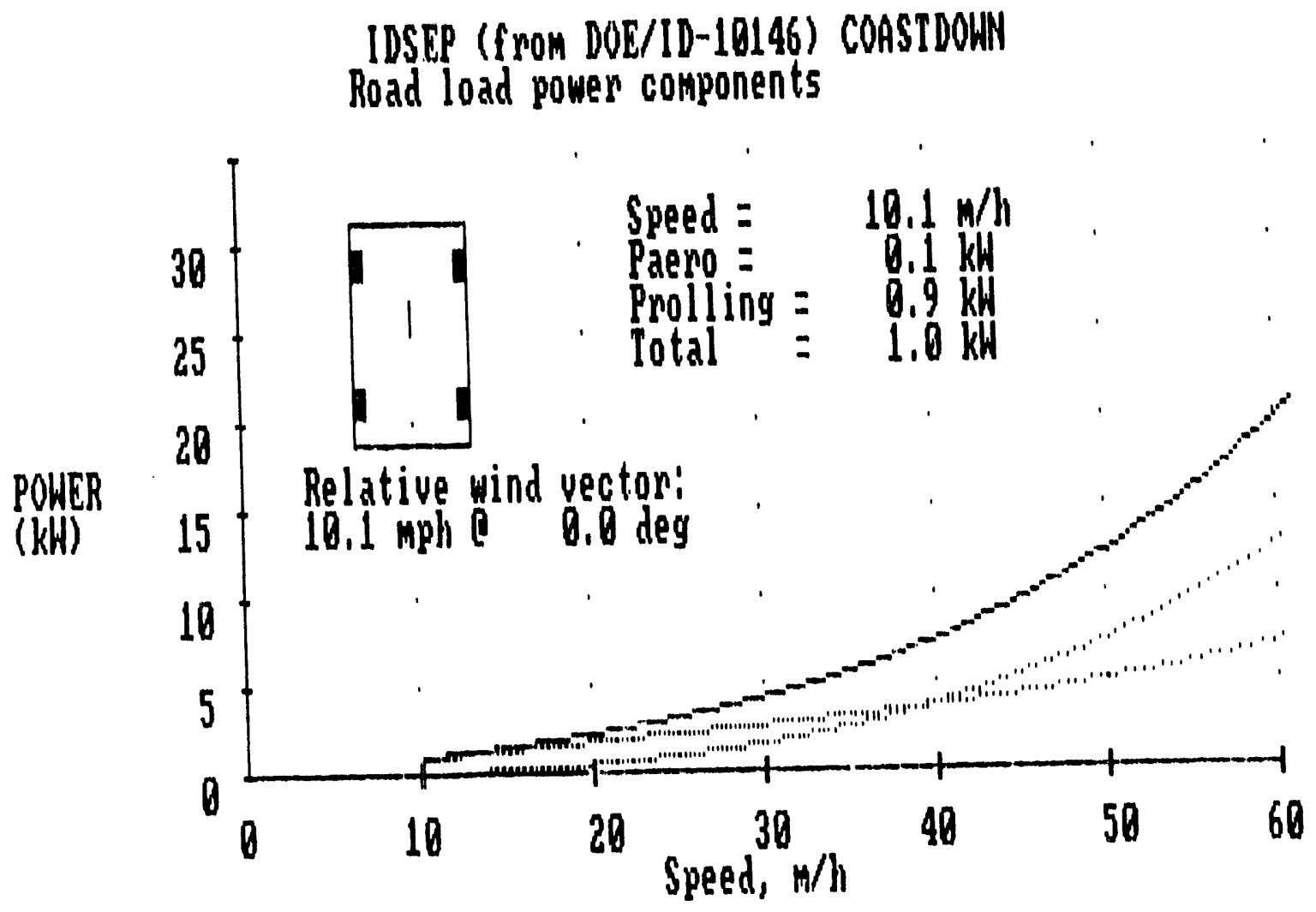

Figure 24. Coastdown graphical display for menu selection 2. 


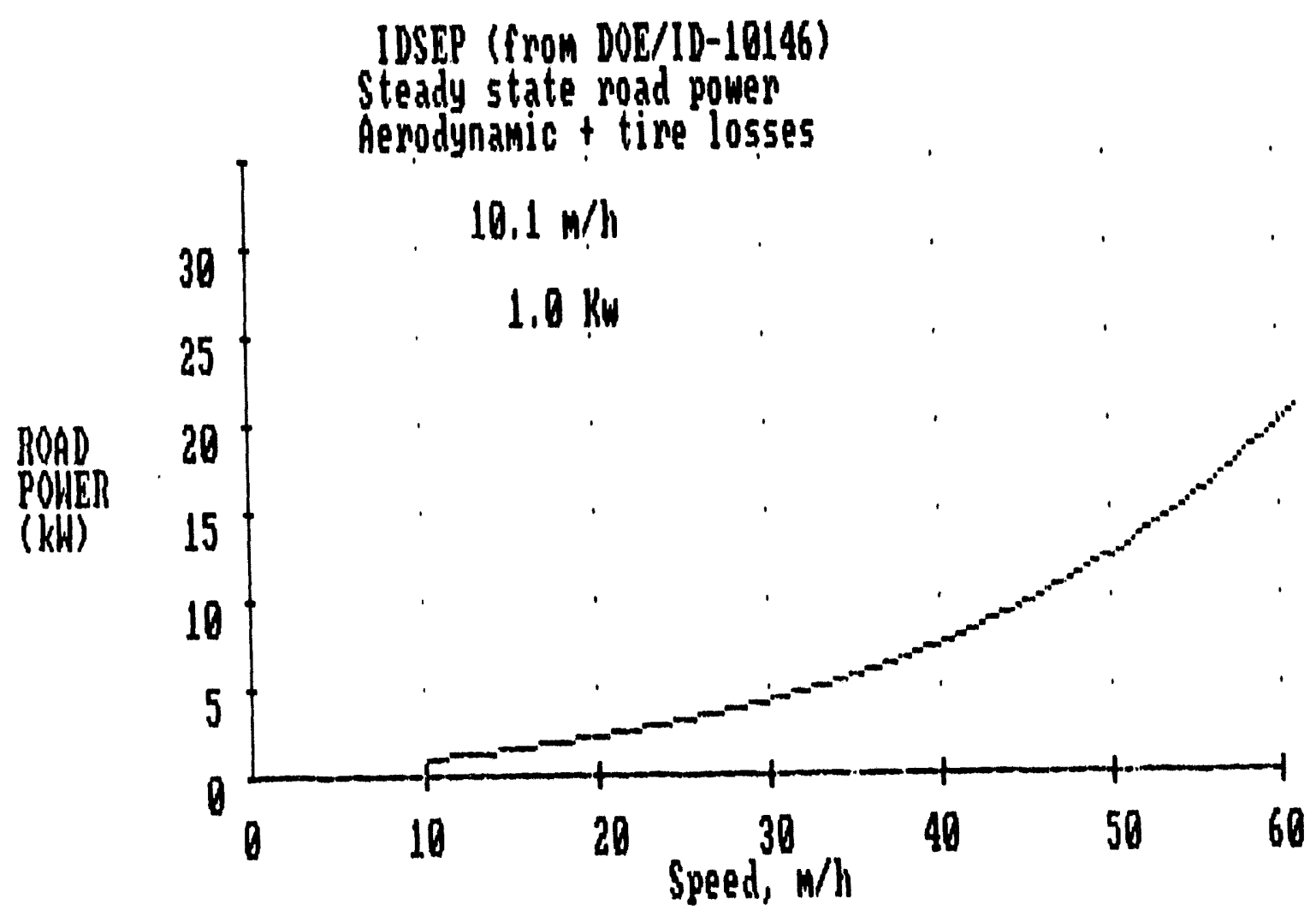

Figure 25. Coastdown graphical display for menu selection 3 . 


\section{SIMPLEV OUTPUT}

In addition to the screen graphics (which may be sent to the printer) and the ASCII files of selected calculated results, SIMPLEV automatically provides three pages of printed output (Figures 26 through 28 ). The system date and time that each SIMPLEV run is started is printed at the top of each page with the page number. With this information you can distinguish between runs. The specific information contained on these output pages is described below.

\section{Page 1 - Input Data}

In general, page 1 of the output shown in Figure 26 contains a header (giving program title and version) and the inputs used for the particular SIMPLEV run. These data were obtained from the component data files or input interactively during the input session.

\section{Vehicle Characteristics}

The first section of information under "VEHICLE CHARACTERISTICS BASED UPON ..." gives the vehicle parameters used during the particular program run. As a reminder that some of these data may have been changed from the the data contained in the ".VEH" data file, the header reads "MODIFIED VEHICLE CHARACTERISTICS BASED UPON ...". This information is given in both English and SI units.

Drivel ine Component Information

This next section gives information of the driveline components used for each program run.

Controller/Inverter. The name or origin of the component is given; it is read from the ". INV" data file, the name of the data file used, scaling factors used (if any) and the minimum voltage and maximum current limits of this component. 


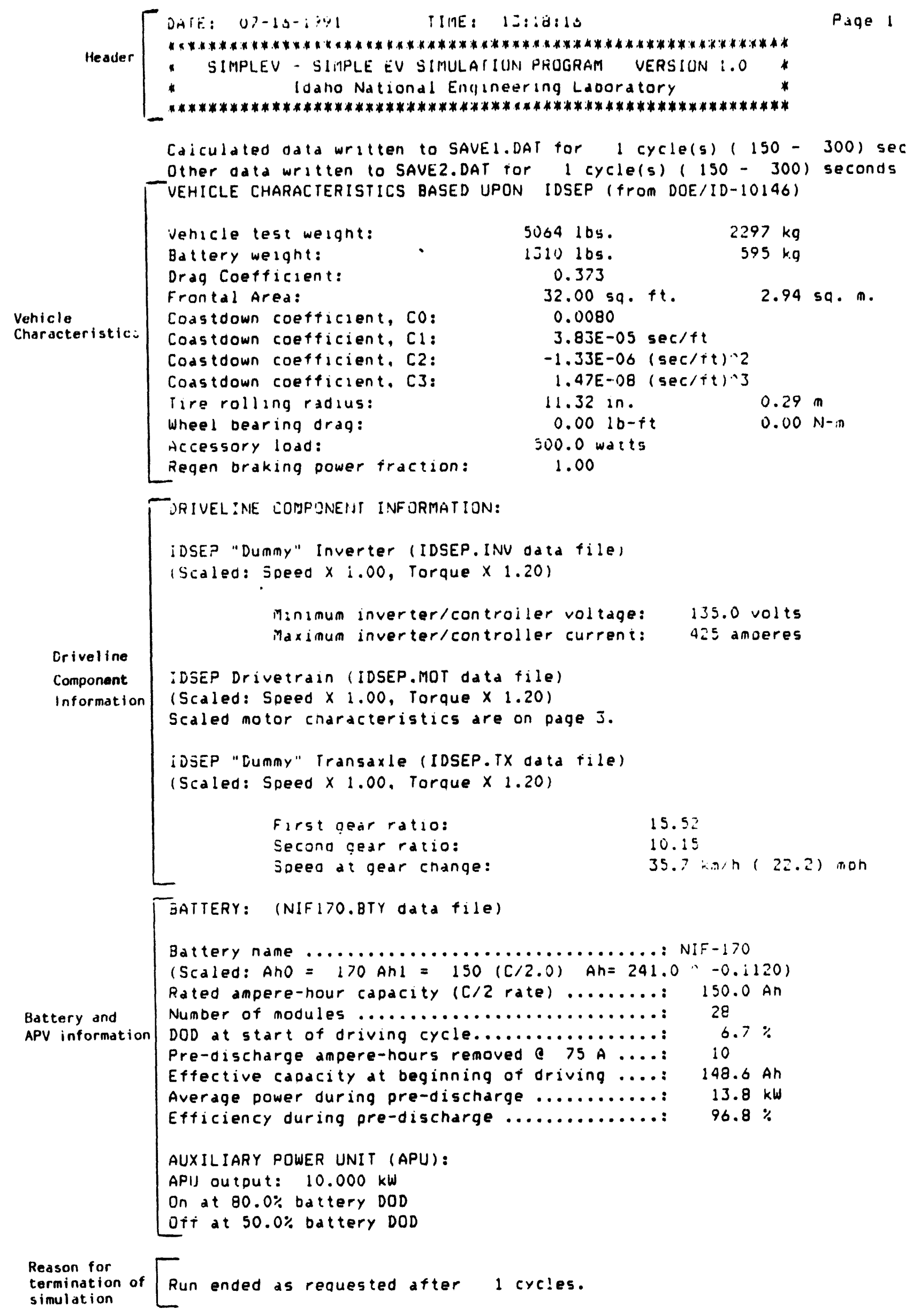

Figure 26. Page 1 of printed output. 


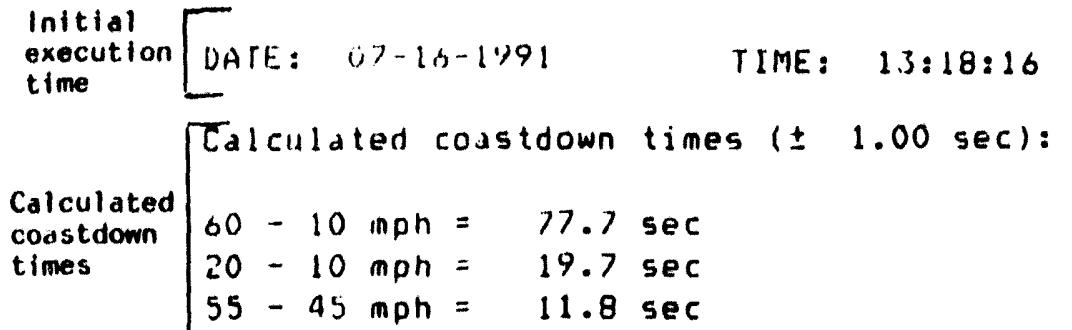

Figure 27. Page 2 of printed output. 


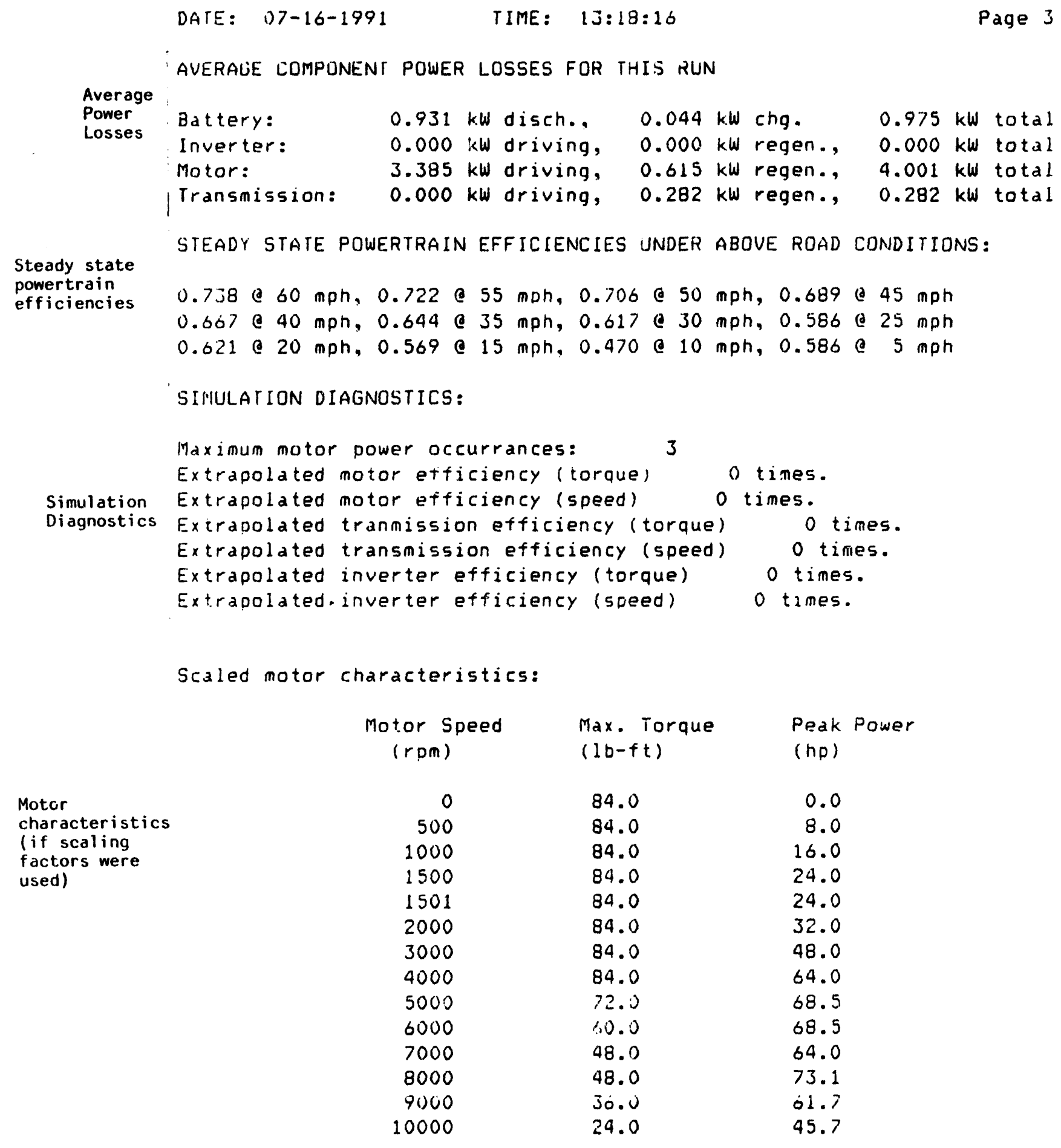

Figure 28. Page 3 of printed output. 
Motor. The name or origin of the motor and (read from the ".MOT" data file), the name of the data file selected, scaling factors (if any) are printed. In addition to this information, reference to the peak motor torque and power versus speed (rpm) is given if any scaling factors were employed.

Transmission. The name or origin of the transmission/transaxle selected (read from the ".TX" data file), the name of the data file selected, scaling factors (if any), gear ratios, and the speed at which a gear change occurs is printed.

\section{Battery Information}

Information printed for the battery selected in the program run includes the result of any scaling employed, the selected initial starting condition of the battery (ampere-hours removed at the specified $C$ rate), output power, and "on" and "off" depth-of-discharge (DOD) of the auxiliary power unit if applicable.

\section{other Information}

Other useful information is printed on page 1 as applicable includes the name (and drive:path) of any data files which were chosen to be written as SIMPLEV executes. A notation giving the reason for the simulation termination is also printed on page 1 if no graphical outputs were requested. If graphical outputs were requested, then this notation appears after the last graph.

\section{Graphical Output}

As SIMPLEV executes, the computer monitor displays the results in graphical form according to the formai chosen in the Coastdown Graphical Display Menu (if the vehicle coastdown option is chosen) and the Screen Graphics Menu. If option "3" is chosen in the Screen Graphics Menu, only a notation giving the cycle number and battery $D O D$ is displayed, this gives an indication that SIMPLEV is running. In the lower left corner of the display, 
a notation giving the execution speed ( 1 through 4 , with 4 being the slowest) and whether or not the current graph will be printed (indicated by a " $Y$ " or

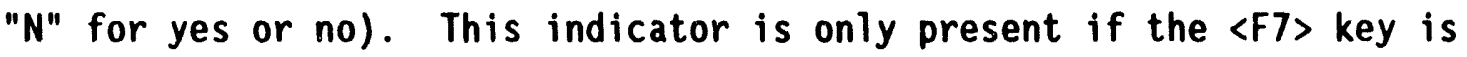
pressed. Both indicators are erased prior to the display being printed. Figures 20 and 21 are representative of these graphs.

Indicators representing limiting conditions on a driving cycle may occasionally flash. In general, they indicate that the simulated vehicle cannot meet the performance requested of the particular driving cycle. A blinking VOLTS means that the battery voltage is clamped at the minimum controller/inverter voltage at that point in the cycle. A blinking AMPS means that the inverter/controller has reached its maximum current limit. A blinking MOTOR means that the motor is operating at the maximum torque.

Any graphical outputs requested are printed between pages 1 and 2 . Sample outputs using the IDSEP vehicle and component data and the $170 \mathrm{Ah}$ NIF-170 nickel-iron battery data supplied with the simulation code are shown in Figures 20 and 21.

\section{Simulation Results}

Samples of the printed output (pages 2 and 3) are shown in Figure 27 and Figure 28, respectively. The date and time of the initial execution of SIMPLEV appears at the top of each page. These identifiers are be useful if the three pages of output from a particular run become separated.

\section{Calculated Coastdown Times}

If the vehicle coastdown option is chosen from the menus, the estimated coastdown times for three different speed ranges are printed: 60-10 mph, 20-10 mph, and 55-45 mph. The calculated times for these speed ranges are linearly interpolated from the calculated data. A notation as to the resolution accuracy of these values is made based upon the time interval supplied by you. 


\section{Steady State Road Loads}

Calculated constant speed road loads are given for various road speeds at chosen road conditions (grade, wind speed and direction, and air density). The small negative load at low speeds in Figure 27 represents braking energy required to maintain this constant speed. This is due to the negative road grade of $-1 \%$ used in this example.

\section{Detailed Results}

The remainder of page 2 contains a detailed summary of the results of the simulation run. The calculated results are given in English and Standard International (SI) units. An explanation as to the meaning or significance of the calculated quantities appearing on page 2 is given below. Depending upon how the simulation was terminated, the value of the following calculated results in subsequent analyses may be limited. All parameters listed below represent results only based upon each particular simulation from the initiation of a "test run" until the point of termination.

Cycle and Road Conditions. The driving cycle simulated along with a notation as to the driving cycle speed versus time data file is given as well as the time increment of the speeds used. In general, the time increment for relatively complicated driving cycles (e.g., FUDS or SAE J227a cycles) is $1 \mathrm{~s}$, while less complicated driving events such as constant speeds have a longer time increment. The road conditions (air density, vehicle heading, wind speed and direction, and road grade) are also listed. If the simulation is under road conditions other than still air, the equation and the coefficients used for correcting the vehicle aerodynamic drag coefficient is given.

Maximum Battery Power. The point in the driving cycle at which the maximum discharge battery power occurred is retained by SIMPLEV. The maximum battery power (kW) is listed along with the calculated battery current and voltage.

Average Battery Current and Power. The average battery current and power for charge, discharge, and net is given. 
Ampere-hours Removed. This value represents the ampere hours removed from the battery from the beginning until the end of the simulation run.

Effective Battery Capacity. The effective battery capacity (in ampere-hours) represents the estimated battery capacity based upon the Peukert curve for the battery used and the average discharge current.

Net Battery Energy. This quantity is net energy which passes through the battery terminals (i.e., discharge energy minus charge energy).

Gross Battery Energy. This quantity is the sum of all discharge energy passed through the battery terminals.

Energy Supplied By APU and Regenerative Braking. These values represent the total energy either supplied by the APU or returned to the battery from regenerative braking.

Percent of Energy Recovered. This quantity (expressed as a percentage) is the charge fraction of energy compared to the total energy discharged at the battery terminals. The energy may come from either the APU (if employed) or from regenerative braking.

Component Efficiencies. The average component efficiencies for the simulation run are calculated and printed. Separate efficiencies for the two modes of component operation are given as charge or regenerative braking and discharge or driving. These efficiencies are calculated from the energy into a component divided by the energy out of a component. The powertrain efficiency is the combined average efficiencies (i.e., energy into the inverter/controller divided into the energy out of the transmission) of the controller/inverter, motor, and transaxle.

Energy Economy. The energy economies (energy/distance traveled) are calculated for each simulation run. The energy economies represent the net and gross energy supplied by the battery divided by the distance driven.

Maximum Battery Power Density. The maximum battery power density 
encountered is calculated from the captured maximum battery power divided by the battery weight. Generally, ancillary battery equipment (charger, heaters, etc.) is not included in the battery weight unless included by the user.

Average Speed. The average speed is calculated from the distance traveled during the simulation divided by the driving time. For driving cycles that specify "vehicle off" rest periods (e.g., FUDS and SFUDS), these rest periods are not included in this calculation.

Total Distance Traveled. The distance traveled during the simulation run is calculated by integration of the calculated vehicle speed at each time increment of the cycle simulated.

Test Time. The real time of the simulation is calculated. For driving cycles that specify "vehicle off" rest periods (e.g., FUDS and SFUDS), these rest periods are not included in the calculated test time.

Cycle Number of Termination. The cycle number (or number of screens for non-cyclic speed versus time events) at which the simulation run is terminated, is printed.

DOD at Termination. The DOD of the traction battery when the simulation was terminated is calculated and printed.

Battery Voltage and Current at Termination. The calculated traction battery voltage and current at the point of termination of the simulation run is printed.

FUDS Cycle Information. This information is printed only for FUDS cycle simulations where the "flag point" [described in the draft SAE J227 Eiectric Vehicle Test Procedure (time, cycle number and distance)] is printed. 
Average Component Power Losses. The average component losses for the test run is calculated for each driveline component. The losses for each component generally represent heat. These losses are totaled for both the driving and regeneration modes of component operation.

Steady State Powertrain Efficiencies. The driveline efficiencies under constant speed conditions and the input road conditions for the simulation run are calculated and displayed.

Simulation Diagnostics. This section of the printed output provides an indication of the quality of the simulation. SIMPLEV cannot invent component behavior. To avoid termination because of missing or incomplete component data, efficiencies and current and torque/speed envelopes in the component data files may be extrapolated beyond known values. In this case, SIMPLEV continues to execute and tally the number of times the information in the data files was extrapolated. In general, a low number (compared to the number of speed points in the simulation) indicates a good quality run, while a high number indicates that the component operated outside its defined regime, and the simulation results may be suspect.

\section{Troubleshooting}

SIMPLEV contains many built-in checks on input data validity as well as provisions for extrapolating data beyond the information contained in the input files. The result of these checks and extrapolations allows SIMPLEV to run without encountering computation errors. Therefore, problems during the program execution can most likely be attributed to some other root cause.

SIMPLEV has been used extensively on IBM DOS equipment with minimal problems; ranging from IBM PCS and XTs, to PS/2s. Some Terminate and Stay Resident (TSR) software programs, as well as some PC networks, are incompatible with SIMPLEV, which produces random and unpredictable execution problems. If an unexplained problem occurs during the program execution, it is suggested that these TSR programs be unloaded from the computer RAM prior to executing SIMPLEV. 
If printed graphs do not appear (as on the computer monitor), the user should check to verify that the DOS GRAPHICS command has been executed.

SIMPLEV is written in 8 interconnected modules. These modules are listed below with a brief description of the function of each.

SIMPLEV - This module contains the algorithms that perform the mathematical calculations of the simulation. In addition, this module controls the simulation output both to the computer monitor and printer, and calls the other modules as necessary. Most serious errors that cause failure in execution occur in this module, and are attributed to faulty input parameters that cause division by zero.

LOADVEH - This module reads the selected data file containing the vehicle descriptive parameters. The specific information read by this module and the proper file format is discussed under the heading Vehicle Definition in the next section of this report.

LOADMOT - This module reads the selected motor and inverter/controller data file containing the efficienciy matrices and other information. Scaling of motors and inverters/controllers is also performed in this module. The specific information read by this module and the proper file format is discussed under the headings Motors and Inverters/Controllers in the following section of this report.

LOADTX - This module reads the selected transmission data file containing the efficiency matrices, gear ratios, and other information. Scaling of conventional transmissions, as well as defining continuously variable transmissions, are also performed in this module. The specific information read by this module and the proper file format is discussed under the heading Transmissions in the next section of this report.

LOADBTY - This module reads the selected battery data file containing open circuit voltage and battery resistance descriptions. Scaling of 
the battery is also performed in this module. The specific information read by this module and the proper file format is discussed under the heading Battery files in the next section of this report.

LOADCYC - This module reads the selected driving cycle data file containing the speed versus time description of the cycle. Additionally, weather and road conditions are input to SIMPLEV through this module. The specific information read by this module and the proper file format is discussed under the heading Driving Schedule Files in the next section of this report.

COASTOWN - This module performs a simulated vehicle coastdown with all its associated calculations and outputs to the computer monitor and ASCII files. Division by zero errors due to faulty input parameters may occur in this module, however, they are less common than in the SIMPLEV module.

RITEDATA - This module performs all of the writing to output file operations.

\section{Compiler Error Messages}

Error messages produced by the BASIC compiler generally identify the module in which the error occurred. The following compller error messages likely to be generated are given below along with a description of the probable cause of the error.

out of Memory. There is not enough computer memory available to run SIMPLEV, it requires approximately $200 \mathrm{kB}$ of computer RAM to run. You should free some memory by unloading any memory resident programs, or run SIMPLEV on a PC with at least $200 \mathrm{kB}$ of available memory.

Out of String Space. This is not a very common error. It is caused by exceeding the maximum space available for string variables. To correct this situation, shorten the text comments and text identifiers in the component data files that were read previous to this error. 
Device Timeout. Either SIMPLEV tried to use your printer or external disk drive and it was not turned on, or you do not have a parallel printer attached to the PC. Turn on or attach the appropriate device.

Device Fault. Either SIMPLEV tried to use your printer or external disk drive and it was not turned on, or you do not have a parallel printer attached to the PC. Turn on or attach the appropriate device. Other causes of this error can be associated with device failure or trying to read unformatted disks.

Printer out of Paper. The printer attached to the PC parallel communications port (usually LPT1) is out of paper. The user should put paper in the printer.

File Not Found. Either SIMPLEV could not find the component data file as specified or the diskette in which data was initially output to was taken out of the diskette drive. Common causes of this error are not specifying the full path of component data files, incorrect path specification, the data files selected from the menus are not in the same drive/directory as SIMPLEV.EXE, or data file names were misspelled.

Disk Full. SIMPLEV tried to write data to a full disk. Files created by SIMPLEV can become very large.

Permission Denied. SIMPLEV tried to write data to a write-protected file or diskette. Removing the write-protection as appropriate will eliminate this error.

Drive Door Open. The diskette drive door specified for either input or output files is open.

Path Not Found. SIMPLEV was unable to find the path specified for either the input or output files. Either the intended path does not exist or it was misspelled. 


\section{PROGRAM DESCRIPTION}

\section{Description of Operation}

\section{Vehicle/Powertrain Configuration}

The electric vehicle model is based upon conventional component arrangements as shown in Figure 29. The battery is electrically connected to the inverter/controller. Auxiliary loads and auxtliary power units are also assumed to be directly connected to the traction battery. The motor and inverter/controller are also connected via a direct electrical connection. The single motor is mechanically linked to the vehicle wheels through a transmission that may have either 1 or 2 gear ratios. Losses between components are not explicitly modeled (e.g., electrical transmission losses) but may be included in the component efficiency definitions if desired. Friction and windage losses in rotating components are associated with the particular component and also may be reflected in the efficiency maps.

\section{Road Load Power}

In theory, SIMPLEV's operation is easily understood; the power required at the driveshaft of the vehicle to move the vehicle from the speed at one time step to the speed at the next time step (i.e., $v_{t-1}$ to $v_{t}$ ) is calculated using:

$$
\begin{aligned}
& P(t)=P_{\text {acc }}+P_{\text {grade }}+P_{\text {aero }}+P_{\text {rolling }}+P_{\text {bearing }} \\
& \begin{array}{ll}
P_{\text {acc }} & =M_{e} \cdot d v(t) / d t \\
P_{\text {grade }} & =W \cdot \sin (\theta) \cdot v(t) \\
P_{\text {aero }} & =\left[1 /{ }_{2} \rho C_{d}(\gamma) A \cdot v_{r}(t)^{2}\right] \cdot v(t) \\
P_{\text {rolling }} & =\left[\left(C_{0}+C_{1} v(t)+C_{2} v(t)^{2}+C_{3} v(t)^{3}\right) \cdot W\right] \cdot v(t) \\
P_{\text {bearing }} & =\tau_{B} \cdot S_{w}(t)
\end{array}
\end{aligned}
$$




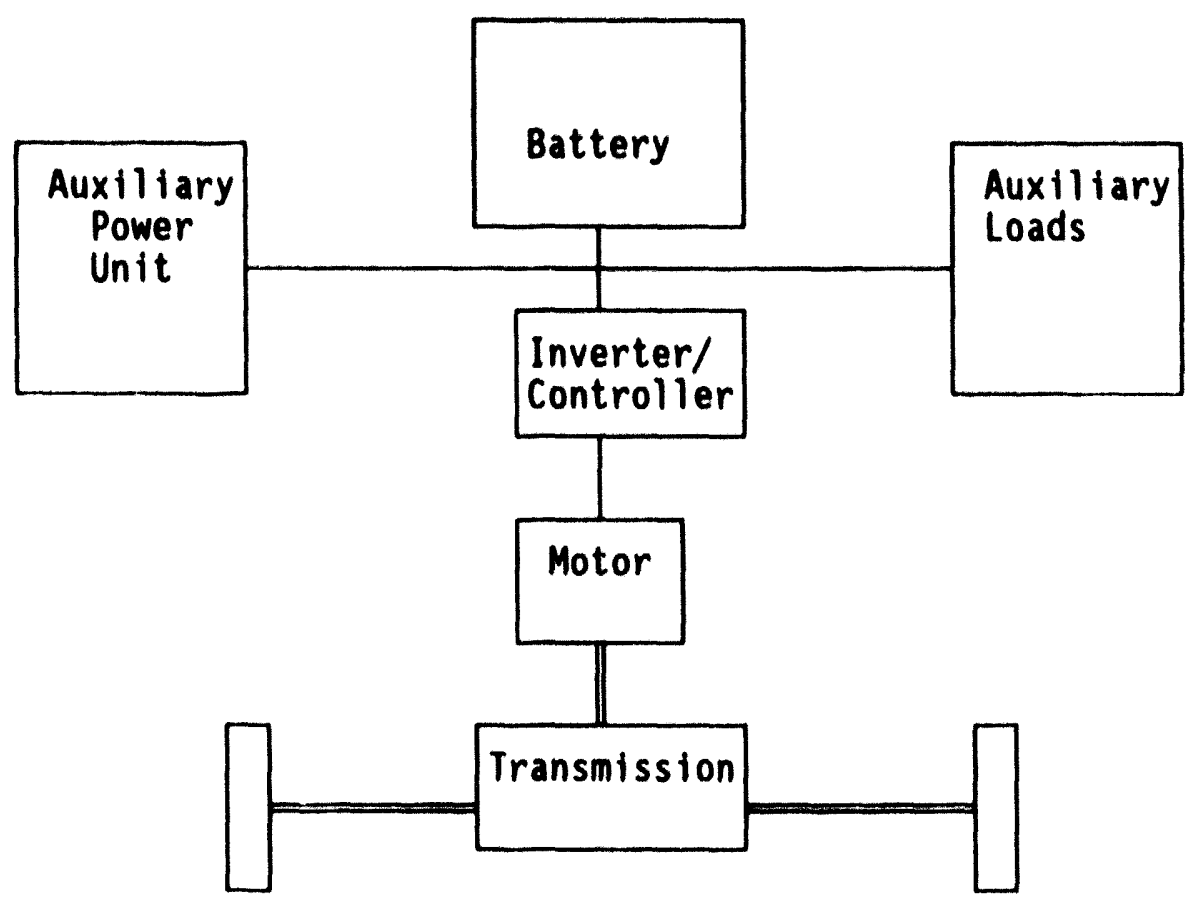

Figure 29. Electric vehicle block diagram assumed for SIMPLEV. 
where

$$
\begin{array}{ll}
P(t) & =\text { power as a function of time } \\
P_{\text {acc }} & =\text { acceleration/deceleration inertia power } \\
P_{\text {grade }} & =\text { power associated with gravity } \\
P_{\text {dero }} & =\text { aerodynamic drag power } \\
P_{\text {rolling }} & =\text { rolling resistance power } \\
P_{\text {bearing }} & =\text { wheel bearing loss power } \\
M_{e} & =\text { mass equivalent, includes rotational inertia of } 3 \% \\
\text { of } & \text { vehicle weight (i.e., } M_{e}=1.03 \cdot W / g, \\
\text { where } g & =\text { acceleration of gravity } \\
P & =\text { density of air } \\
C_{d}(\gamma) & =\text { aerodynamic drag coefficient as a function of wind } \\
& \text { yaw angle } \gamma \\
A & =\text { frontal area of vehicle } \\
v(t) & =\text { vehicle speed as a function of time } \\
V_{r}(t) & =\text { relative wind speed in direction of travel as a } \\
& =\text { function of time } \\
C_{0}, C_{1}, C_{2}, C_{3} & =\text { coefficients of rolling resistance } \\
W & =\text { weight of vehicle } \\
T_{B} & \text { wheel bearing torque drag } \\
\theta & \text { road grade angle measured from horizontal } \\
S_{w}(t) &
\end{array}
$$

The aerodynamic drag coefficient input by you, $C_{d}$, is corrected for $\gamma$ according to the following equations:

$$
\begin{array}{ll}
v_{\text {wind, } x}(t) & =-v(t) \cdot \sin (\alpha)-v_{w \text { ind }} \cdot \sin (\beta) \\
v_{\text {wind,y }}(t) & =-v(t) \cdot \cos (\alpha)-v_{w i n d} \cdot \cos (\beta) \\
v_{r}(t) & =\left[\left(v_{w i n d, x}(t)\right)^{2}+\left(v_{w i n d, y}(t)\right)^{2}\right]^{1 / 2} \\
\psi & =\tan ^{-1}\left(v_{\text {wind, }}+v_{\text {wind,y }}\right)
\end{array}
$$


where

$$
C_{d}(\gamma) \quad=C_{d}\left(1+a \cdot|\gamma|^{b}\right), \text { for }|\gamma| \leq 17.5^{\circ}
$$

$v_{\text {wind, }}(t)=\underset{\text { component of air speed relative to vehicle in direction of }}{\text { travel }}$

$v_{\text {wind,y }}(t)=$ component of air speed relative to vehicle perpendicular to direction of travel

a $\quad$ vehicle direction of travel (North $=0)$

$\beta \quad=$ wind direction (North=0)

$v_{w i n d} \quad=$ wind speed in direction $\beta$

$\checkmark \quad=$ wind direction relative to vehicle

$v_{r}(t) \quad=$ wind speed relative to vehicle

$\gamma \quad=$ wind yaw angle (direction of $v_{r}(t)$ relative to vehicle)

$a$ and $b=$ coefficients input you. Default values of $a=0.00194$ and

b

$=1.657026$ are assumed in lieu of values specified by you.

Driveshaft/Transmission Power

The driveshaft torque is calculated from and dependent upon the resultant direction (positive or negative) of the road load power, $P_{d}$. If the power required is positive, the power at the driveshaft of the vehicle is calculated as

$$
P_{d}(t) \quad=P_{\text {acc }}+P_{\text {grade }}+P_{\text {aero }}+P_{\text {rolling }}+P_{\text {bearing }}
$$

If the power required to move the vehicle from $v_{t-1}$ to $v_{t}$ is negative, the power at the driveshaft is calculated as

$$
P_{d}(t) \quad=P_{a c c}
$$

This latter case represents power that must be absorbed to slow the vehicle (i.e., when $v_{t-1}-v_{t}<0$ ) when $P_{d}<0$. 
The driveshaft torque, $\tau_{d}$, is then calculated from the vehicle speed, $v_{t}$, and the tire rolling radius $(r)$, for the appropriate condition. These relationships are

$$
\begin{aligned}
& s_{w}=v_{t} \div 2 \pi r \\
& \tau_{d}=P_{d} \div S_{w}, P_{d}>0 \\
& \tau_{d}=f_{r} \cdot\left(P_{d} \div S_{w}\right), \quad P_{d}<0
\end{aligned}
$$

where

$f_{r}$ is the fraction of torque available for regenerative braking and $s_{w}$ is wheel speed. Conversely, 1- $f_{r}$ is the fraction of torque absorbed in the vehicle friction brakes.

Motor

Using the driveshaft torque and speed, the efficiency is then determined from the data input via the transmission file for the appropriate gear ratio using a double linear interpolation scheme. From the calculated driveshaft power, $P_{d}$, and the transmission efficiency, $\eta_{t r}$, the power at the transmission/motor interface, $P_{m}$, is calculated from

$$
\begin{aligned}
& P_{m}=P_{d} \cdot \eta_{t r}, \text { for } P_{d}<0 \text { (regenerative braking quadrant of operation) } \\
& P_{m}=P_{d} \div \eta_{t} \text { for } P_{d}>0 \text { (driving quadrant of operation). }
\end{aligned}
$$

The motor speed, $s_{m}$, and motor torque, $\tau_{m}$, are then calculated from the transmission gear ratio, $r_{\text {gear }}$, the transmission driveshaft speed, and previously calculated motor power $P_{m}$ shown as

$$
\begin{aligned}
& s_{m}=s_{d} \cdot r_{\text {gear }} \\
& \tau_{m}=P_{m} \div s_{m} .
\end{aligned}
$$

From the motor torque and speed, the motor efficiency, $\eta_{m}$, is obtained via a double linear interpolation. Because the inverter/controller efficiency 
tables are also given in terms of motor output speed and torque, the inverter/controller efficiency is likewise determined.

Maximum Motor Torque. At this point, a check is performed to determine if the maximum motor torque envelope has not been exceeded; comparing $\tau_{m}$ to the interpolated maximum torque value, $\tau_{\operatorname{m}, \max }$, from the motor file. If the maximum motor torque envelope has been exceeded, $\tau_{m}$ is set equal to $\tau_{m, \max }$ and a solution for the following relationship is found by iteration of $v_{t}$ and is written

$$
P_{m, \max }=P_{d} \div \eta_{t r}
$$

where $P_{m, \max }=$ function of motor speed, $P_{d}=$ function of vehicle speed, and $\eta_{\mathrm{tr}}=$ function of driveshaft torque and speed.

This solution now provides the fastest speed possible within the maximum motor torque envelope.

\section{Inverter/Controller}

From the motor power, $P_{m}$, and the motor efficiency at the current operating point, $\eta_{m}$, the power at the motor/(inverter/controller) interface, $P_{i}$, is calculated by one of the following relationships

$$
\begin{aligned}
& P_{i}=P_{m} \cdot \eta_{m} \text {, for } P_{m}<0 \text { (regenerative braking quadrant of operation) } \\
& P_{i}=P_{m} \div \eta_{m} \text { for } P_{m}>0 \text { (driving quadrant of operation). }
\end{aligned}
$$

\section{Battery}

From the inverter/controller power, $P_{i}$, and the inverter/controller efficiency at the current operating point, $\eta_{i}$, the traction power at the battery/(inverter/controller) interface, $P_{B, t r a c t}$, is calculated by one of the following relationships 
$P_{B, \text { tract }}=P_{i} \cdot \eta_{i}$, for $P_{i}<0$ (regenerative braking quadrant of operation)

$P_{B, \text { tract }}=P_{i}+\eta_{i}$, for $P_{i}>0$ (driving quadrant of operation).

The total battery power, $P_{B, \text { total }}$, is determined by algebraically adding any power contributed by the auxiliary power unit, $P_{B, A P U}$, and auxiliary loads $P_{B, \text { aux }}$ as

$$
P_{B, \text { total }}=P_{B, \text { APU }}+P_{B, \text { aux }} \text {. }
$$

By convention, battery power and current is positive out of the battery (discharge) and negative into the battery (discharge). By this rule $P_{B \text {,aux }}$ is generally positive.

From the calculated total battery power, $P_{B, \text { total }}$, and the battery characteristics (i.e., open circuit voltage, $V_{o c}$, and resistance, $d V / d I_{B}$ at the current depth-of-discharge) is found by linear interpolation of the data input via the battery file, the battery current $\left(I_{B}\right)$ is determined by solving for the real root of the quadratic equation given as

$$
P_{B, \text { total }}=d V / d I \cdot I_{B}^{2}+V_{O C} \cdot I_{B}
$$

which is given by

$$
\left(-V_{O C}+\left(V_{O C}{ }^{2}-4 \cdot d V / d I \cdot P_{B, \text { tota } 1}\right)^{1 / 2}\right) \div 2 \cdot d V / d I
$$

The battery voltage under load, $V_{B}$, is then calculated from the relationship

$$
V_{B}=P_{B, \text { total }} \div I_{B} \text {. }
$$

Because the battery, auxiliary power unit, auxiliary loads, and powertrain are assumed to be electrically connected in parallel (Figure 29), the respective current to each of these components can be calculated as follows 


$$
\begin{array}{ll}
I_{A P U} & =P_{A P U}+V_{B} \\
I_{\text {aux }} & =P_{\text {aux }}+V_{B} \\
I_{\text {tract }} & =P_{B, \text { tract }} \div V_{B} .
\end{array}
$$

\section{Minimum Voltage}

The calculated battery voltage, $V_{B}$, is then compared to the minimum voltage, $V_{\min }$, as specified by you.

If $V_{B}<V_{\min }$, then $V_{B}$ is set equal to $V_{\min }$ and the maximum battery current at this voltage is found from the relationship

$$
I_{V_{\min }}=\left(V_{\min }-V_{O C}\right)+d I / d V
$$

The remaining current and power at the minimum battery voltage available to the powertrain is then calculated

$$
\begin{aligned}
& I_{V_{\text {min,tract }}}=I_{V_{\text {min }}}-\left(P_{A P U}+V_{B}\right)-\left(P_{\text {aux }}+V_{B}\right) \\
& P_{\text {tract, } V_{\text {min }}}=I_{V_{\text {min, tract }}} \cdot V_{\text {min }} .
\end{aligned}
$$

A solution for $v_{t}$ is then found by iteration, that satisfies the relationship

$$
P_{\text {tract, } V_{\min }}=P_{d} \div\left(\eta \cdot \eta_{m} \cdot \eta_{i}\right)
$$

where

$$
P_{d}=\text { function of vehicle speed; and } \eta, \eta_{m} \text {, and } \eta_{i} \text { are ultimately }
$$

functions of the driveshaft torque and vehicle speed, $\left(\tau_{d}\right.$ and $\left.v_{t}\right)$.

This solution gives the maximum vehicle speed possible while being constrained by the minimum battery voltage.

\section{Maximum Current}

The calculated current required to the powertrain is compared to the maximum allowable current, $I_{\max }$, which is a function of motor speed, $s_{m}$. If 
the maximum current for the calculated motor speed is encountered (i.e., $I_{\text {tract }}>I_{\max }$ ) then $I_{\text {tract }}$ is set equal to $I_{\max , \text { tract }}$ and the battery voltage, $V_{B}$, is determined from the relationship

$$
V_{B}=V_{\text {oC }}-\left(I_{\text {max }}+I_{A P U}+I_{\text {aux }}\right)+d I / d V \text {. }
$$

This battery voltage, $V_{B}$, is then compared to the minimum voltage, $V_{\min }$, as specified by you. If $V_{B}<V_{\min }$, then $V_{B}$ is set equal to $V_{\min }$ and the procedure outlined above is followed. If $V_{B} \geq V_{\min }$, the maximum power available to the powertrain, $P_{\text {tract }}$, and the currents required for auxiliary loads, auxiliary power unit, and total battery current, $I_{B}$, is calculated according to the following relationships

$$
\begin{aligned}
& P_{\text {tract }}=V_{\text {min }} \cdot I_{\text {max }} \\
& I_{\text {aux }}=P_{\text {aux }} \div V_{\text {min }} \\
& I_{\text {APU }}=P_{A P U} \div V_{\text {min }} \\
& I_{B}=I_{\max }+I_{\text {aux }}+I_{A P U} .
\end{aligned}
$$

A solution for $v_{t}$ is then found by iteration, that satisfies the relationship

$$
P_{\text {tract }}, v_{\min }=P_{d} \div\left(\eta \cdot \eta_{m} \cdot \eta_{i}\right)
$$

where

$P_{d}=$ function of vehicle speed; and $\eta, \eta_{m}$, and $\eta_{i}$ are ultimately functions of the driveshaft torque and vehicle speed, $\left(\tau_{d}\right.$ and $\left.v_{t}\right)$.

Battery Capacity and DOD

During the program execution, the ampere-hours into and out of the battery are summed as well as the average ampere-hours through the battery. These quantities are then divided by the appropriate time to calculate the average charge, $\left(I_{\text {avg }}\right.$, charge $)$ discharge $\left(I_{\text {avg }}\right.$, discharge $)$, and net current, $\left(I_{a v g}\right)$ respectively. This is shown by the following equations 


$$
\begin{array}{ll}
\mathrm{I}_{\text {avg, charge }} & =\Sigma\left(\mathrm{I}_{\text {charge }} \cdot \Delta \mathrm{t}_{\text {charge }}\right)+\Sigma \Delta \mathrm{t}_{\text {charge }} \\
\mathrm{I}_{\text {avg,disch }} & =\Sigma\left(\mathrm{I}_{\text {disch }} \cdot \Delta \mathrm{t}_{\text {disch }}\right)+\Sigma \Delta \mathrm{t}_{\text {dischg }} \\
\mathrm{I}_{\text {avg }} & =\Sigma\left(\mathrm{I}_{B} \cdot \Delta \mathrm{t}\right)+\Sigma \Delta \mathrm{t}
\end{array}
$$

where

$$
A h_{\text {net }} \Delta t \quad=\Sigma\left(I_{B} \cdot \Delta t\right)
$$

The average battery current, $I_{\text {avg }}$, is used to calculate the available battery capacity $\left(A h_{C a p}\right)$ from the Puekert relationship using the constants from the battery file. This equation is of the form

$$
A h_{\text {Cap }}=a \cdot I_{\text {avg }}{ }^{b},
$$

where

$a$ and $b$ are constants.

The DOD at each time increment of the simulation is then given by the following

$$
D O D=A h_{\text {net }} \div A h_{\text {Cap }}
$$

\section{Battery Scaling}

Battery scaling methodology is easily understood. After you enter a modified battery ampere-hour capacity, the Puekert relationship, dV/dI versus $D O D$, and battery weight is adjusted according to the following relationships

$$
\begin{aligned}
A h_{\text {Cap , 1 }} & =A h_{\text {Cap }} \\
\left(\mathrm{dV} / \mathrm{dI}_{B}\right)_{1} & =\mathrm{dV} / \mathrm{dI_{B }} \cdot A h_{\text {Cap }, 1} \div A h_{\text {Cap }} \\
\mathrm{b}_{1} & =b \cdot\left(A h_{\text {Cap , 1 }} \div A h_{\text {Cap }}\right)^{1-b} \\
W_{\text {module, 1 }} & =W_{\text {module }} \cdot A h_{\text {Cap , 1 }}+A h_{\text {Cap }}
\end{aligned}
$$

where 


$$
\begin{aligned}
& \begin{array}{l}
\text { Ah } h_{\text {Cap }, 1} \\
\text { the new ampere-hour capacity for which the } \\
\text { battery is to be scaled }
\end{array} \\
& \begin{array}{l}
b_{1} \text { new Peukert constant } \\
(\mathrm{dV} / \mathrm{dI})_{1} \text { represent the new values of battery } \mathrm{dV} / \mathrm{dI}_{\mathrm{B}}
\end{array} \\
& W_{\text {module, }}, W_{\text {module }}=\text { new and initial battery module weight, } \\
& \text { respectively. }
\end{aligned}
$$

\section{Energy}

Energy calculations are based upon the summation of the calculated power at each component interface over the appropriate time intervals.

$\begin{array}{ll}E_{B, \text { gross }} & =\Sigma\left(P_{B, \text { total }} \cdot \Delta t\right) \text { when } P_{B, \text { total }}>0 \\ E_{B, \text { chg }} & =\Sigma\left(P_{B, \text { total }} \cdot \Delta t\right) \text { when } P_{B, \text { total }}<0 \\ E_{A P U} & =\Sigma\left(P_{A P U} \cdot \Delta t\right) \text { when } P_{A P U} \neq 0 \\ E_{\text {aux }} & =\Sigma\left(P_{\text {aux }} \cdot \Delta t\right) \text { when } P_{\text {aux }} \neq 0 \\ E_{\text {tract,driving }} & =\Sigma\left(P_{B, \text { tract }} \cdot \Delta t\right) \text { when } P_{B, \text { tract }}>0 \\ E_{\text {tract, regen }} & =\Sigma\left(P_{B, \text { tract }} \cdot \Delta t\right) \text { when } P_{B, \text { tract }}<0 \\ E_{i, \text { driving }} & =\Sigma\left(P_{i} \cdot \Delta t\right) \text { when } P_{i}>0 \\ E_{i, \text { regen }} & =\Sigma\left(P_{i} \cdot \Delta t\right) \text { when } P_{i}<0 \\ E_{m, \text { driving }} & =\Sigma\left(P_{m} \cdot \Delta t\right) \text { when } P_{m}>0 \\ E_{m, \text { regen }} & =\Sigma\left(P_{m} \cdot \Delta t\right) \text { when } P_{m}<0 \\ E_{d, \text { driving }} & =\Sigma\left(P_{d} \cdot \Delta t\right) \text { when } P_{d}>0 \\ E_{d, \text { regen }} & =\Sigma\left(P_{d} \cdot \Delta t\right) \text { when } P_{d}<0 \\ E_{B, \text { net }} & =E_{B, \text { gross }}-E_{B, \text { chg }}\end{array}$

where

$\begin{array}{ll}E_{B, \text { gross }} & =\text { total energy discharged from the battery } \\ E_{B, \text { chg }} & =\text { total energy into the battery } \\ E_{A P U} & =\text { total energy supplied by the auxiliary power } \\ & \text { unit } \\ E_{\text {aux }} & =\text { total energy consumed by auxiliary loads } \\ E_{\text {tract, driving }} & =\text { total battery energy used for vehicle traction } \\ E_{\text {tract, regen }} & =\text { total battery energy recovered from }\end{array}$


regenerative braking

$E_{i \text {,driving }}$
$E_{i \text {,regen }}$
$E_{m, \text { driving }}$
$E_{m \text {, regen }}$
$E_{B \text {, net }}$
$E_{d \text {,driving }}$
$E_{d, \text { regen }}$

Average Battery Power
$=$ total energy out of inverter/controller

= total energy into inverter/controller

= total energy out of motor

= total energy into motor

$=$ net battery energy

= total energy delivered to wheels

= total energy at driveshaft from regenerative braking

The average battery discharge, charge, and net power is calculated from the appropriate energy divided by the appropriate total time using

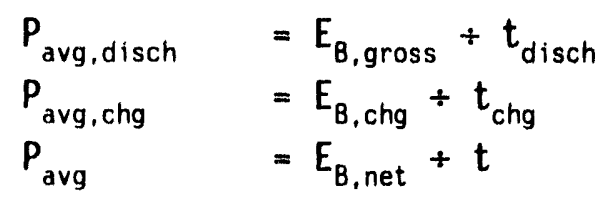

where

$\begin{array}{ll}P_{\text {avg,disch }} & =\text { average battery discharge power } \\ P_{\text {avg,chg }} & =\text { average power into battery } \\ P_{\text {avg }} & =\text { average battery power } \\ P_{\text {disch }} & =\text { total time during battery discharge } \\ t_{\text {chg }} & =\text { total time during battery charge } \\ t & =\text { total time of simulation. }\end{array}$

\section{Average Component Efficiencies}

The average component efficiencies are obtained for each mode of operation (driving and regeneration) by division of the appropriate calculated energy quantities. The specific average component efficiencies that are calculated in the simulation are given below.

$$
\begin{array}{ll}
\eta_{\text {avg,trans,driving }} & =E_{d, \text { driving }}+E_{m, \text { driving }} \\
\eta_{\text {avg,trans, regen }} & =E_{m, \text { regen }}+E_{d, \text { regen }}
\end{array}
$$




$\begin{array}{ll}\eta_{\text {avg,m,driving }} & =E_{m, d r i v i n g}+E_{i, \text { driving }} \\ \eta_{\text {avg,m, regen }} & =E_{i, \text { regen }}+E_{m, \text { regen }} \\ \eta_{\text {avg, i,driving }} & =E_{i, d r i v i n g}+E_{\text {tract,driving }} \\ \eta_{\text {avg,i,regen }} & =E_{\text {tract,regen }}+E_{i, \text { regen }} \\ \eta_{\text {avg,ptrn,driving }} & =E_{d, d r i v i n g}+E_{\text {tract,driving }} \\ \eta_{\text {avg,ptrn, regen }} & =E_{\text {tract, regen }}+E_{d, \text { regen }} .\end{array}$

\section{Battery Efficiency}

The battery efficiency is obtained for each mode of operation (charge and discharge). The fictitious battery power assuming no $\mathrm{dV} / \mathrm{dI}$ losses is calculated for each time step and summed to determine the total battery energy without losses. These energy values are then used to determine the battery energy efficiency according to the following equations

$\begin{array}{ll}P_{\text {sys }} & =V_{O C} \cdot I_{B} \\ E_{\text {sys,disch }} & =\Sigma\left(P_{\text {sys }} \cdot \Delta t\right) \text { when } P_{\text {sys }}>0 \\ E_{\text {sys, chg }} & =\Sigma\left(P_{\text {sys }} \cdot \Delta t\right) \text { when } P_{\text {sys }}<0 \\ \eta_{\text {avg, batt,disch }} & =E_{B, \text { gross }}+E_{\text {sys, disch }} \\ \eta_{\text {avg, batt, chg }} & =E_{B, \text { chg }}+E_{\text {sys, chg }} .\end{array}$

Average Component Losses

The average component power losses are calculated from the energy through each component for each mode of operation as follows

$\begin{array}{ll}L_{B, \text { disch }} & =\left(E_{\text {sys,disch }}-E_{B, \text { gross }}\right) \div \Sigma \Delta t \\ L_{B, \text { chg }} & =\left(E_{B, \text { chg }}-E_{\text {sys, chg }}\right)+\Sigma \Delta t \\ L_{m, \text { driving }} & =\left(E_{m, \text { driving }}-E_{i, \text { driving }}\right)+\Sigma \Delta t \\ L_{m, \text { regen }} & =\left(E_{i, \text { regen }}-E_{m, \text { regen }}\right)+\Sigma \Delta t \\ L_{i, \text { driving }} & =\left(E_{i, \text { driving }}-E_{\text {tract,driving }}\right)+\Sigma \Delta t \\ L_{i, \text { regen }} & =\left(E_{\text {tract, regen }}-E_{i, \text { regen }}\right) \div \Sigma \Delta t \\ L_{\text {trans,driving }} & =\left(E_{d, \text { driving }}-E_{m, \text { driving }}\right)+\Sigma \Delta t \\ L_{\text {trans, regen }} & =\left(E_{m, \text { regen }}-E_{d, \text { regen }}\right)+\Sigma \Delta t\end{array}$




\section{Coastdown Calculations}

The calculation of vehicle coastdown times and loads is an iterative solution for the vehicle speed, $v(t)$, in the road load equation where in the energy dissipated via aerodynamic drag, wheel bearing drag, and tire losses are equal to the change in vehicle kinetic energy from one time step to the next. In other words, $v(t)$ is found; which satisfies the following equation.

$$
-P_{\text {acc }}=P_{\text {grade }}+P_{\text {aero }}+P_{\text {rolling }}+P_{\text {bearing }} \text {. }
$$

The coastdown times for the speed ranges listed in the simulation output are linearly interpolated from the calculated times at the speeds closest to the desired speeds.

\section{Input Parameters and Component Definition}

As previously described, the input parameters are either read from component files or input from the PC keyboard. The following sections describe the data contained in the component files and the format of these files. From this information, you may construct component files in ASCII format. All parameters must be present in the order and location specified. If a parameter value (such as $C_{2}$ is not used, a " 0 " must be entered at the appropriate place as a "place holder" in order for the information to be properly read by SIMPLEV.

\section{Vehicle Definition}

The simulated vehicle is completely described mathematically by the coefficients in the road load equation. These coefficients are initially read from the vehicle files (i.e., those ASCII files with the ".VEH" extension. The listing of these files supplied with SIMPLEV Version 1.0 can be found in Appendix B. You can write your own vehicle files and input them into the program at the appropriate prompt as described in Section 1 of this report. 


\section{Vehicle File}

The vehicle file structure is shown by example of the IDSEP vehicle in Figure 30. Except for the first line of the vehicle file, numerical values should be the first to appear on a line. Descriptions of these values or notations may be entered after the numerical values on the same line.

Line 1. The first line of the vehicle file must contain a character string. The information on this line is used to identify the vehicle in the program output.

Line 2. Line 2 contains the weight (in pounds) of the vehicle chassis and body. SIMPLEV will add the payload and calculated total battery weight to this weight to calculate the total vehicle weight. The battery weight is either with or without ancillary subsystems depending upon whether or not these are included in the battery file.

Line 3. The weight of any payload including driver (in pounds) should be entered on 1 ine 3 .

Line 4. The vehicle aerodynamic drag coefficient, $C_{d}$, is dimensionless and should be entered on line 4 .

Line 5. The projected frontal area, A, of the vehicle is entered on line 5 . 


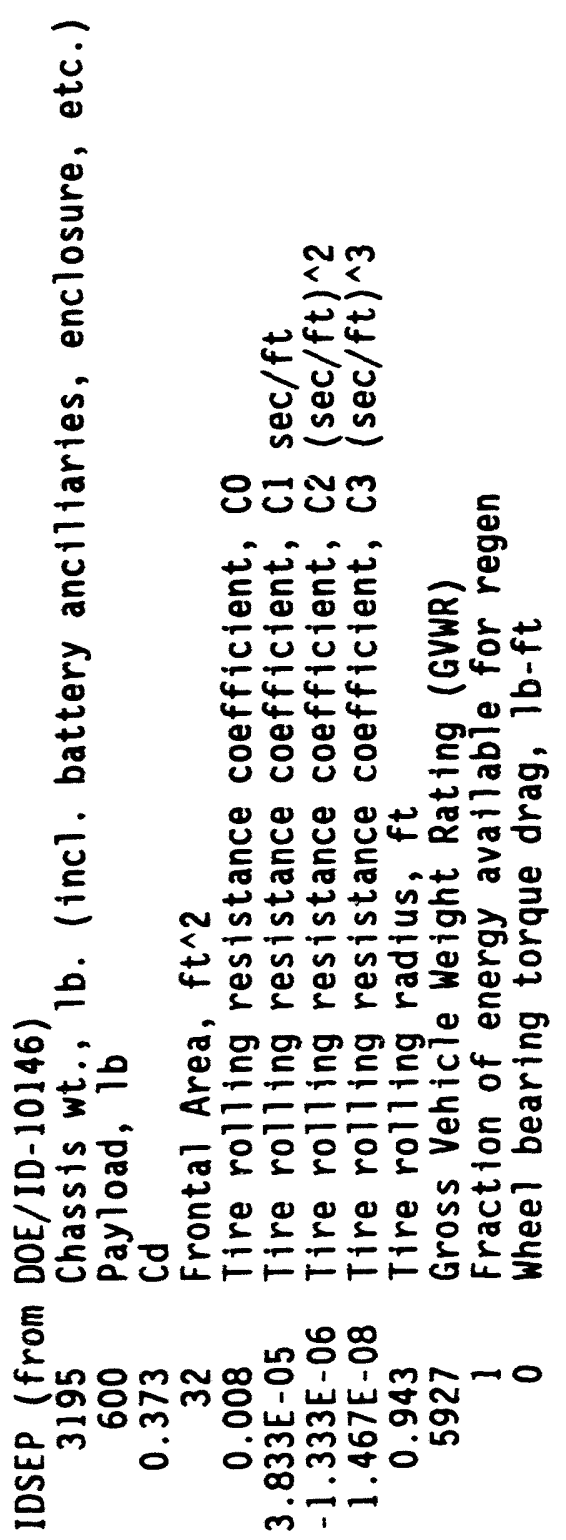


Lines 6 through 9. The coefficients of tire rolling resistance, $C_{0}, c_{1}$, $C_{2}$, and $C_{3}$ should be entered on 1 ines $6,7,8$, and 9 respectively. The respective dimensions of $C_{1}, C_{2}$, and $C_{3}$ are $s / f t,(s / f t)^{2}$ and, $(s / f t)^{3}, C_{0}$ is dimensionless.

Line 10. The tire rolling radius (in $\mathrm{ft}$ ) of the drive wheel(s) is entered on line 10.

Line 11. The gross vehicle weight rating in pounds (GWWR) is entered on line 11. If the total calculated vehicle weight exceeds this value, a caution warning is displayed on the "Change Vehicle Parameters Menu" during the input session and on the printed output. SIMPLEV will still run even if the GVWR is exceeded.

Line 12. The fraction of energy at the drive wheel(s) (a value between 0 and 1 that may be used for regeneration) is entered on line 12. A value of zero represents a vehicle with no regenerative braking, while a value of 1 represents a vehicle that brakes by regeneration only with no energy being absorbed by friction braking.

Line 13. Wheel bearing drag $\left(\tau_{B}\right)$ in $1 \mathrm{~b}$ - $\mathrm{ft}$ should be entered on line 13.

The numerical values contained in this file will be displayed in the "Change Vehicle Parameters Menu" where you will be given the opportunity to change or modify them.

Transmissions

Two types of transmissions or motor to wheel interfaces are possible in SIMPLEV. A conventional one- or two-speed geared transmission is described by the torque and speed versus efficiency file. This file defines the performance of the transmission in two quadrants of operation: positive speed and both positive and negative torque. A simple continuously variable transmission model is also available and is defined by parameters input from the PC keyboard. 
One-or Two-Speed Geared Transmissions. This type of transmission is defined by the ASCII transmission files (those with ".TX" filename extensions) according to the example of the IDSEP transmission file shown in Figure 31 . The efficiency matrix for the transmission is in terms of the transmission output torques and output speeds. In this example the values in the efficiency matrix are either unity or zero; because the entire driveline efficiency is included on the motor efficiency matrix. Zero values reflect no regeneration below the equivalent driveshaft speed of $16 \mathrm{~km} / \mathrm{h}(10 \mathrm{mph})$. Although, including zero efficiency is not a completely accurate description of vehicle operation; it produces the same result as would be accomplished in real hardware. The added benefit of this approach can be seen in the printed output where the average transmission loss during regeneration shows the average power that is dissipated in the vehicle brakes for the cycle if regeneration were deactivated below this speed.

The first line of the transmission file contains a character string identifier that will be used in the program output to identify the transmission used. Line 2 contains the value for the low ratio. Integer values on lines 3 and 4 define the size of the low gear efficiency matrix (rows and columns, respectively). The maximum size of the low gear efficiency matrix is 1 imited to 30 rows by 20 columns.

The transmission matrix is entered next as shown in Figure 31 . Column headings of transmission output torque (in $1 \mathrm{~b}-\mathrm{ft}$ ) are entered on 1 ine 5 in increasing order (negative torque represents the regenerative braking quadrant of operation). The transinission output speeds (in rpm) and efficiencies are then entered beginning on line 6 . The first value to appear on these lines must be the speed coinciding with the efficiencies entered on the remainder of this line. The number of efficiencies entered must coincide with the number of torque entries on line 5. For single speed transmissions, the high gear data described below may be omitted.

Following the low gear transmission efficiency matrix, the second gear ratio and the vehicle speed (in $\mathrm{mph}$ ) at which a gear change occurs is entered. If the vehicle speed is below this value, the transmission is assumed to operate in low gear. Likewise, if the vehicle speed is equal to or above this 
IDSEP "Dummy" Transaxle

15.52 Low gear ratio, no regen $<10 \mathrm{mph}$ 11

$\begin{array}{lllll}4 & -3000 & -.001 & 0 & 3000\end{array}$

$\begin{array}{rrrrr}0 & 0 & 0 & 1.0 & 1.0 \\ 100 & 0 & 0 & 1.0 & 1.0\end{array}$

$\begin{array}{lllll}100 & 0 & 0 & 1.0 & 1.0\end{array}$

$\begin{array}{lllll}148 & 0 & 0 & 1.0 & 1.0\end{array}$

$\begin{array}{lllll}148.001 & 1.0 & 1.0 & 1.0 & 1.0\end{array}$

$\begin{array}{lllll}200 & 1.0 & 1.0 & 1.0 & 1.0\end{array}$

$\begin{array}{lllll}300 & 1.0 & 1.0 & 1.0 & 1.0\end{array}$

$\begin{array}{lllll}400 & 1.0 & 1.0 & 1.0 & 1.0\end{array}$

$\begin{array}{lllll}500 & 1.0 & 1.0 & 1.0 & 1.0\end{array}$

$\begin{array}{lllll}600 & 1.0 & 1.0 & 1.0 & 1.0\end{array}$

$\begin{array}{lllll}700 & 1.0 & 1.0 & 1.0 & 1.0\end{array}$

$\begin{array}{lllll}1000 & 1.0 & 1.0 & 1.0 & 1.0\end{array}$

10.15 High gear ratio, no regen $<10 \mathrm{mph}$

22.2 Shift speed, mph 11

$\begin{array}{rrrrr} & -3000 & -.001 & 0 & 3000 \\ 0 & 0 & 0 & 1.0 & 1.0 \\ 100 & 0 & 0 & 1.0 & 1.0 \\ 148 & 0 & 0 & 1.0 & 1.0 \\ 148.001 & 1.0 & 1.0 & 1.0 & 1.0 \\ 200 & 1.0 & 1.0 & 1.0 & 1.0 \\ 300 & 1.0 & 1.0 & 1.0 & 1.0 \\ 400 & 1.0 & 1.0 & 1.0 & 1.0 \\ 500 & 1.0 & 1.0 & 1.0 & 1.0 \\ 600 & 1.0 & 1.0 & 1.0 & 1.0 \\ 700 & 1.0 & 1.0 & 1.0 & 1.0 \\ 1000 & 1.0 & 1.0 & 1.0 & 1.0\end{array}$

Figure 31. IDSEP transmission file. 
value, the transmission is assumed to operate in second gear. The speed at which the transmission is shifted may be changed on the "Change Vehicle Parameters Menu" during the input session. Next, the size of the high gear efficiency matrix (rows $X$ columns) is defined by integer values. The high gear efficiency matrix is then entered as described above for the low gear efficiency matrix. The maximum size of the low gear efficiency matrix is limited to 30 rows by 20 columns. Comments following the numerical values for gear ratios and gear change speeds are for user convenience and are ignored by SIMPLEV.

During program execution, SIMPLEV performs a double linear interpolation from the data in the transmission efficiency matrix. If either the transmission output speed or output torque is beyond the data supplied, then a linear extrapolation is performed. This calculated efficiency is then used to determine the transmission input power.

Scaling of One- or Two-Speed Transmissions. During the input session, the user is given the opportunity of scaling the transmission. The user is prompted for scaling factors for output speed and output torque. If this option is chosen, the row and column values for speed and torque are multiplied by the scaling factor supplied. The efficiency values in the transmission matrix will therefore represent efficiencies at different torques and speeds than what is in the transmission file.

Continuously Variable Transmissions (CVT). The continuously variable transmission (CVT) is also rather simple. SIMPLEV assumes a constant efficiency (input by the user at the prompt). The user also inputs values for the low and high ratios of the CVT and the motor speed that is to be held constant. SIMPLEV will hold this motor speed by calculating the gear ratio for the CVT that is between the high and low ratios. The low ratio is used if the vehicle speed requires a ratio lower than the minimum and the hi ratio is used if the vehicle speed is higher than the maximum. The graph in Figure 32 is a qualitative representation of the CVT operation strategy and compares it to a two-speed transmission. 


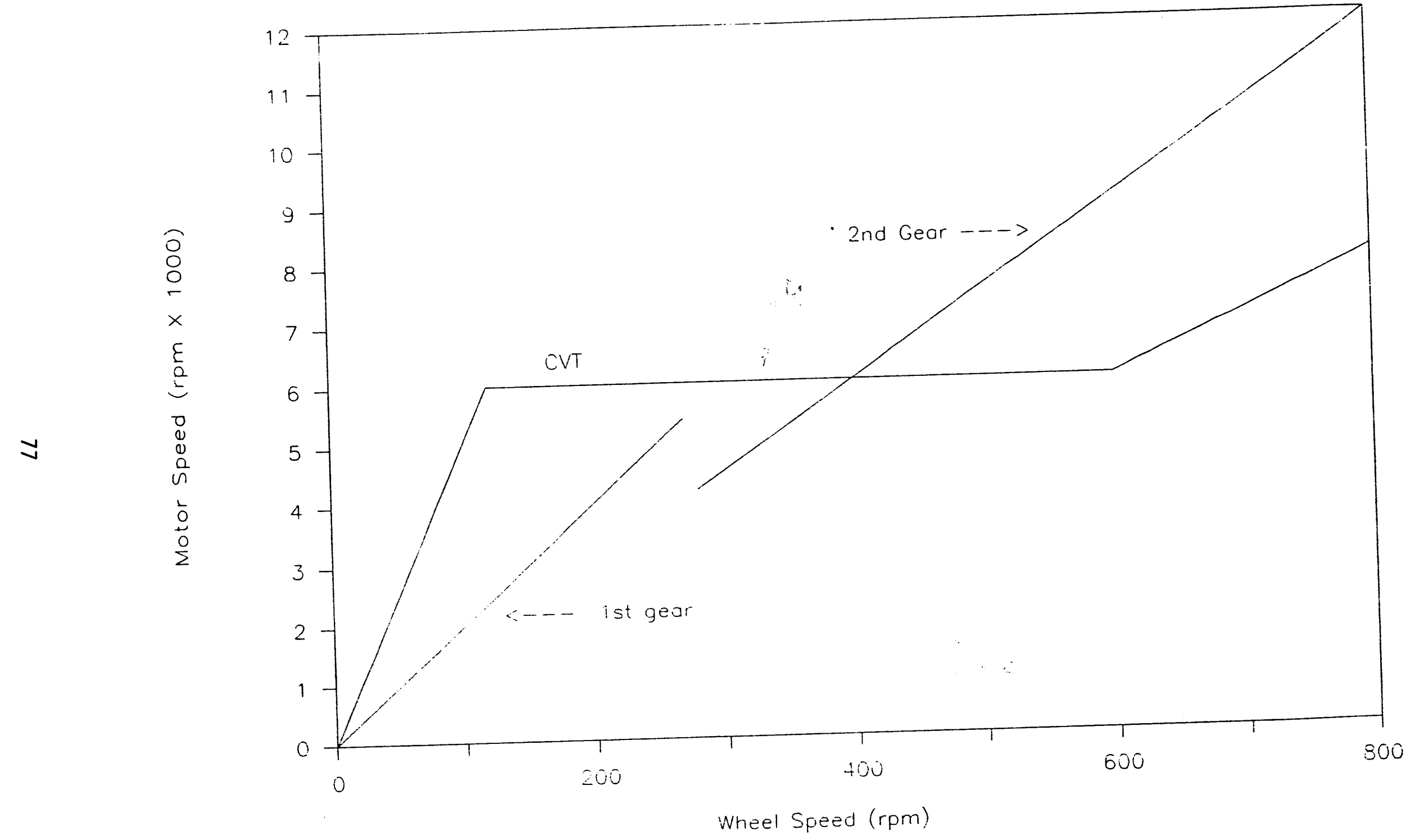

Figure 32. Continuously variable transinssion operating strategy. 
Motors

Motors are defined by the ASCII motor files (those with ".MOT" filename extensions) according to the example of the IDSEP motor file shown in Figure 33. The numerical information in this file contains the efficiency matrix for the motor in terms of the motor output torque and output speed and the peak torque versus speed of the motor. In this example, the values in the efficiency matrix include the transmission and inverter losses and represent the entire driveline efficiency. It should also be noted that the efficiency is set equal to ' $O$ ' for those cells representing regenerative braking below 16 $\mathrm{km} / \mathrm{h}$ (2305 rpm).

The first line of the motor file contains a character string identifier which will be used in the program output to identify the motor used. Integer values on lines 2 and 3 define the size of the motor efficiency matrix (rows and columns, respectively). The maximum size of the motor efficiency matrix is limited to 30 rows by 20 columns.

The motor efficiency matrix is entered next as shown in Figure 33. Column headings of motor output torque (in $1 \mathrm{~b}-\mathrm{ft}$ ) are entered on line 4 in increasing order (negative torque represents the regenerative braking quadrant of operation). The motor output speeds (in rpm) and efficiencies are then entered beginning on line 5. The first value to appear on these lines must be the speed coinciding with the efficiencies entered on the remainder of this line. The last entry on each line is the motor peak torques $(1 \mathrm{~b}-\mathrm{ft}$ ) corresponding to the speed entered on the beginning of each line. Character strings are allowed only on the first line of this file.

During program execution, SIMPLEV performs a double linear interpolation from the data in the motor efficiency matrix. If either the motor output speed or output torque is beyond the data supplied, then a linear extrapolation is performed. This calculated efficiency is then used to determine the motor input power.

Scaling Motor Efficiencies. During the input session, the user is given the opportunity of scaling the motor. The user is prompted for scaling 


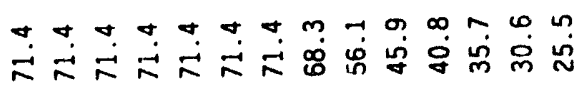

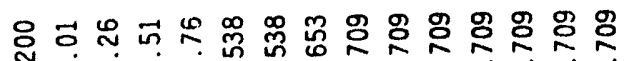

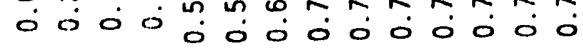

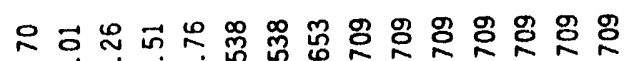

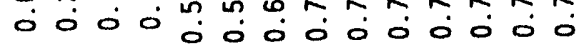

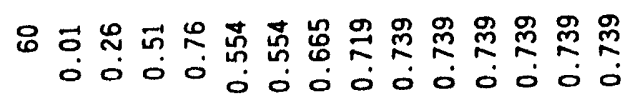

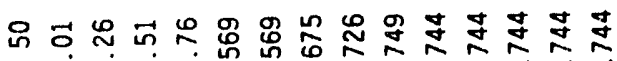

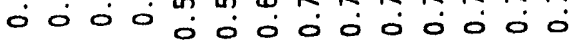

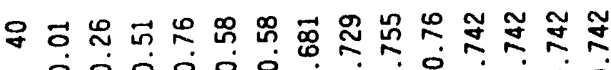
○0 $0000 \%$ 0.

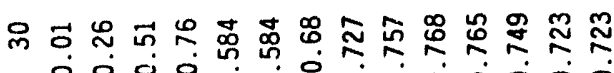

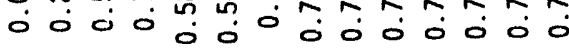

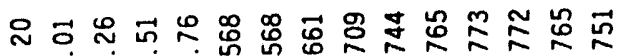

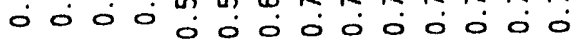

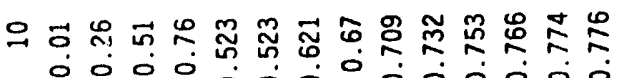

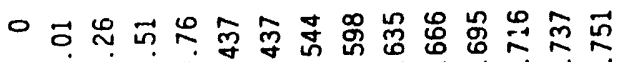
○ं 00 O

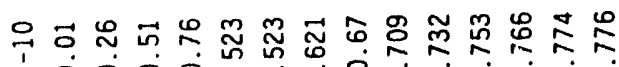

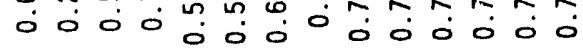

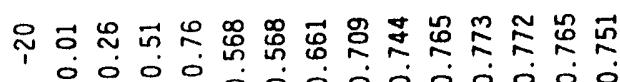

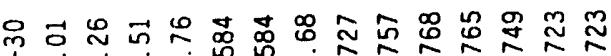

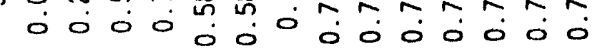

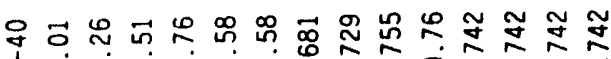

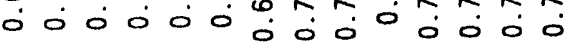

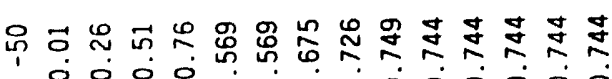

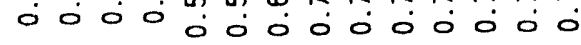

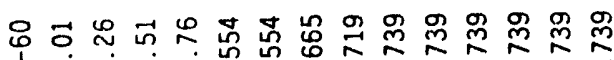

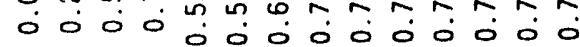

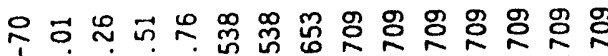

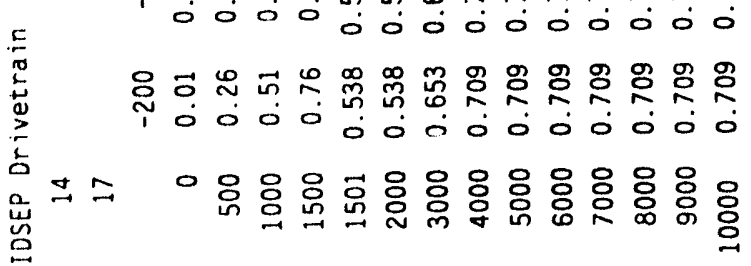


factors for output speed and output torque. If this option is chosen, the row and column values for speed and torque are multiplied by the scaling factor

supplied. The efficiency values in the motor matrix will therefore represent efficiencies at different torques and speeds than appeared in the motor file.

\section{Inverters/Controllers}

Inverters or controllers are defined by the ASCII files (those with ".INV" filename extensions) according to the example of the IDSEP inverter file shown in Figure 34 . The numerical information in this file contains the efficiency matrix for the inverter in terms of the motor output torque and speed and peak inverter/controller current versus motor speed. In this example, the values in the efficiency matrix are all unity.

The first line of the inverter/controller file contains a character string identifier that will be used in the program output to identify the inverter/controller used. The minimum inverter/controller voltage is entered on line 2. SIMPLEV will "clamp" this voltage during the simulation and will not allow the battery voltage under load to depress below this value. The maximum current limit (in amperes) is entered on line 3. SIMPLEV will adjust this value according to the $I / I_{\max }$ versus motor speed information in this file. SIMPLEV will "clamp" this current during the simulation and will not allow the battery current to exceed the calculated value of maximum current at any particular motor speed. Under either of these conditions, vehicle performance will be limited and a "best effort" attempt at the specified driving cycle will be simulated. Integer values on lines 4 and 5 define the size of the efficiency matrix (rows and columns, respectively). The maximum size of the inverter/controller efficiency matrix is limited to 30 rows by 20 columns. Comments following the numerical values for minimum voltage and maximum current are for user convenience and are ignored by SIMPLEV.

The inverter/controller efficiency matrix is entered next as shown in Figure 33. Column headings of motor output torque (in $1 b-f t$ ) are entered on line 6 in increasing order (negative torque represents the regenerative braking quadrant of operation). The motor output speeds (in rpm) and efficiencies are then entered beginning on 1 ine 7 . The first value to appear 
ค0.00000000

$00000000000 \%$

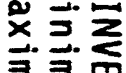

.000000000000

害要

000000000000

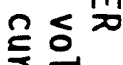

.

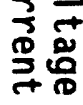

00000000000

00000000000 
on these lines must be the speed coinciding with the efficiencies entered on the remainder of this line. The last entry on each line is the ratio of peak current attainable to the absolute peak current, $I / I_{\max }$, corresponding to the speed entered on the beginning of each line. The number of efficiencies entered must coincide with the number of torque entries on line 6 .

During program execution, SIMPLEV performs a double linear interpolation from the data in the inverter/controller efficiency matrix. If either the output speed or output torque is beyond the data supplied, then a linear extrapolation is performed. This calculated efficiency is then used to determine the battery traction input power.

Scaling Inverter/Controller Efficiencies. During the input session, the user is given the opportunity of scaing the inverter/controller. The user is prompted for scaling factors for output speed and output torque. If this option is chosen, the row and column values for speed and torque are multiplied by the scaling factor supplied. The efficiency values in the inverter/controller matrix will therefore represent efficiencies at different torques and speeds than what is in the file.

Battery files. The battery is modeled using the open circuit voltage (VOC) and internal resistance ( $d V / d I)$ versus depth of discharge (DOD) characteristics. This information is read into SIMPLEV from the ASCII battery files (with the ".BTY" file extensions). Figure 35 listing the NIF-170 battery is an example a typical battery file.

The first line of the battery file contains a character string which is used by SIMPLEV to identify the battery used in the printed output. The second line is an integer value of the number of series components making up a module. SIMPLEV assumes cells and modules are connected in series. Line 3 contains the module battery weight in kilograms. The module weight is multiplied by the number of modules specified during the input session to arrive at the total battery weight. 


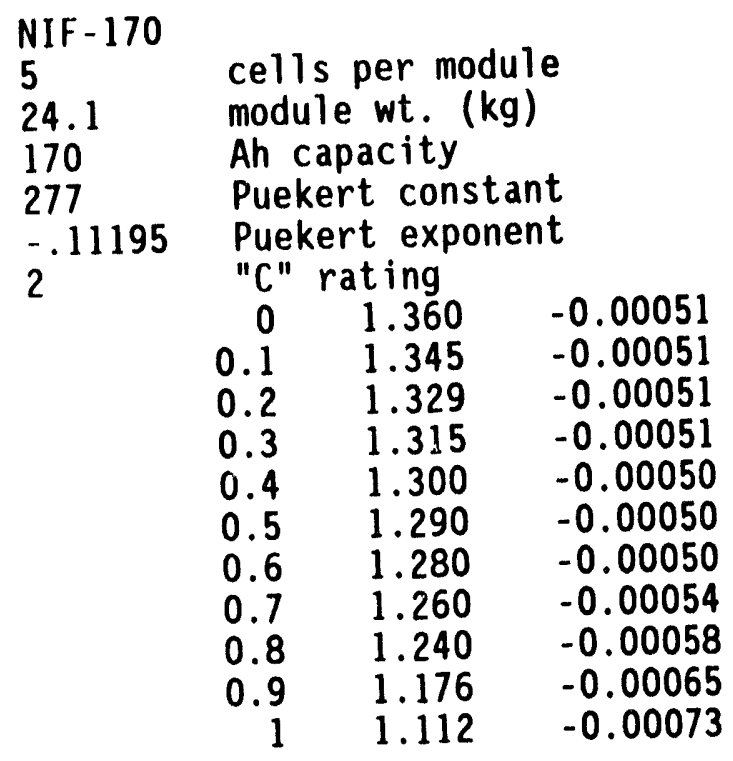

Figure 35. Example battery file. 
The rated ampere-hour capacity of the battery is entered on line 4. This value is used in conjunction with the hour rating on 1 ine 7 to estimate the initial DOD of the battery at the beginning of each simulation run.

The Peukert curve coefficients of the battery are entered on 1 ines 5 and 6. The Peukert relationship is discussed above in previous sections. Line 7 contains the " $C$ " hour rating as discussed above.

The remaining lines contain battery data giving the depth of dischargc versus open circuit voltage and internal resistance (dI/dV), respectively. This information must be entered in ascending order of DOD and must cover the range of anticipated operation in the simulation. Data may be entered for any values of DOD. This matrix is limited to 11 rows of data. Notations for the convenience of the user may be entered after the values appearing on lines 2 through 7. This information is ignored by SIMPLEV.

\section{Driving Schedule Files}

The ASCII driving schedule files contain the speed versus time information that is used by SIMPLEV. All driving schedule files have the ".CYC" file extension. The example in Figure 36 of the SAE J227a A cycle file supplied with SIMPLEV shows the format of these ASCII files. Line 1 contains a character string that identifies the driving cycle. This character string is used by SIMPLEV to identify the driving cycle. The value on 1 ine 2 is the time increment (in seconds). The remainder of the file lists sequentially the speed versus time profile. SIMPLEV ignores the listed time, and speeds are in mph. 


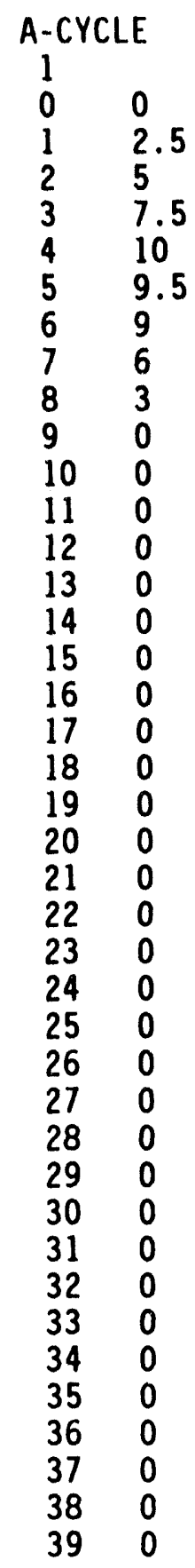

Figure 36. Example of driving schedule file. 


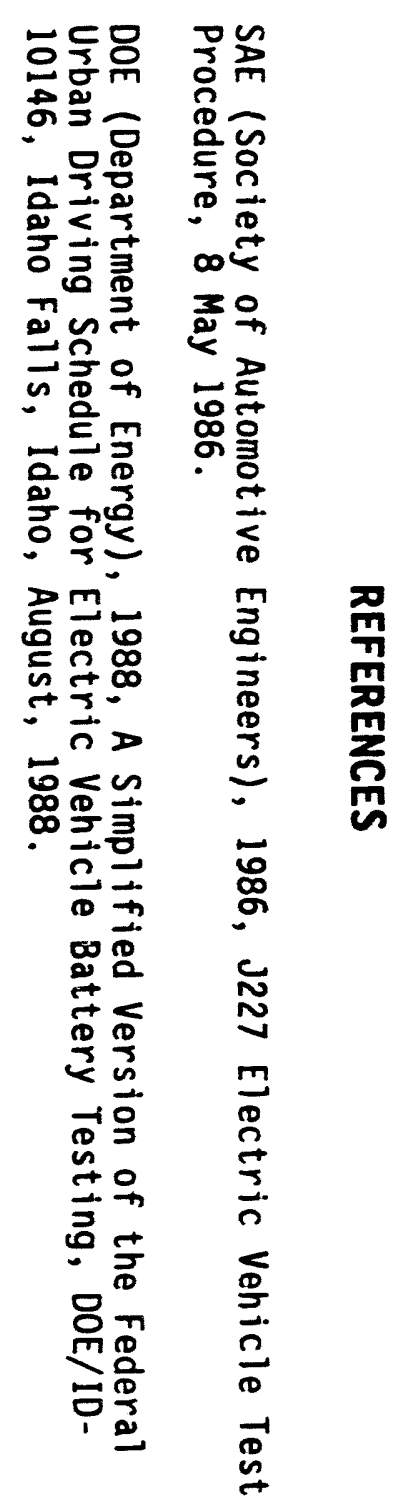




\section{APPENDIX A}

SAMPLE SIMPLEV OUTPUTS USING

' $D$ ' AND ' $G$ ' OPTION AT INTRODUCTION SCREEN

$A-1$ 


\title{
APPENDIX A
}

SAMPLE SIMPLEV OUTPUTS USING

' $D$ ' AND 'G' OPTION AT INTRODUCTION SCREEN

\begin{abstract}
DATE: $\quad 07-16-1991$
TIME: 14:51:13

*********************************************************************1 * SIMPleV - Simple eV SIMULation program Version 1.0 * * Idaho National Engineering Laboratory $* * * * * * * * * * * * * * * * * * * * * * * * * * * * * * * * * * * * * * * * * * * * * * * * * * * * * * * * * * * * * * * *$
\end{abstract}

Page 1

THIS IS A SAMPLE RUN.

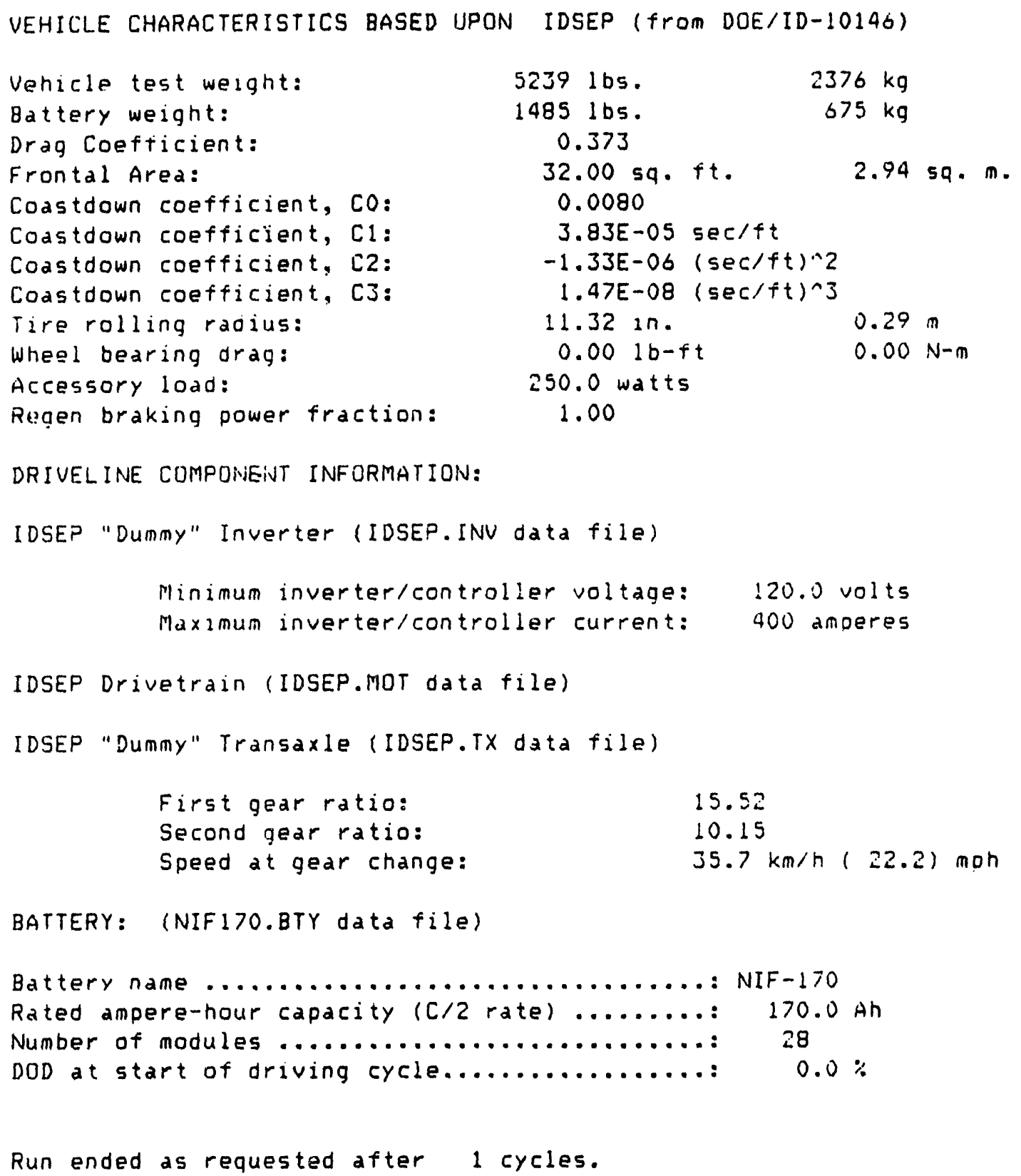



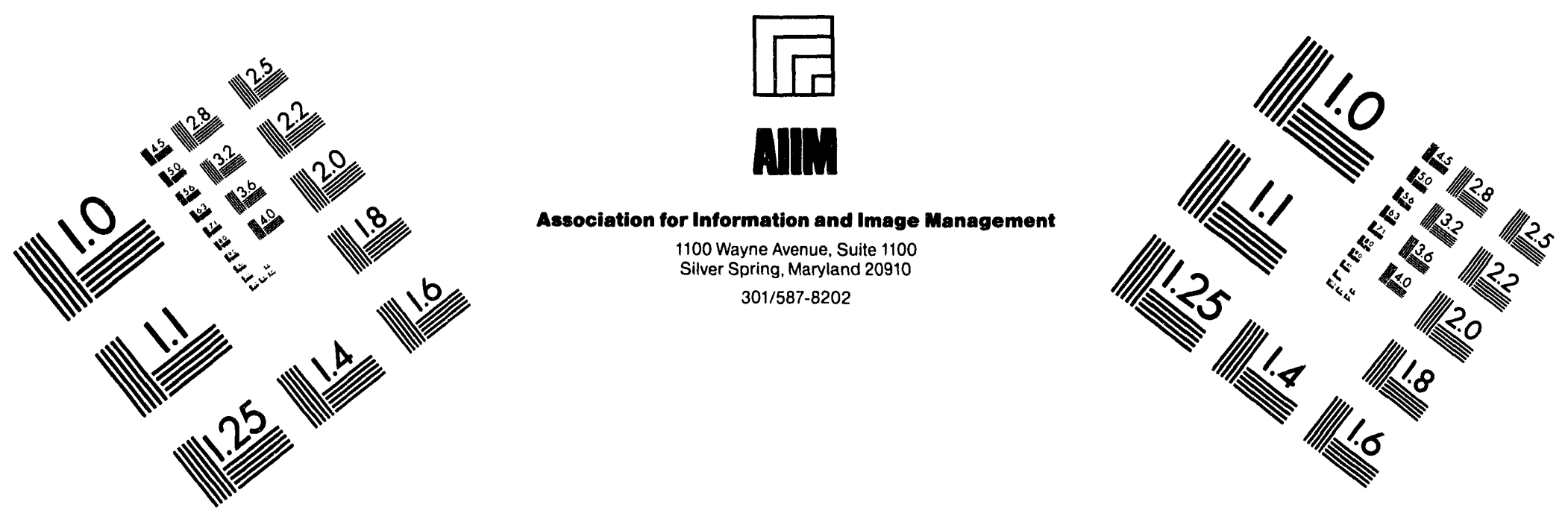

Centimeter

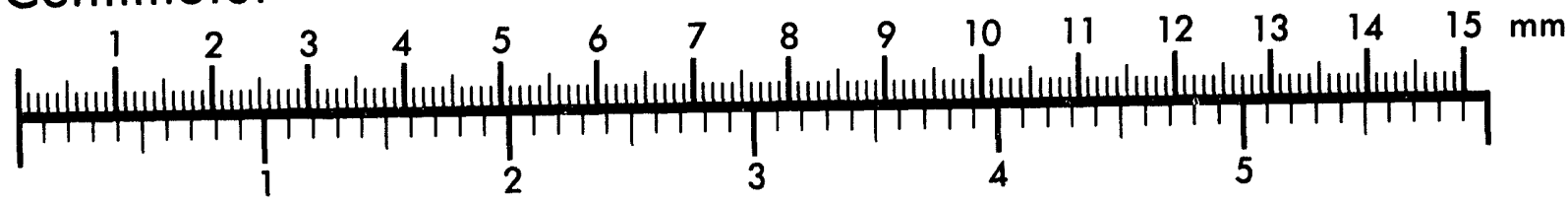
Inches
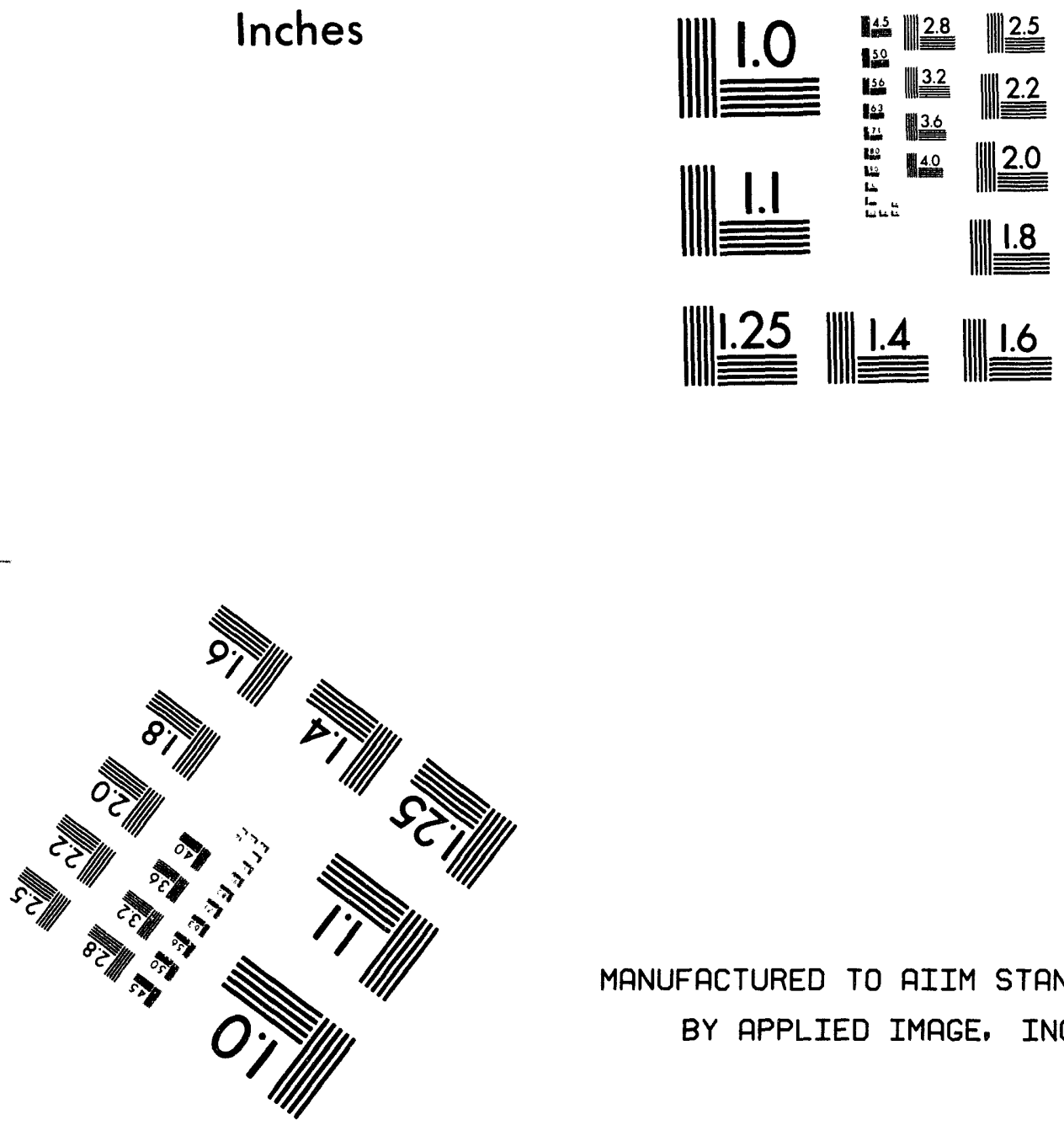

MANUFACTURED TO AIIM STANDARDS

BY APPLIED IMAGE, INC.

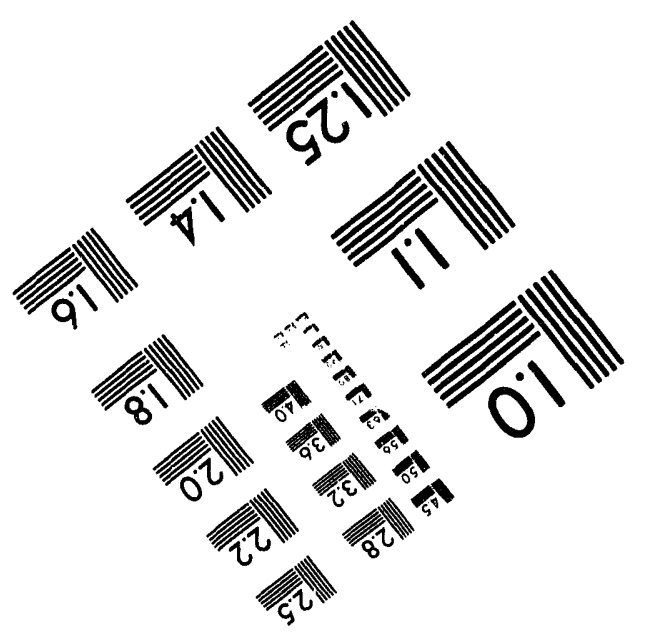



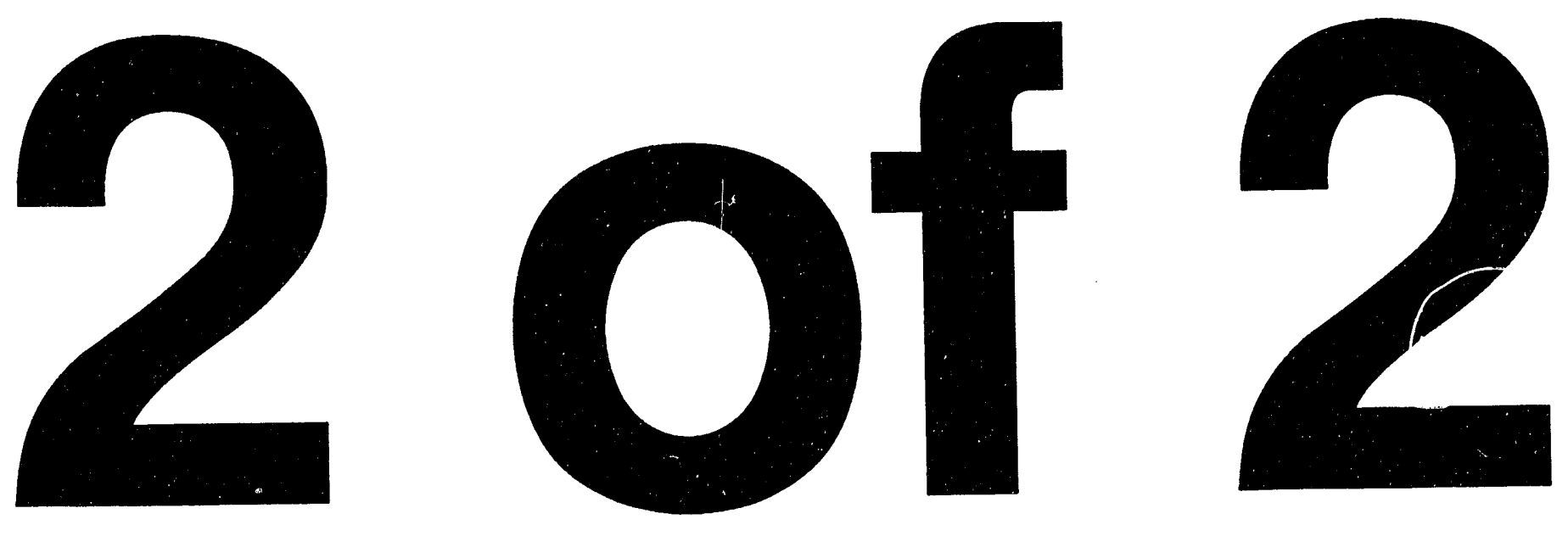


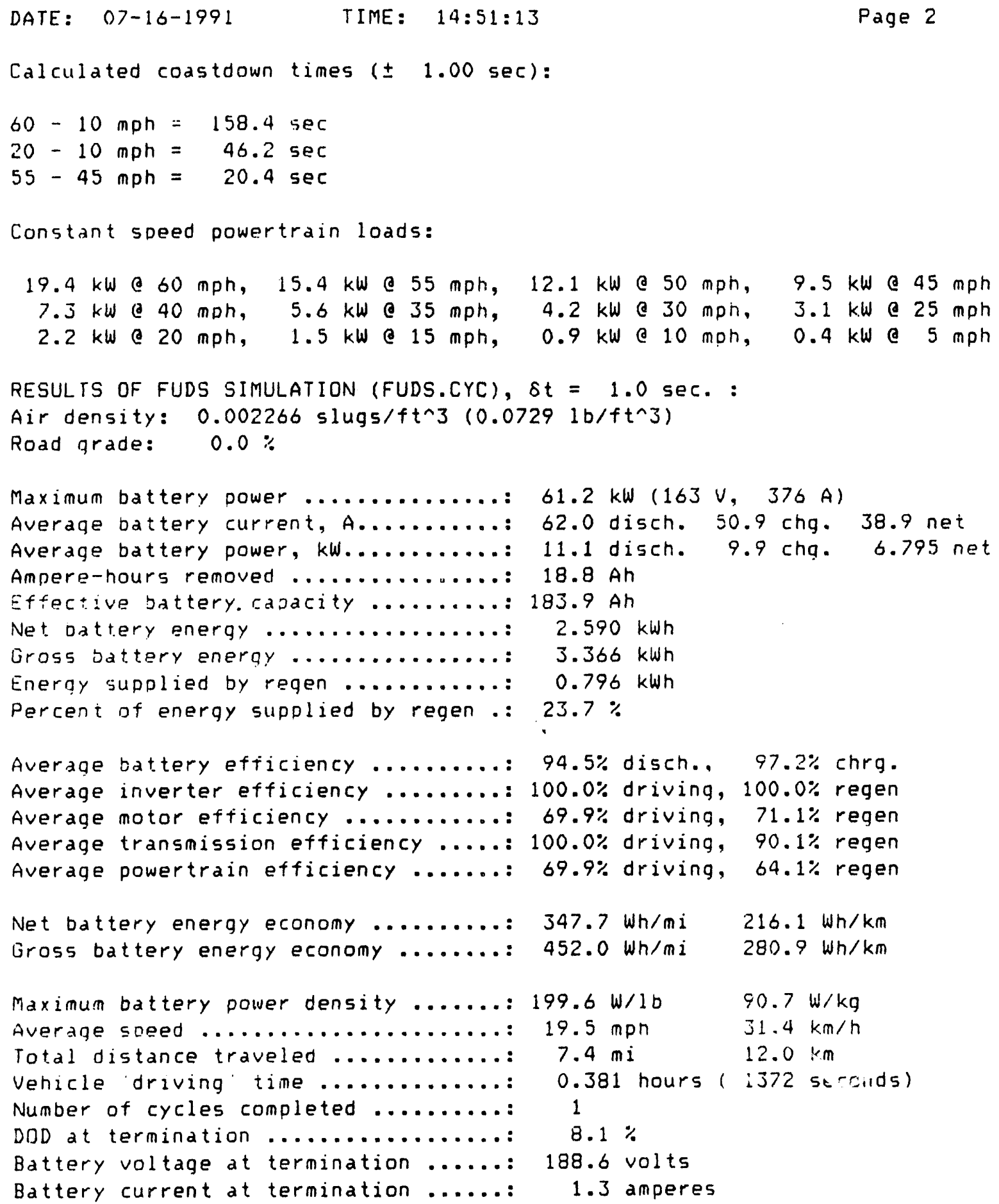


DATE: $07-16-1991$

TIME: $14: 51: 13$

Page 3

AVERAGE COMPONENT HOWER LOSSES FOR THIS RUN

\begin{tabular}{|c|c|c|c|c|c|c|c|}
\hline Battery: & 0.514 & $k w$ & disch., & 0.056 & $\mathrm{~kW}$ & chg. & $0.570 \mathrm{~kW}$ \\
\hline Inverter: & 0.000 & $k w$ & driving, & 0.000 & $\mathrm{kw}$ & regen., & $0.000 \mathrm{kw}$ \\
\hline lotor: & 2.595 & $\mathrm{~kW}$ & driving, & 0.848 & $\mathrm{kw}$ & regen.. & $3.443 \mathrm{kw}$ \\
\hline Transmission: & 0.000 & $\mathrm{~kW}$ & driving, & 0.321 & $\mathrm{~kW}$ & regen., & $0.321 \mathrm{kw}$ \\
\hline
\end{tabular}

SIEADY STAIE POWERTRAIN EFFICIENCIES UNDER ABUVE RUAD CONDITIONS:

0.769 ( $60 \mathrm{mph}, 10.769$ e $55 \mathrm{mph}, 0.762$ e $50 \mathrm{mph}, 0.747$ a $45 \mathrm{mph}$

0.723 e $40 \mathrm{mph}, 0.697$ e $35 \mathrm{mph}, 0.665$ e $30 \mathrm{mph}, 0.628$ e $25 \mathrm{mph}$

0.645 \& $20 \mathrm{mph}, 0.592$ e $15 \mathrm{mph}, 0.493$ e $10 \mathrm{mph}, 0.586$ e $\mathrm{mph}$

SIMULATION DIAGNOSTICS:

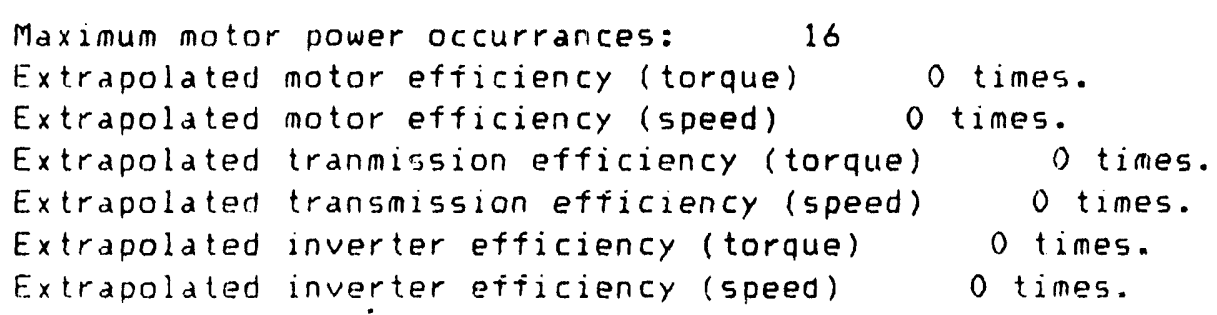


DATE: $07-16-1991$ TIME: 14:56:58

***********************************************************************⿰𠄌

* SimpleV - Simple ev simulation program version 1.0 *

* Idaho National Engineering Laboratory *

**********************************************************************

THIS IS A SAMPLE RUN.

VEHICLE CHARACTERISTICS BASED UPON IDSEP (frOM DOE/ID-10146)

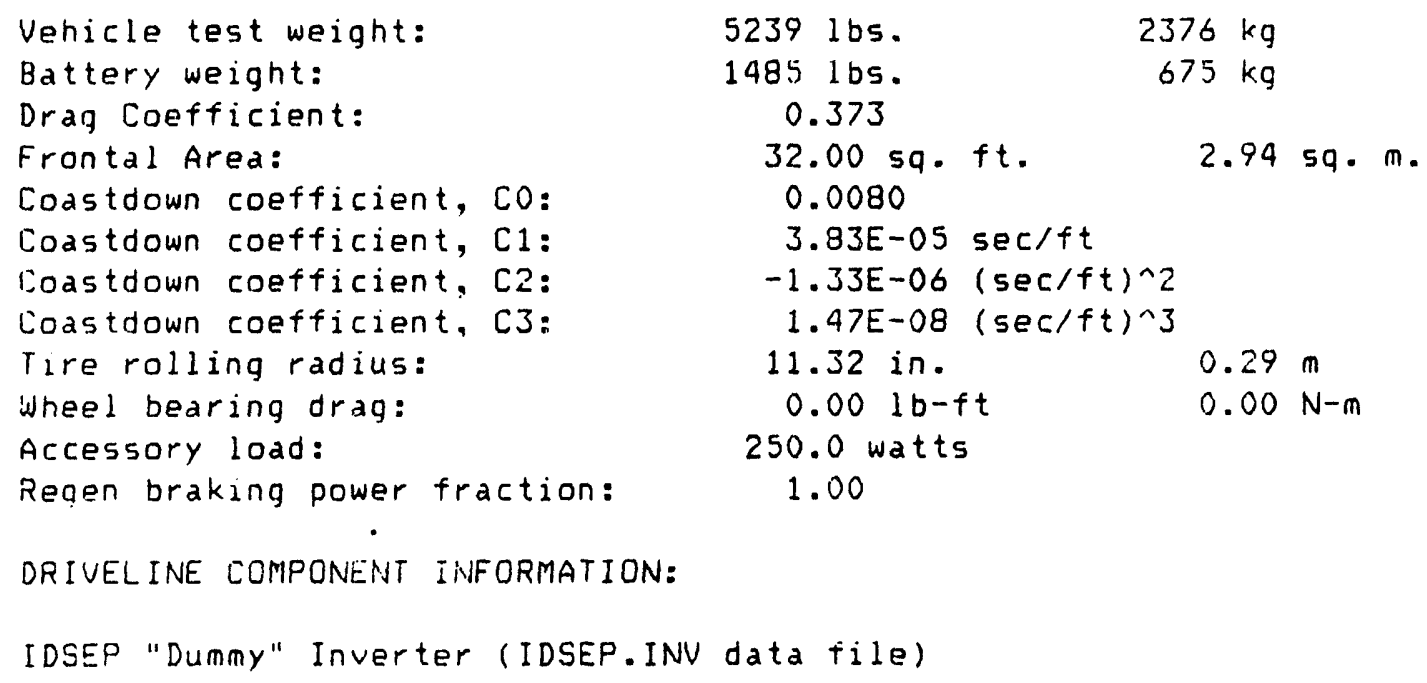

DRIVELINE COMPONENT INFORMATION:

IDSEP "Dummy" Inverter (IDSEP. INV data file)

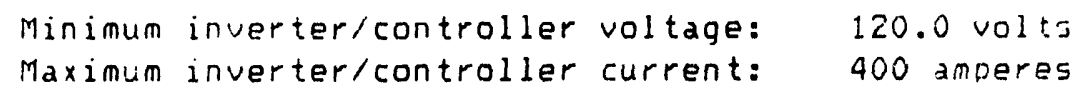




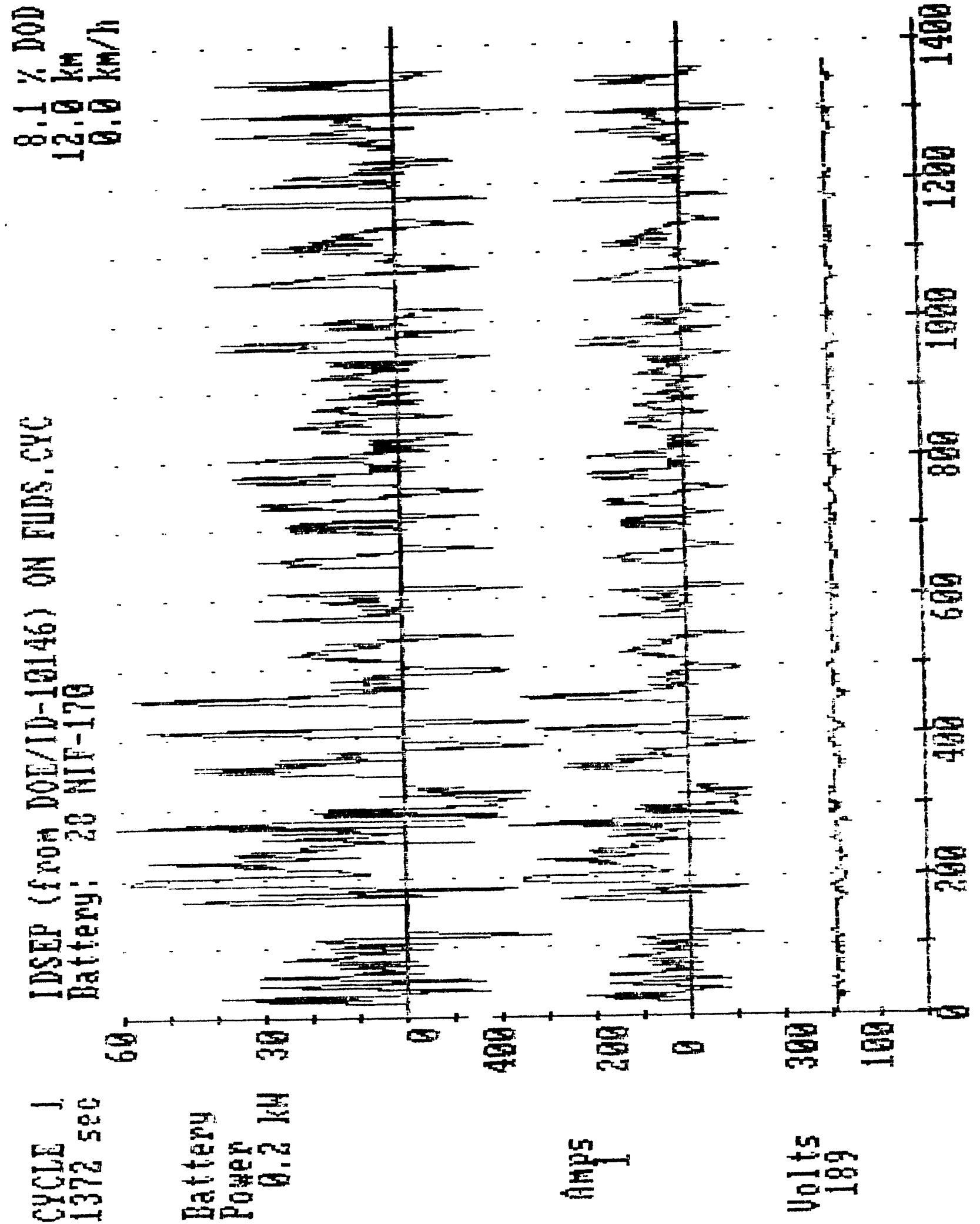




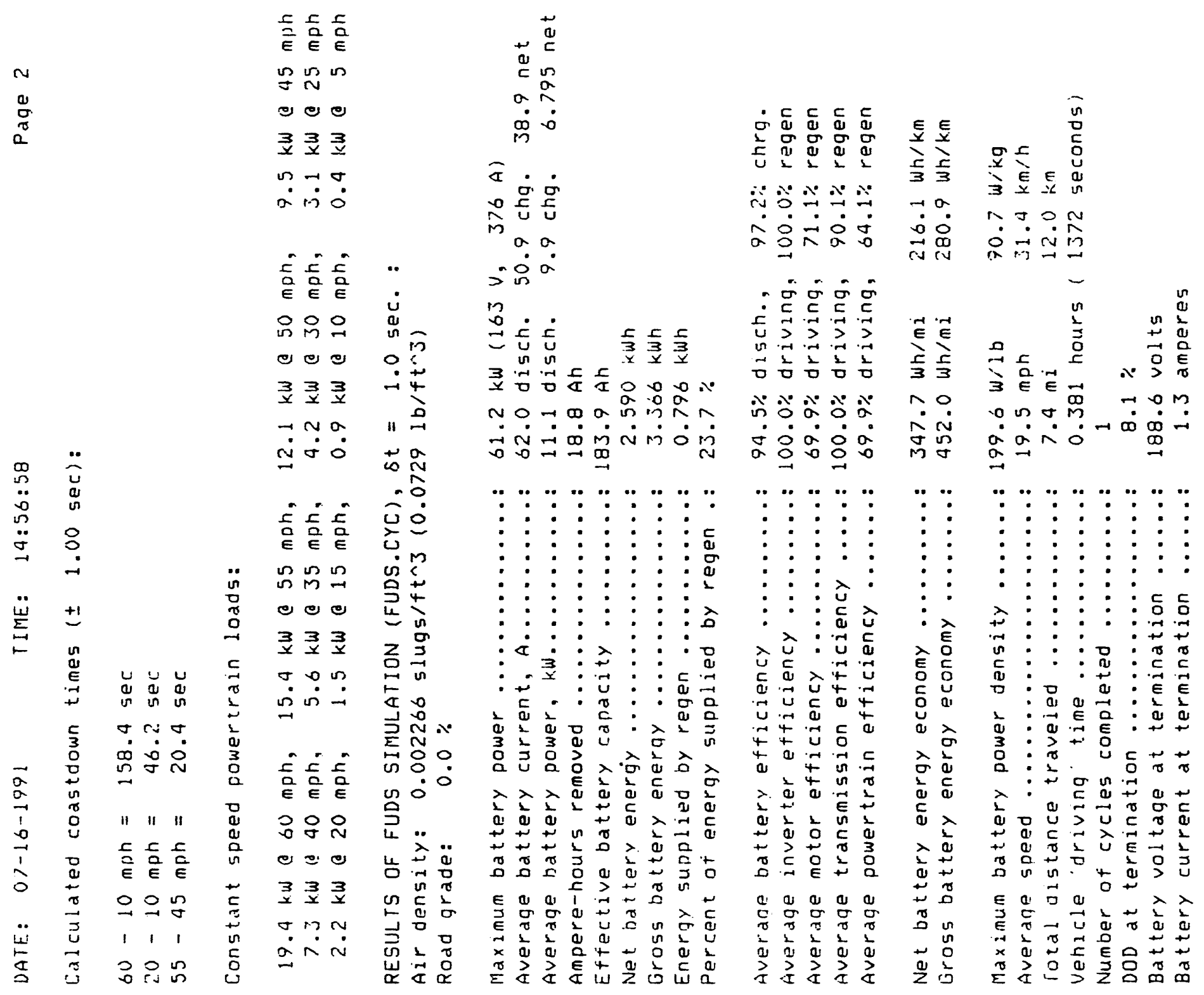


DATE: $\quad 07-16-1991$

AVERAGE COMPUNENT POWER LOSSES FOR THIS RUN

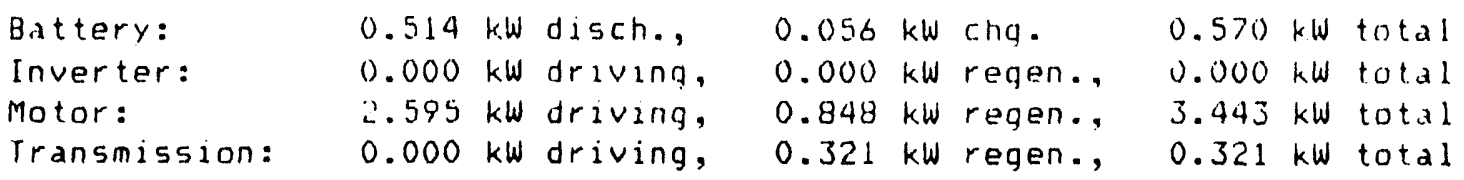

SIEADY STAIE POWERTRAIN EFFICIENCIES UNDER ABOVE ROAD CONDITIONS:

1).769 d bo moh, 0.769 a $55 \mathrm{moh}, 0.762$ a $50 \mathrm{mph}, 0.74 \%$ da $4 j \mathrm{mph}$

0.723 a $40 \mathrm{mph}, 0.697$ o $35 \mathrm{mph}, 0.365$ e $30 \mathrm{mph}, 0.628$ d $25 \mathrm{mph}$

1). 645 e $20 \mathrm{mph}, 0.592$ d $15 \mathrm{mph}, 0.493$ d $10 \mathrm{mph}, 0.586$ e $5 \mathrm{moh}$

SIMULATION DIAGNOSTICS:

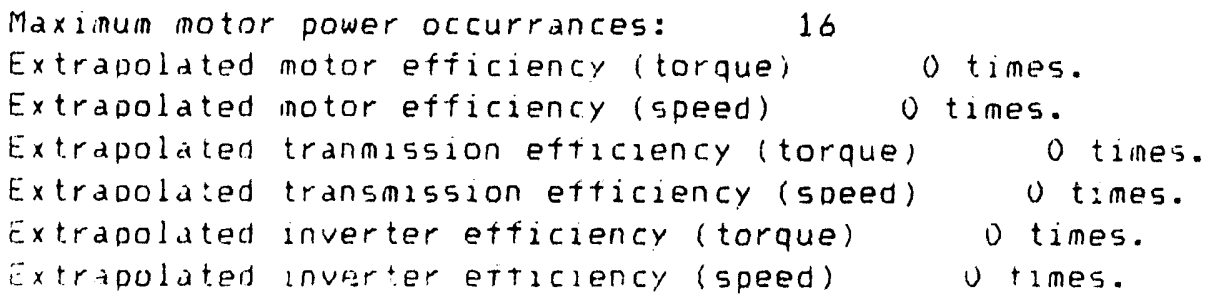


APPENDIX B

SIMPLEV VEHICLE FILE LISTINGS

B-1 
APPENDIX B

SIMPLEV VEHICLE FILE LISTINGS

\section{BEDVAN.VEH}

Bedford Van

4260 Chassis wt, 1b (incl. battery anciliaries, enclosure, etc.)

0 Payload, ib

0.463 Cd

36.5 Frontal Area, $\mathrm{ft}^{\wedge} 2$

0.0077 Tire rolling resistance coefficient, CO

$0.00 \mathrm{E}+00$ Tire rolling resistance coefficient, $\mathrm{Cl} \mathrm{sec} / \mathrm{ft}$

4.86E-08 Tire rolling resistance coefficient, $\mathrm{C2}(\mathrm{sec} / \mathrm{ft})^{\wedge} 2$

0 Tire rolling resistance coefficient, $\mathrm{C} 3(\mathrm{sec} / \mathrm{ft})^{\wedge} 3$

1.1 Tire rolling radius, $\mathrm{ft}$

7171 Gross Vehicle Weight Rating (GVWR)

0.7 Fraction of energy available for regen

0 Wheel bearing torque drag, $1 \mathrm{~b}-\mathrm{ft}$

Bedford van vehicle data were obtained from INEL tests and ELVEC bulk data files.

\section{DSEP.VEH}

Eaton DSEP TB-2

3700 Chassis wt, Ib (incl. battery anciliaries, enclosure, etc.)

460 Payload, Ib

$0.375 \mathrm{Cd}$

31.8 Frontal Area, $\mathrm{ft}^{\wedge} 2$

0.0095 Tire rolling resistance coefficient, CO

$0.00 \mathrm{E}-00$ Tire rolling resistance coefficient, $\mathrm{Cl} \mathrm{sec} / \mathrm{ft}$

$0.00 E+00$ Tire rolling resistance coefficient, $\mathrm{C2}(\mathrm{sec} / \mathrm{ft})^{\wedge} 2$

$0.00 \mathrm{E}+00$ Tire rolling resistance coefficient, $\mathrm{C} 3(\mathrm{sec} / \mathrm{ft})^{\wedge} 3$

1.1083 Tire rolling radius, $\mathrm{ft}$

6000 Gross Vehicle Weight Rating (GVWR)

0.3 Fraction of energy available for regen

0 Wheel bearing torque drag, $1 \mathrm{~b}-\mathrm{ft}$

DSEP vehicle data were obtained from INEL tests testing and Eaton Corporation. 


\section{ETV-1.VEH}

Chrysler/GE ETV-1

2167 Chassis wt, Ib (incl. battery anciliaries, enclosure, etc.)

443 Payload, 1b

$0.32 \mathrm{Cd}$

19.81 Frontal Area, $\mathrm{ft}^{\wedge} 2$

0.0095 Tire rolling resistance coefficient, CO

5.00E-07 Tire rolling resistance coefficient, $\mathrm{Cl} \mathrm{sec} / \mathrm{ft}$

0 Tire rolling resistance coefficient, C2 $(\mathrm{sec} / \mathrm{ft})^{\wedge} 2$

0.921 Tire rolling radius, $\mathrm{ft}$

4000 Gross Vehicle Weight Rating (GVWR)

0.35 Fraction of energy available for regen

0 Wheel bearing torque drag, $1 \mathrm{~b}-\mathrm{ft}$

ETV-1 vehicle data were obtained from INEL and JPL tests.

\section{ETX - I.VEH}

Ford ETX-I (LN-7)

2313 Chassis wt, 1b (incl. battery anciliaries, enclosure, etc.)

300 Payload, Ib

0.416 Cd

19.1 Frontal Area, $\mathrm{ft}^{\wedge} 2$

0.0097 Tire rolling resistance coefficient, CO

5.00E-07 Tire rolling resistance coefficient, $\mathrm{Cl} \mathrm{sec} / \mathrm{ft}$

$0.00 \mathrm{E}+00$ Tire rolling resistance coefficient, $\mathrm{C} 2(\mathrm{sec} / \mathrm{ft})^{\wedge} 2$

$0.00 \mathrm{E}+00$ Tire rolling resistance coefficient, $\left.\mathrm{C} 3(\mathrm{sec} / \mathrm{ft})^{\wedge}\right\}$

0.945 Tire rolling radius, $\mathrm{ft}$

4000 Gross Vehicle Weight Rating (GVWR)

0.6 Fraction of energy available for regen

0 Wheel bearing torque drag, $1 \mathrm{~b}-\mathrm{ft}$

ETX-I vehicle data were obtained from INEL tests and Ford Motor Company. 


\section{ETX-II.VEH}

Ford ETX-II (Aerostar van)

2700 Chassis wt, lb (incl. battery anciliaries, enclosure, etc.)

500 Payload, 1b

$0.37 \mathrm{Cd}$

35.1 Frontal Area, $\mathrm{ft}^{\wedge} 2$

0.009 Tire rolling resistance coefficient, CO

5.00E-07 Tire rolling resistance coefficient, $\mathrm{Cl} \mathrm{sec} / \mathrm{ft}$

$0.00 E+00$ Tire rolling resistance coefficient, $\mathrm{C} 2(\mathrm{sec} / \mathrm{ft})^{\wedge} 2$

$0.00 \mathrm{E}+00$ Tire rolling resistance coefficient, $\mathrm{C} 3(\mathrm{sec} / \mathrm{ft})^{\wedge} 3$

1.053 Tire rolling radius, $\mathrm{ft}$

5100 Gross Vehicle Weight Rating (GVWR)

0.2 Fraction of energy available for regen

0 Wheel bearing torque $\mathrm{drag}, 1 \mathrm{~b}-\mathrm{ft}$

ETX-II vehicle were data obtained from Ford Motor Company.

\section{EVCORT.VEH}

Soleq EVcort (Ford Escort)

2866 Chassis wt, $1 \mathrm{~b}$ (incl. battery anciliaries, enclosure, etc.)

$0.35 \mathrm{Cd}$

22.69 Frontal Area, $\mathrm{ft}^{\wedge} 2$

0.009 Tire rolling resistance coefficient, CO

$0.00 \mathrm{E}+00$ Tire rolling resistance coefficient, $\mathrm{Cl} \mathrm{sec} / \mathrm{ft}$

5.64E-08 Tire rolling resistance coefficient, C2 $(\mathrm{sec} / \mathrm{ft})^{\wedge} 2$

$0.00 E+00$ Tire rolling resistance coefficient, $\mathrm{C} 3(\mathrm{sec} / \mathrm{ft})^{\wedge} 3$

0.9 Tire rolling radius, $\mathrm{ft}$

4406 Gross Vehicle Weight Rating (GVWR)

0.7 Fraction of energy available for regen

0 Wheel bearing torque drag, $1 \mathrm{~b}-\mathrm{ft}$

EVcort data were obtained from INEL tests. 
G-VAN.VEH

GM G-Van

4268 Chassis wt, lb (incl. battery anciliaries, enclosure, etc.)

1100 Payload, 1b

$0.463 \mathrm{Cd}$

37.5 Frontal Area, $\mathrm{ft}^{\wedge} 2$

0.01 Tire rolling resistance coefficient, CO

5.00E-07 Tire rolling resistance coefficient, $\mathrm{Cl} \mathrm{sec} / \mathrm{ft}$

$0.00 \mathrm{E}+00$ Tire rolling resistance coefficient, C2 $(\mathrm{sec} / \mathrm{ft})^{\wedge} 2$

$0.00 E+00$ Tire rolling resistance coefficient, $\mathrm{C} 3(\mathrm{sec} / \mathrm{ft})^{\wedge} 3$

1.181 Tire rolling radius, $\mathrm{ft}$

9000 Gross Vehicle Weight Rating (GVWR)

0.5 Fraction of energy available for regen

0 Wheel bearing torque drag, $1 \mathrm{~b}-\mathrm{ft}$

General Motors G-Van vehicle data were obtained from the open literature.

IDSEP.VEH

IDSEP (from DOE/ID-10146)

3151 Chassis wt, ib (incl. battery anciliaries, enclosure, etc.)

600 Payload, 1b

$0.373 \quad$ Cd

32 Frontal Area, $\mathrm{ft}^{\wedge} 2$

0.008 Tire rolling resistance coefficient, CO

3.833E-05 Tire rolling resistance coefficient, $\mathrm{Cl} \mathrm{sec} / \mathrm{ft}$

$-1.333 \mathrm{E}-06$ Tire rolling resistance coefficient, C2 $(\mathrm{sec} / \mathrm{ft})^{\wedge} 2$

1.467E-08 Tire rolling resistance coefficient, C3 $(\mathrm{sec} / \mathrm{ft})^{\wedge} 3$

0.943 Tire rolling radius, $\mathrm{ft}$

5927 Gross Vehicle Weight Rating (GVWR)

1 Fraction of energy available for regen

0 Wheel bearing torque drag, ib-ft

IDSEP vehicle assumptions were obtained from reports DOE/ID-10146, $\mathrm{DOE} / \mathrm{CE}-0148$, and associated simulation programs (VTOP). 
IMPACT.VEH

GM Impact

1350 Chassis wt, Ib (incl. battery anciliaries, enclosure, etc.)

350 Payload, 1b

$0.19 \mathrm{Cd}$

16.9 Frontal Area, $\mathrm{ft}^{\wedge} 2$

0.0048 Tire rolling resistance coefficient, $\mathrm{CO}$

5.00E-07 Tire rolling resistance coefficient, $\mathrm{Cl} \mathrm{sec} / \mathrm{ft}$

$0.00 \mathrm{E}+00$ Tire rolling resistance coefficient, C2 $(\mathrm{sec} / \mathrm{ft})^{\wedge} 2$

$0.00 \mathrm{E}+00$ Tire rolling resistance coefficient, $\mathrm{C} 3(\mathrm{sec} / \mathrm{ft})^{\wedge} 3$

0.928 Tire rolling radius, $\mathrm{ft}$

2550 Gross Vehicle Weight Rating (GWWR)

0.7 Fraction of energy available for regen

0 Wheel bearing torque drag, $1 \mathrm{~b}-\mathrm{ft}$

General Motors Impact vehicle parameters were obtained from various published sources, including press releases, and engineering judgements.

\section{MEV-75.VEH}

Ford MEV $75 \mathrm{Hp}$

2150 Chassis wt, lb (incl. battery anciliaries, enclosure, etc.)

468 Payload, 1b

$0.34 \mathrm{Cd}$

23.57 Frontal Area, $\mathrm{ft}^{\wedge} 2$

0.011 Tire rolling resistance coefficient, CO

9.07E-06 Tire rolling resistance coefficient, Cl sec/ft

0 Tire rolling resistance coefficient, $\mathrm{C} 2(\mathrm{sec} / \mathrm{ft})^{\wedge} 2$

0 Tire rolling resistance coefficient, $\mathrm{C} 3(\mathrm{sec} / \mathrm{ft})^{\wedge} 3$

0.97 Tire rolling radius, $\mathrm{ft}$

4080 Gross Vehicle Weight Rating (GVWR)

0.3 Fraction of energy available for regen

18 Wheel bearing torque drag, $1 \mathrm{~b}-\mathrm{ft}$

Vehicle assumptions for the $75 \mathrm{Hp}$ Modular Electric Vehicle were obtained from Ford Motor Company. 


\section{SOLQVAN.VEH}

Soleq Van

5682

0

0.463

38.6

0.01

$0.00 E+00$

$6.27 \mathrm{E}-08$

$0.00 \mathrm{E}-00$

1.1

7171

0.7

Chassis wt, lb (incl. battery anciliaries, enclosure, etc.)

Payload, 1b

Cd

Frontal Area, $\mathrm{ft}^{\wedge} 2$

Tire rolling resistance coefficient, $\mathrm{CO}$

Tire rolling resistance coefficient, $\mathrm{Cl} \mathrm{sec} / \mathrm{ft}$

Tire rolling resistance coefficient, $\mathrm{C} 2(\mathrm{sec} / \mathrm{ft})^{\wedge} 2$

Tire rolling resistance coefficient, $\mathrm{C} 3(\mathrm{sec} / \mathrm{ft})^{\wedge} 3$

Tire rolling radius, $\mathrm{ft}$

Gross Vehicle Weight Rating (GVWR)

Fraction of energy available for regen

Wheel bearing torque drag, $1 \mathrm{~b}-\mathrm{ft}$

Soleq van vehicle information was obtained from INEL tests.

\section{IB-1.VEH}

Eaton DSEP TB-1

3626 Chassis wt, lb (incl. battery anciliaries, enclosure, etc.)

200

0.567

27.34 Frontal Area, $\mathrm{ft}^{\wedge} 2$

Payload, Ib

0.0122 Tire rolling resistance coefficient, CO

$0.00 \mathrm{E}-00$

$0.00 \mathrm{E}+00$

$0.00 E+00$

0.975

6000

0.3

Tire rolling resistance coefficient, $\mathrm{Cl} \mathrm{sec} / \mathrm{ft}$

Tire rolling resistance coefficient, $\mathrm{C} 2(\mathrm{sec} / \mathrm{ft})^{\wedge} 2$

Tire rolling resistance coefficient, $\mathrm{C} 3(\mathrm{sec} / \mathrm{ft})^{\wedge} 3$

Tire rolling radius, ft

Gross Vehicle Weight Rating (GVWR)

0.3 Fraction of energy available for regen

Wheel bearing torque drag, $1 \mathrm{~b}-\mathrm{ft}$

Eaton DSEP TB-1 vehicle data were obtained from Eaton Corporation and INEL tests. 


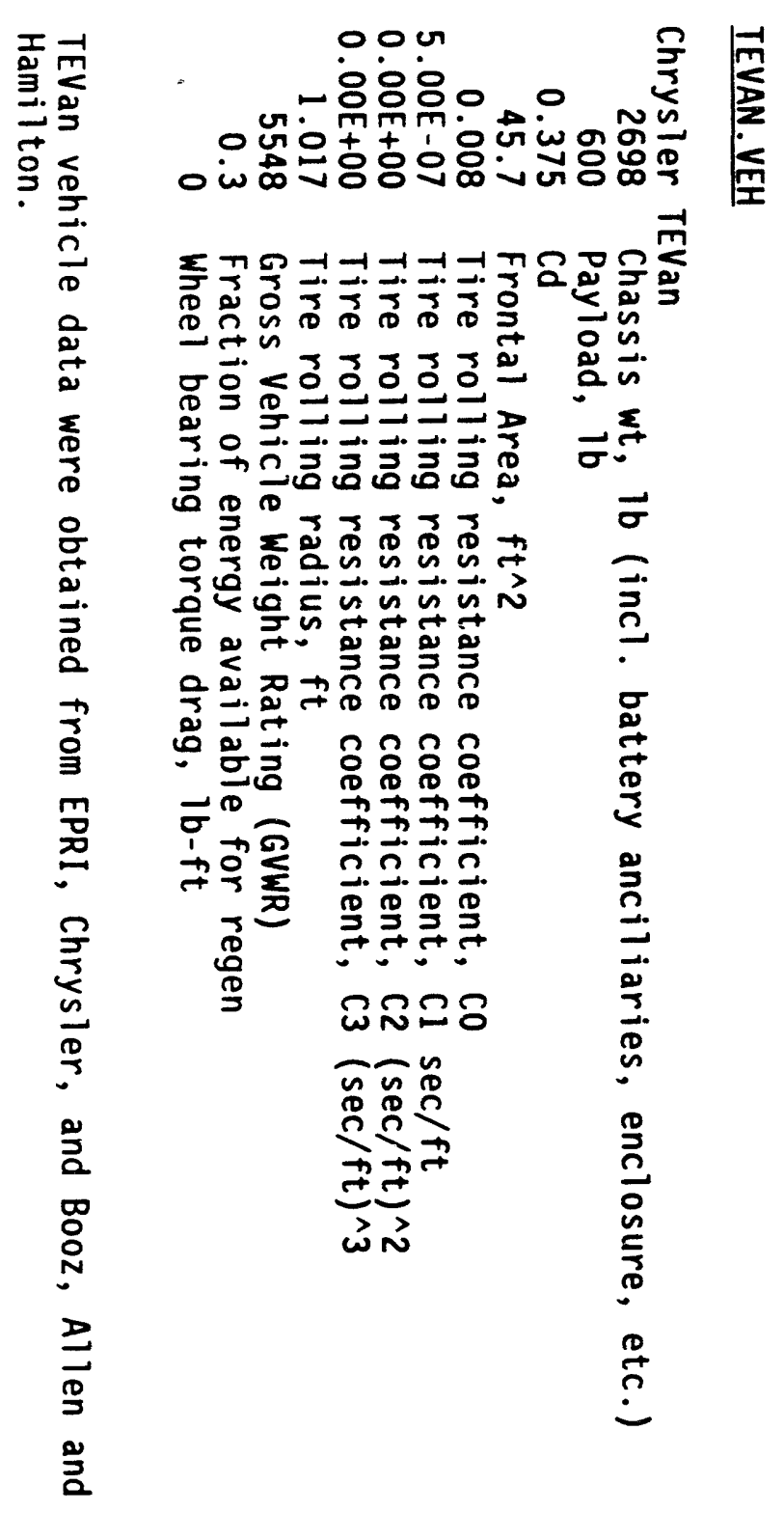


APPENDIX C

SIMPLEV TRANSIMSSION FILES

C-1 


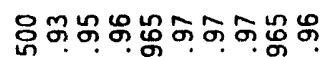

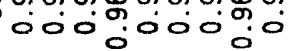

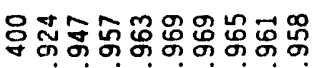
í0000000

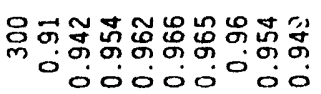

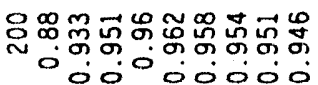

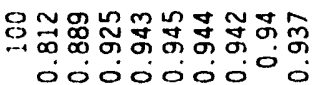

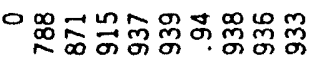

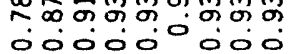

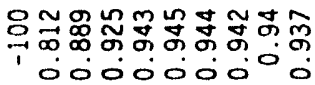

요ㅇㅠㅛ

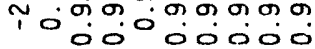

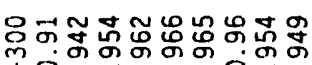

प0\%0

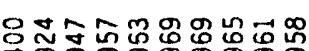

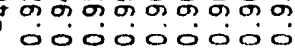

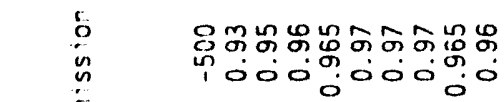

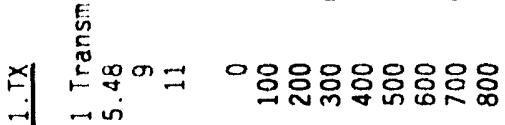

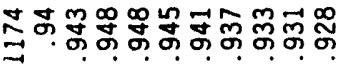

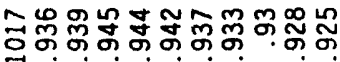

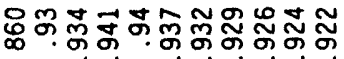

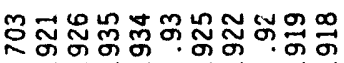

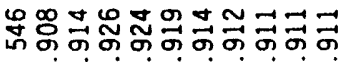

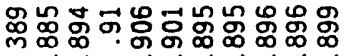

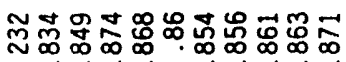

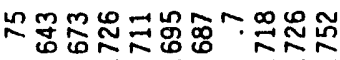

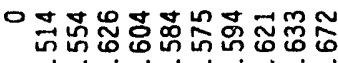

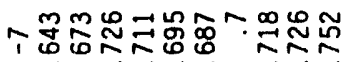

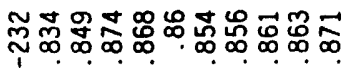

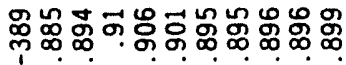

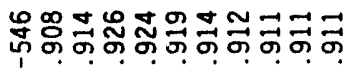

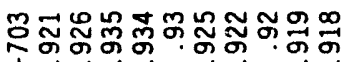
인

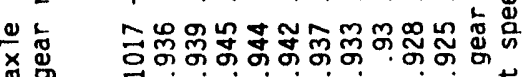

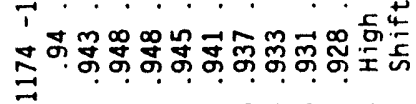

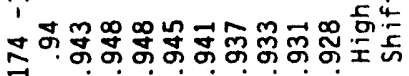
궀윽

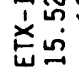

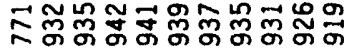

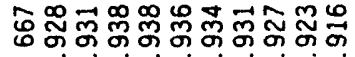

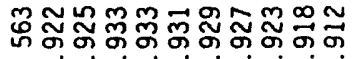

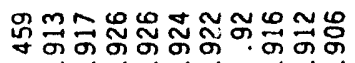

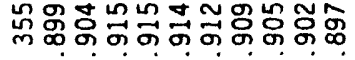

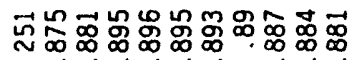

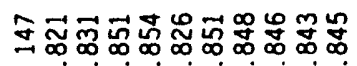
ๆ

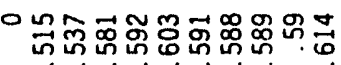
7

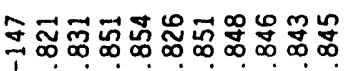

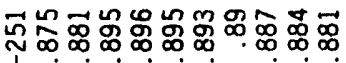

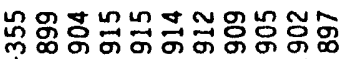

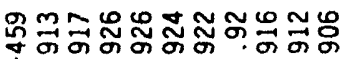

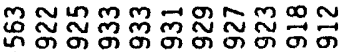

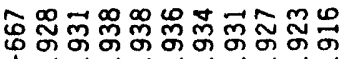
ㅇํำ

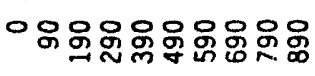




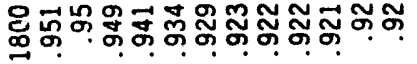

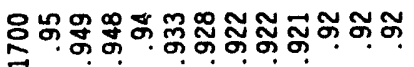

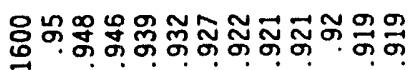

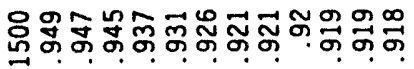

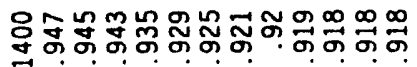

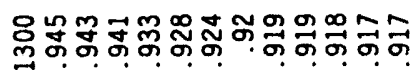

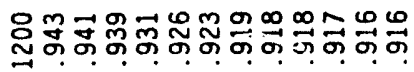

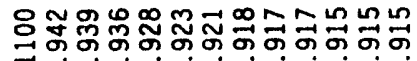

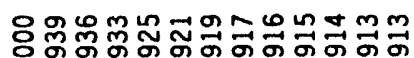

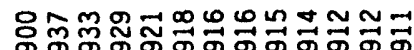
চ ๙

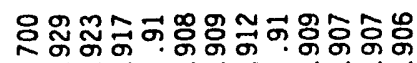

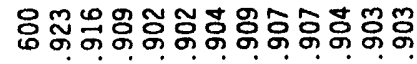

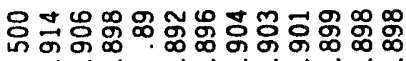

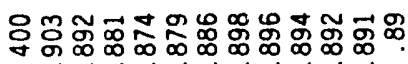

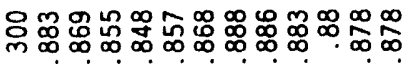

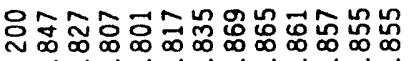

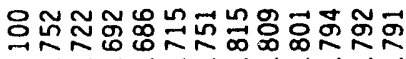

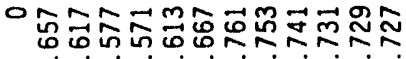

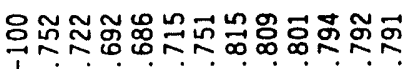

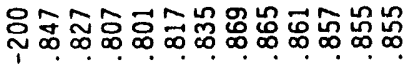

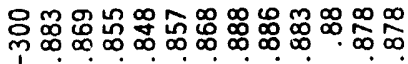

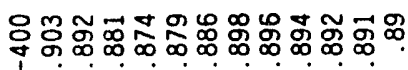

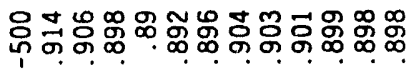

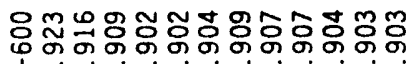

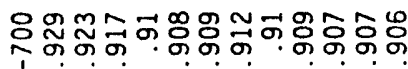

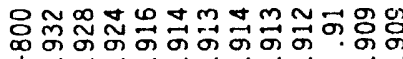

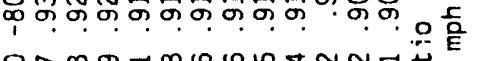

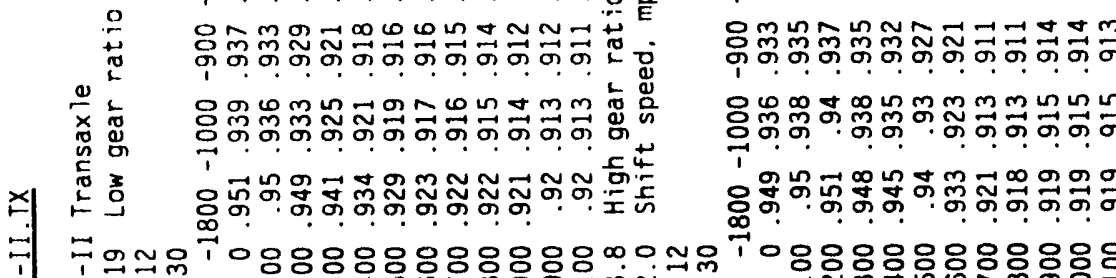
高宾

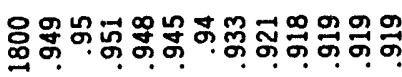

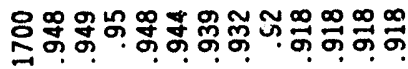

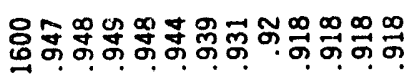

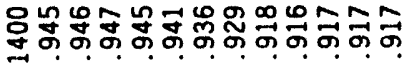

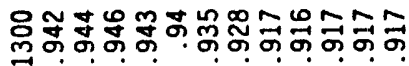

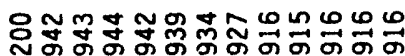

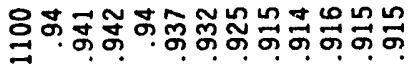

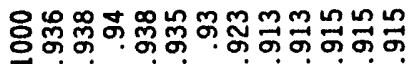

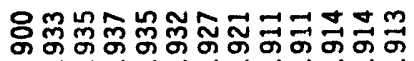

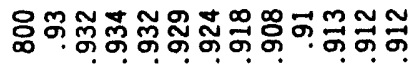

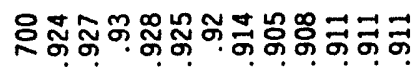

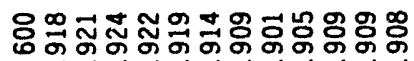

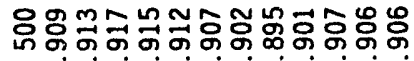

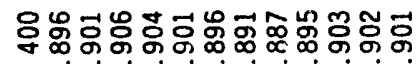

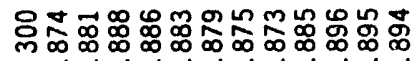

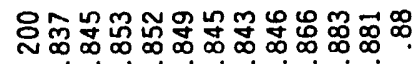

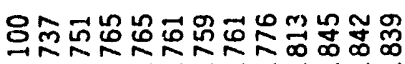
。

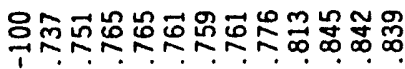
숭.

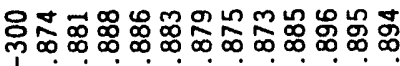

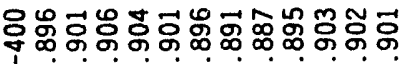

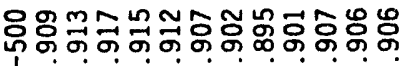

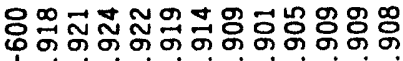

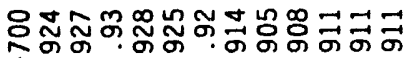

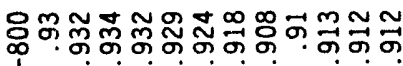

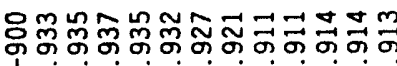
O

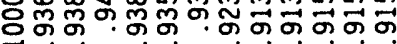

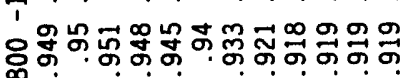

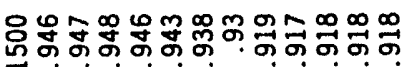




\section{IDSEP.TX}

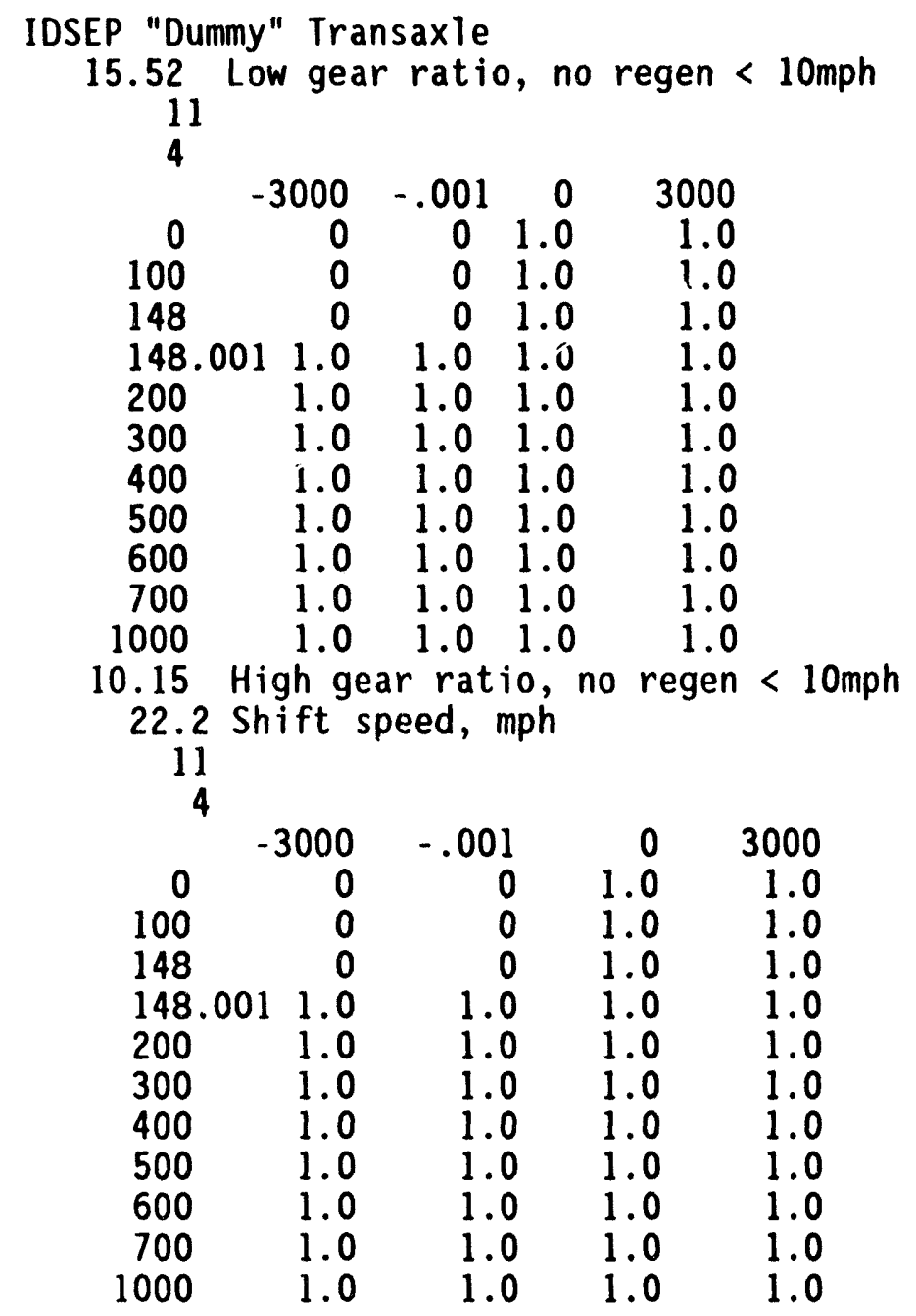




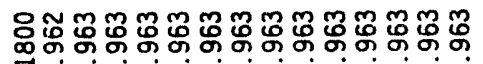

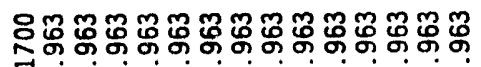

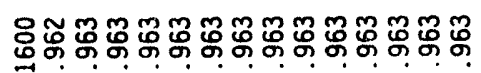

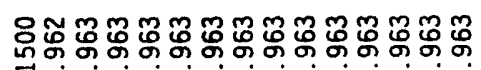

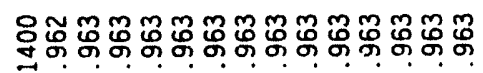

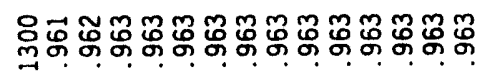

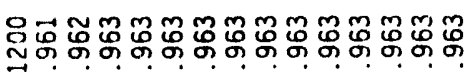

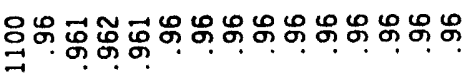

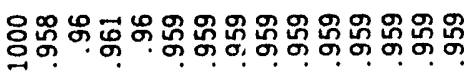

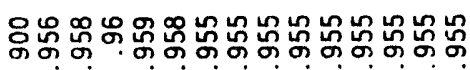

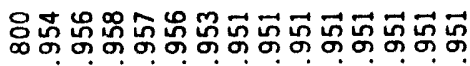

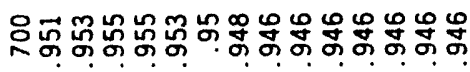

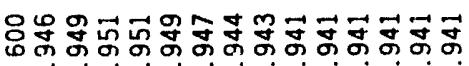

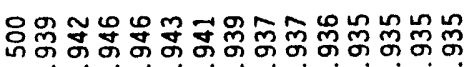

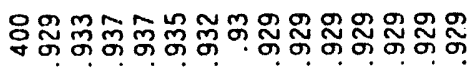

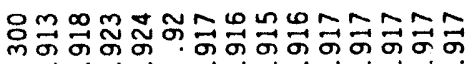

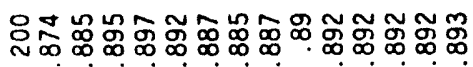

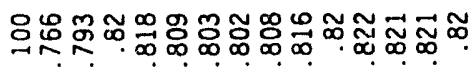

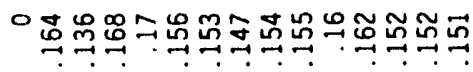

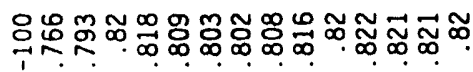

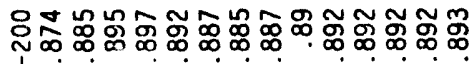

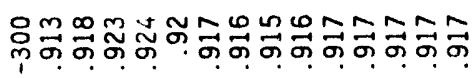

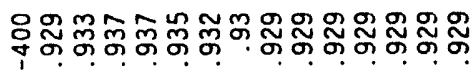

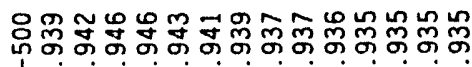

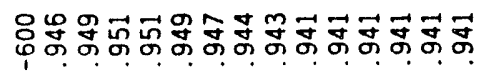

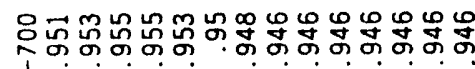

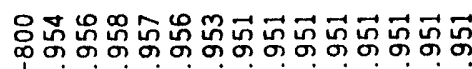

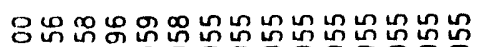
क्षै

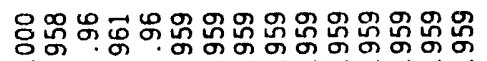
1

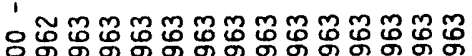

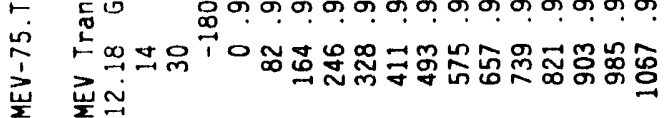

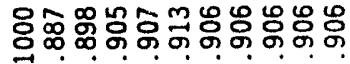

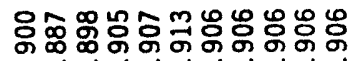

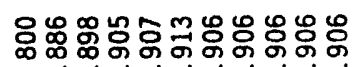

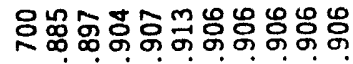

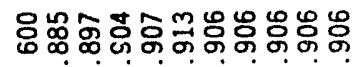

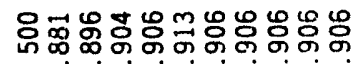

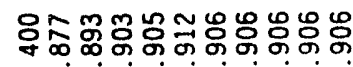

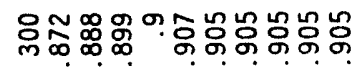

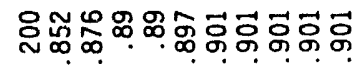

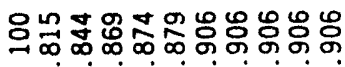

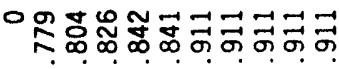

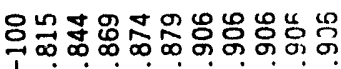
웃 ్ㅜㅇㅇ․

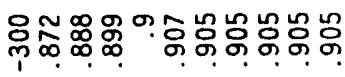

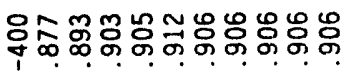

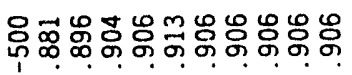

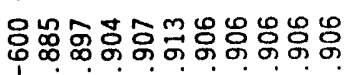

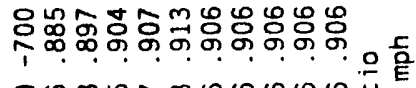

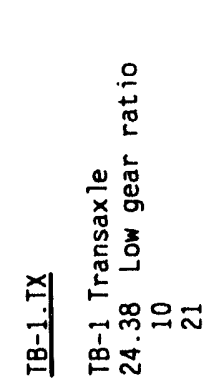

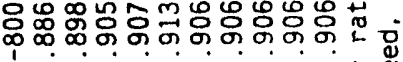

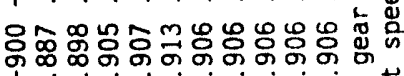

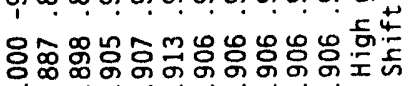
१ं

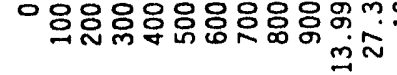

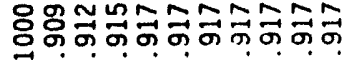

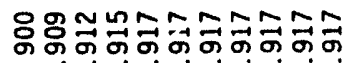

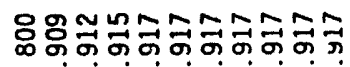

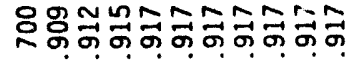

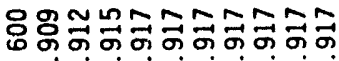
요 $\sim \infty \infty \infty \infty \infty \infty$ 웅후 के के के के के

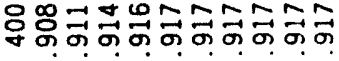

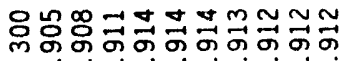

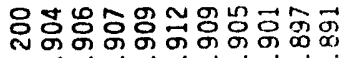

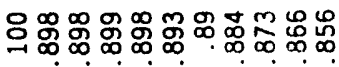
○ gू:

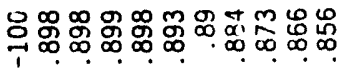

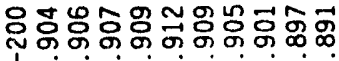

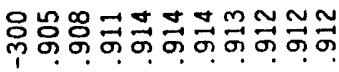

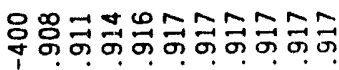
8 워 $\infty \infty \infty \infty \infty \infty$ 융न के ने के ने के के के

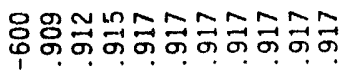

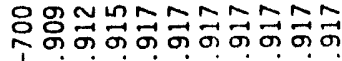

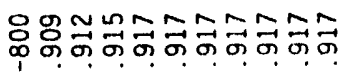

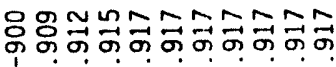

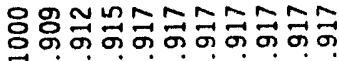

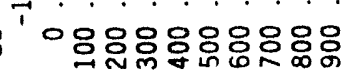


APPENDIX D

SIMPLEV MOTOR FILES

D-1 


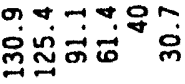

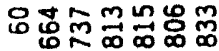
000000

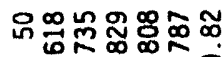

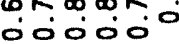

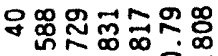
○ं0000

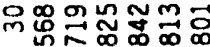
ல0ं0்00்

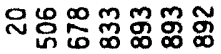
○00000

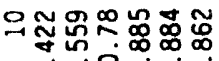

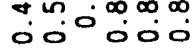

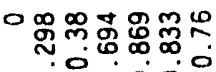
:0:0000

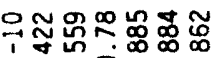
○. 0000

ำํํำ वं00ं0ं0

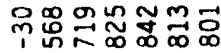
व0ं00ं

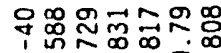
वं0ं0ं0

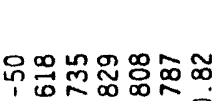
o.000

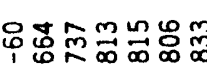
ó00000

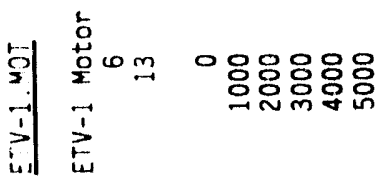

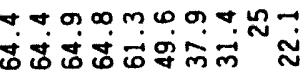

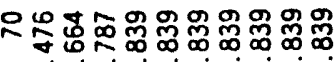

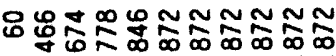

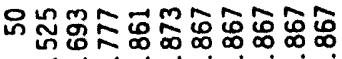

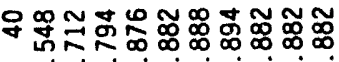

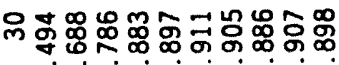

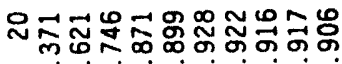

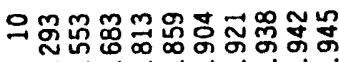

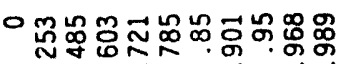

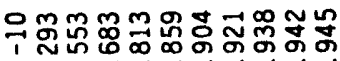

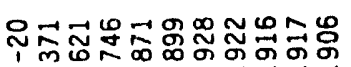

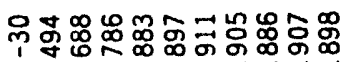

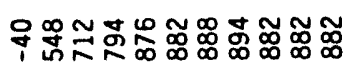

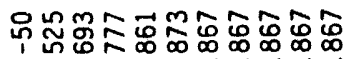

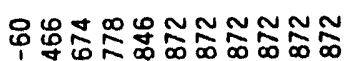

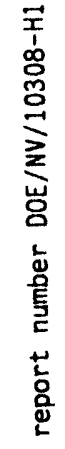

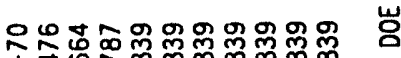

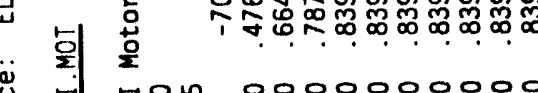
ờ 


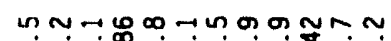

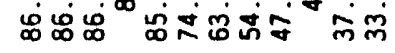

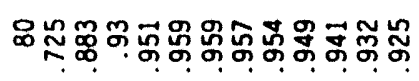

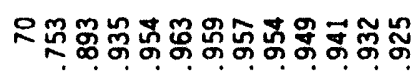

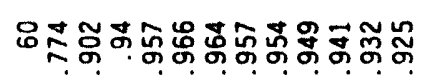

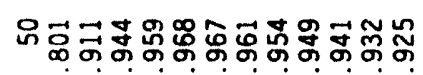

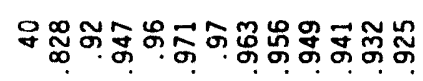

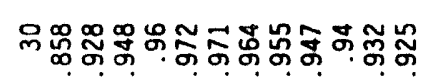

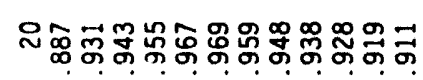

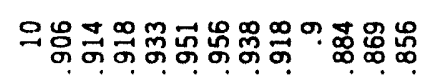

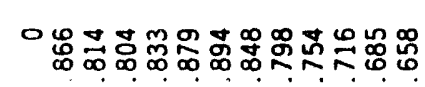

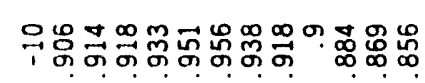

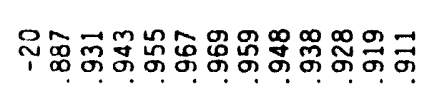

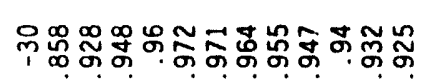

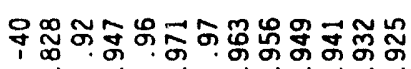

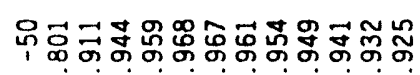

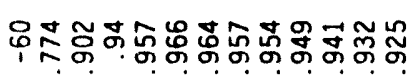

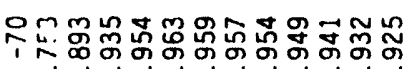

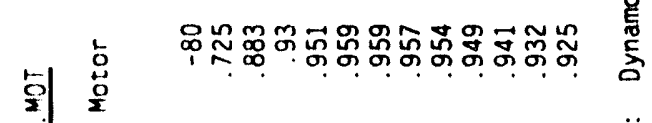

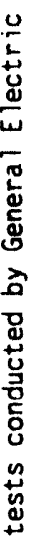

분 


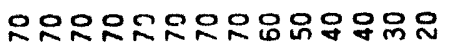

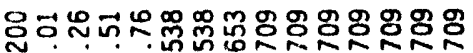

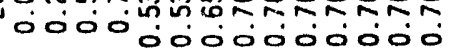

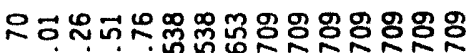
000000000000

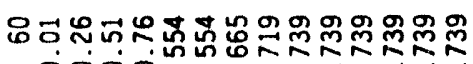
o000 00000

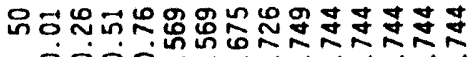

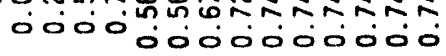

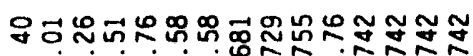

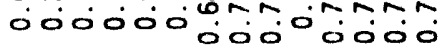

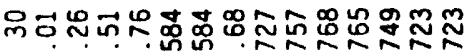

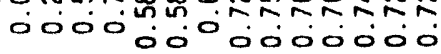

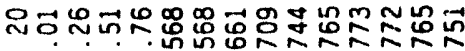

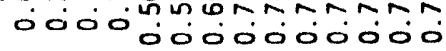

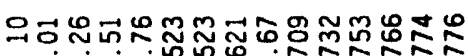
0000 0000000000

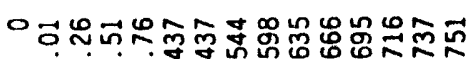
o000 000000000

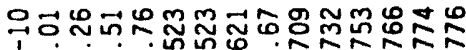

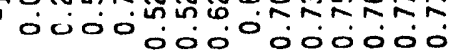

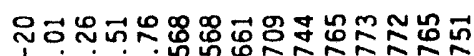

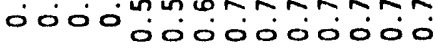

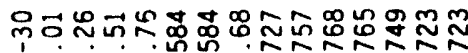

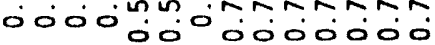

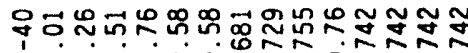

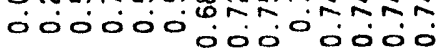

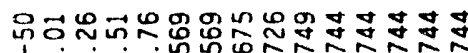

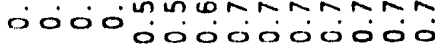

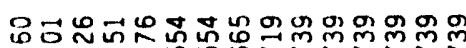

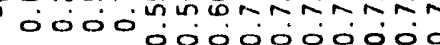

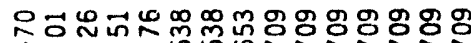

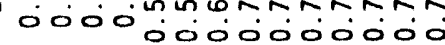

궁요

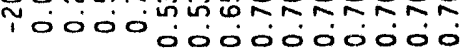




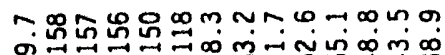

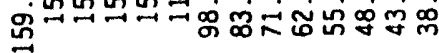

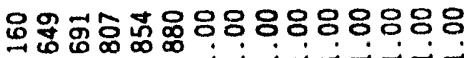

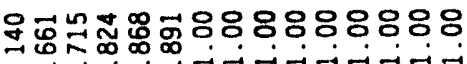

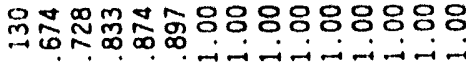

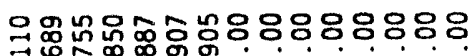

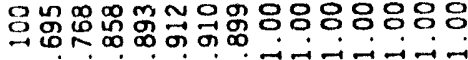

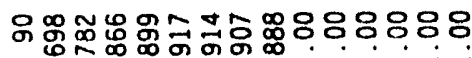

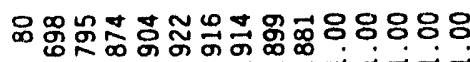

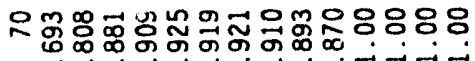

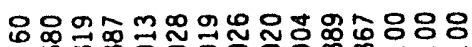

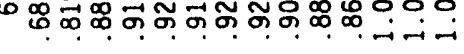

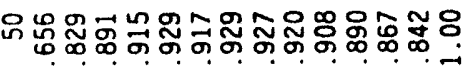

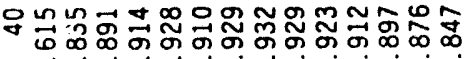

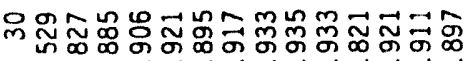

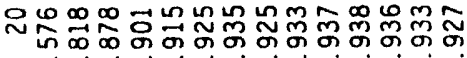

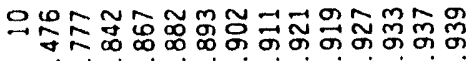

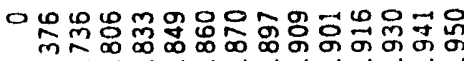

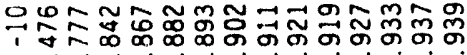

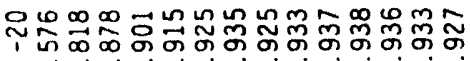

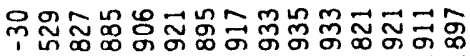

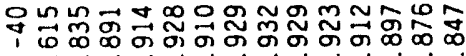

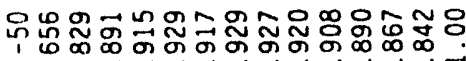

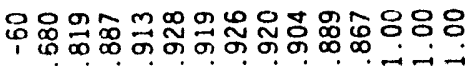

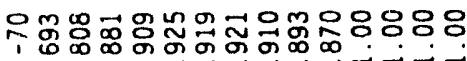

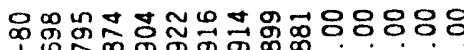

1. -

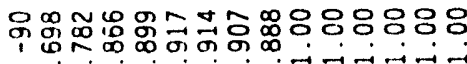

○in

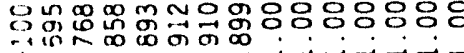

1 ㄱ․․․

떴

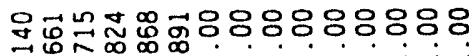

†.

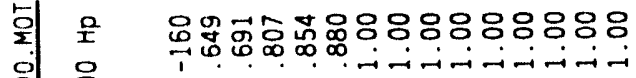

의 음

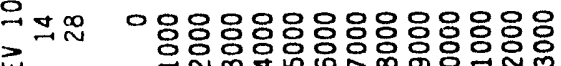

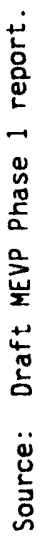




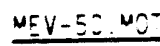

MEV 50Hp Motor (Estimated)

$\vdots 4$
23

$\begin{array}{rrrrrrrrrr}23 & & & & & & & & \\ & -110 & -100 & -90 & -80 & -70 & -60 & -50 & -40 & -30 \\ 0 & .778 & .777 & .775 & .771 & .761 & .742 & .713 & .667 & .597 \\ 1000 & .847 & .857 & .866 & .875 & .883 & .891 & .897 & .901 & .900 \\ 2000 & .911 & .916 & .921 & .926 & .931 & .934 & .937 & .937 & .933 \\ 3000 & 1.00 & .938 & .942 & .945 & .948 & .950 & .945 & .951 & .947 \\ 4000 & 1.00 & .943 & .953 & .956 & .958 & .960 & .960 & .960 & .956 \\ 5000 & 1.00 & 1.00 & 1.00 & 1.00 & 1.00 & .957 & .955 & .953 & .947 \\ 6000 & 1.00 & 1.00 & 1.00 & 1.00 & 1.00 & 1.00 & .959 & .960 & .959 \\ 7000 & 1.00 & 1.00 & 1.00 & 1.00 & 1.00 & 1.00 & .957 & .960 & .962 \\ 8000 & 1.00 & 1.00 & 1.00 & 1.00 & 1.00 & 1.00 & 1.00 & .961 & .962 \\ 9000 & 1.00 & 1.00 & 1.00 & 1.00 & 1.00 & 1.00 & 1.00 & .955 & .959 \\ 10000 & 1.00 & 1.00 & 1.00 & 1.00 & 1.00 & 1.00 & 1.00 & 1.00 & .956 \\ 11000 & 1.00 & 1.00 & 1.00 & 1.00 & 1.00 & 1.00 & 1.00 & 1.00 & .974 \\ 12000 & 1.00 & 1.00 & 1.00 & 1.00 & 1.00 & 1.00 & 1.00 & 1.00 & .95 \\ 13000 & 1.00 & 1.00 & 1.00 & 1.00 & 1.00 & 1.00 & 1.00 & 1.00 & .942\end{array}$

$12000 \quad 1.00 \quad 1.00 \quad 1.00 \quad 1.00 \quad 1.00 \quad 1.00 \quad 1.001 .00$

$13000 \quad 1.00 \quad 1.00 \quad 1.00 \quad 1.00 \quad 1.00$

Source: Draft MEVP Phase 1 report.

\section{MEV-75.MOT}

MEV $75 \mathrm{Hp}$ Motor

14

$\begin{array}{llllllllllllllllllllllllllllll}28 & 150 & -130 & -110 & -100 & -90 & -80 & -70 & -60 & -50 & -40 & -30 & -20 & -10 & 0 & 10 & 20 & 30 & 40 & 50 & 60 & 70 & 80 & 90 & 100 & 110 & 120 & 130 & 150\end{array}$

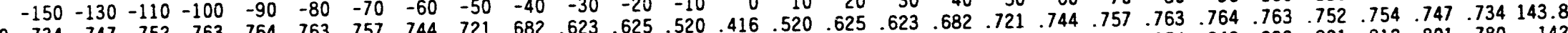

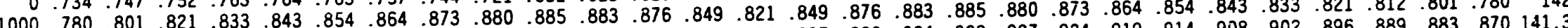

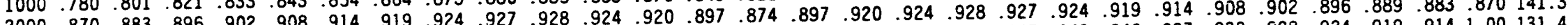

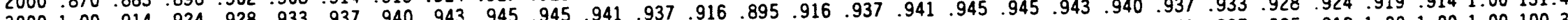

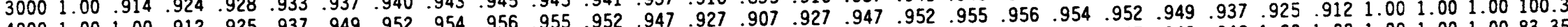

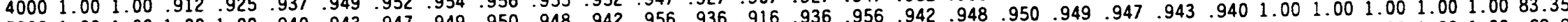
$50001.001 .001 .001 .001 .940 .943 .947 .949 .950 .948 .942 .950 .9343937 .943 \quad 950 \quad 955 \quad 955953 \quad 948 \quad 9421.001 .001 .001 .001 .001 .001 .00 \quad 69.8$

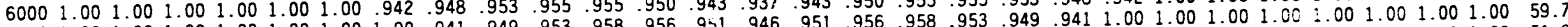

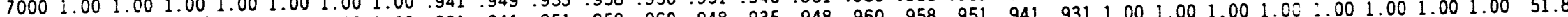

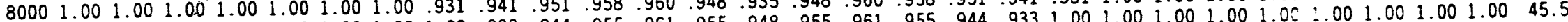

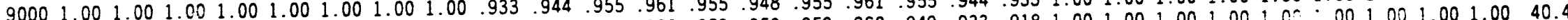

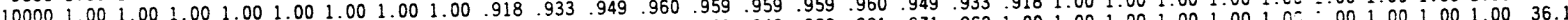

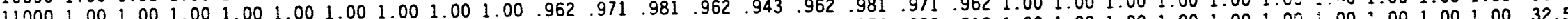

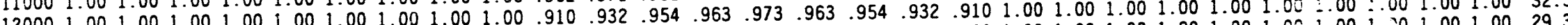

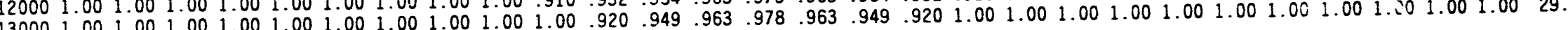

Source: Draft MEVP Phase 1 report. 


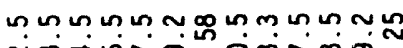
กี่

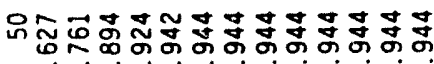
0ं0000000000

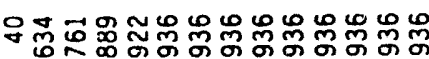
00000000000

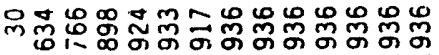

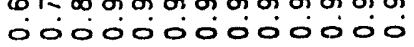

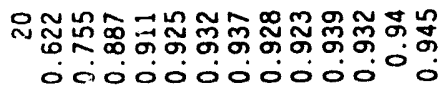

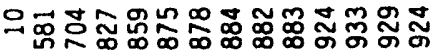

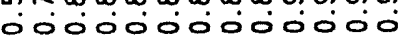

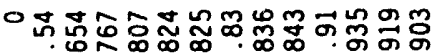

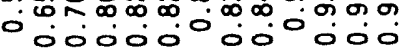

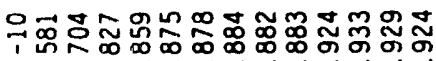
00000000000

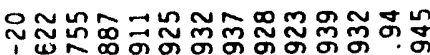
ió00000000

요요

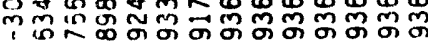
ió00000ं0ं0

品 00000000000

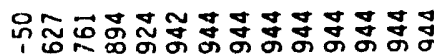

ᄂ 
APPENDIX E

SIMPLEV INVERTER/CONTROLLER FILES

E-1 


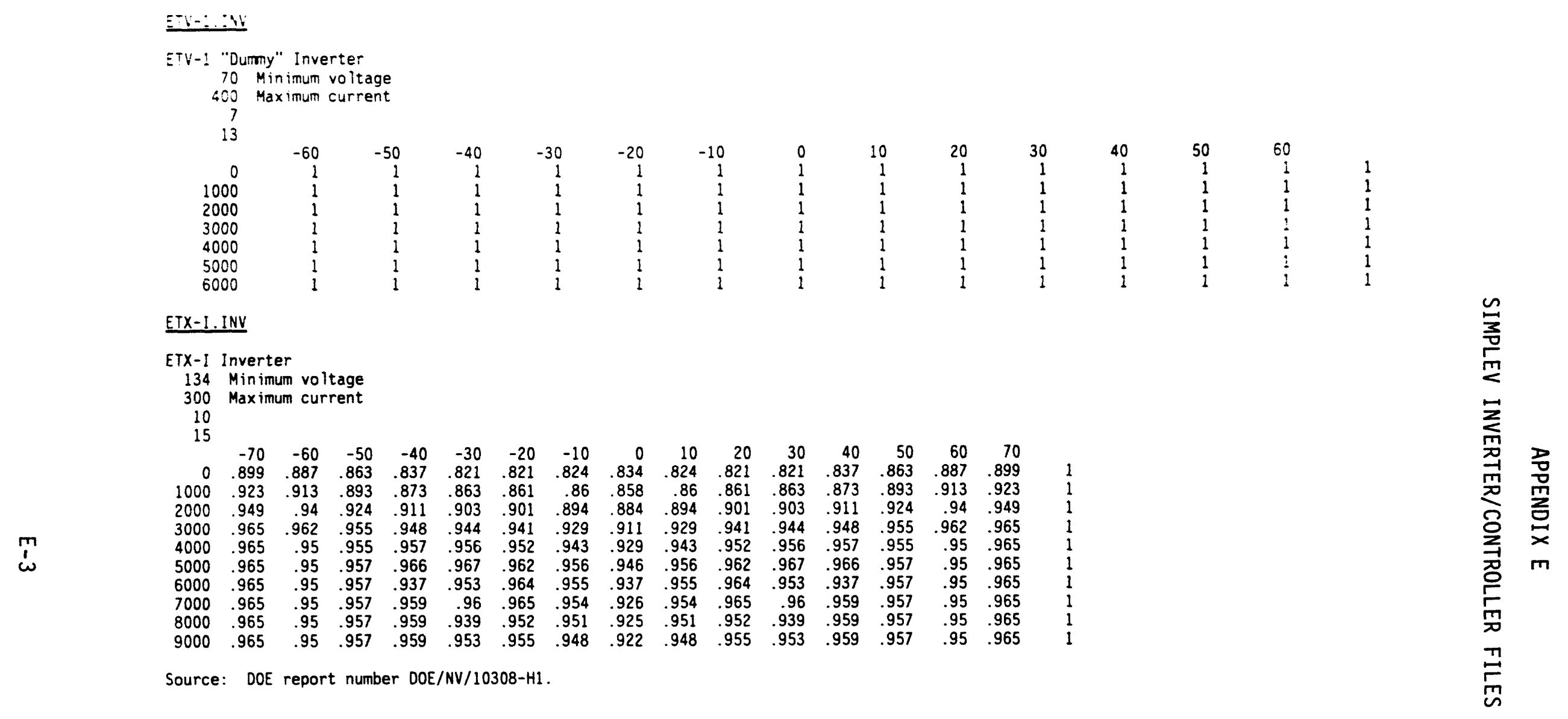




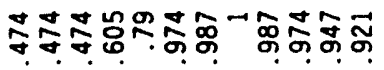

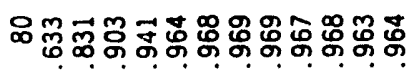

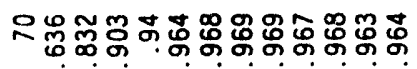

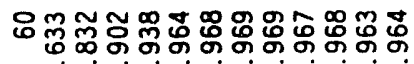

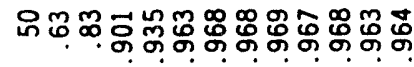

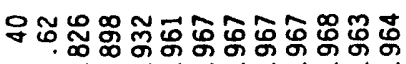

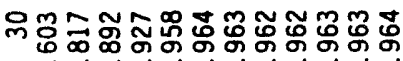

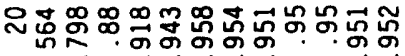

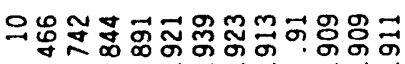

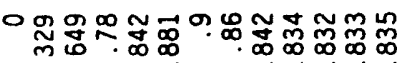

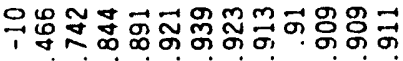

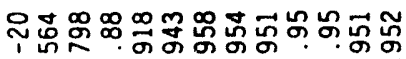

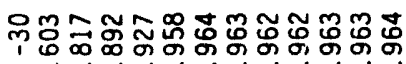

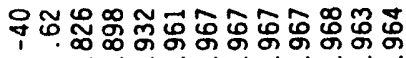

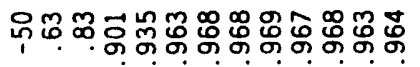

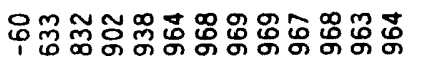

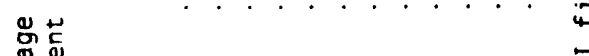

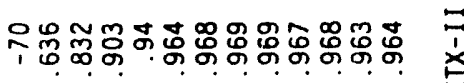

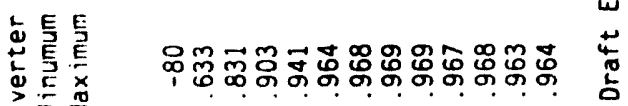

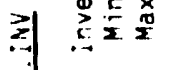

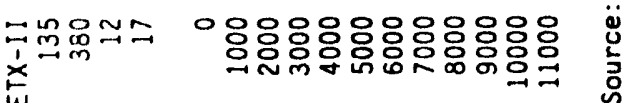




\section{IDSEP. INV}

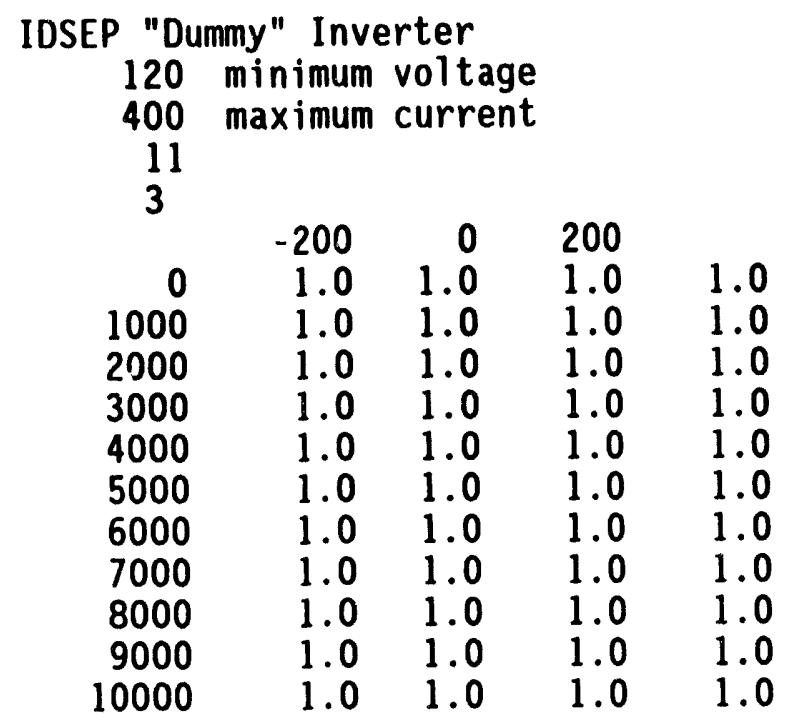




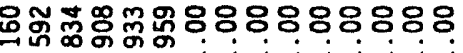

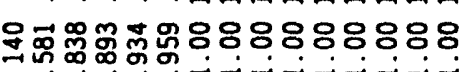

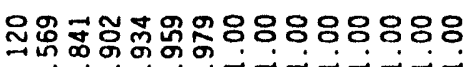

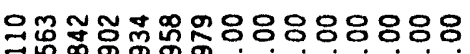

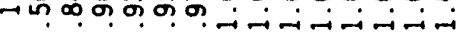

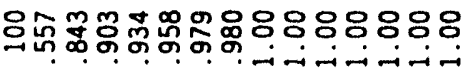

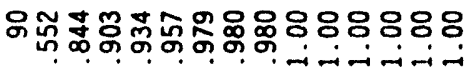

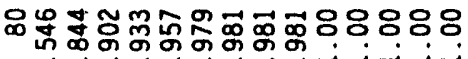

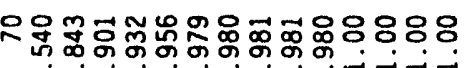

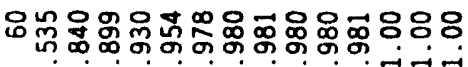

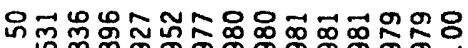

ON

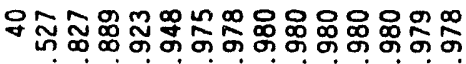

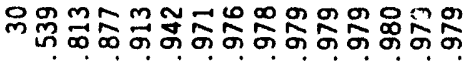

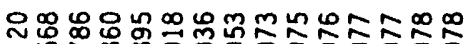

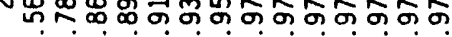

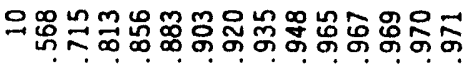

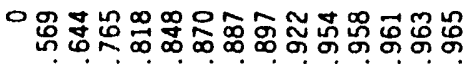

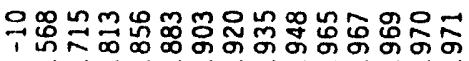

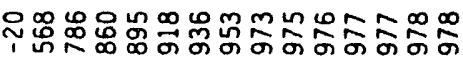

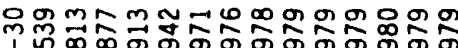

ㅇำ

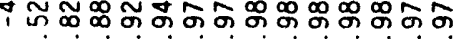

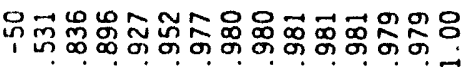

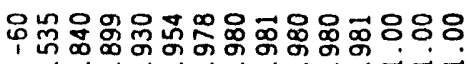

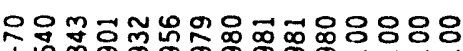

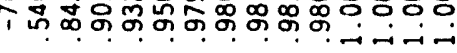

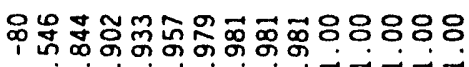

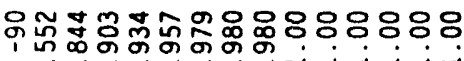

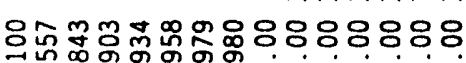

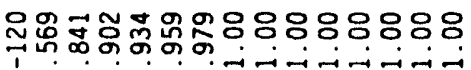

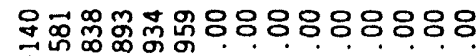

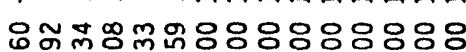

앵ํำ

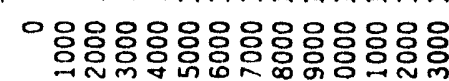

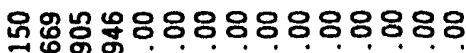

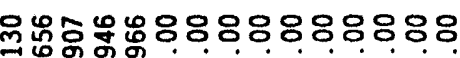

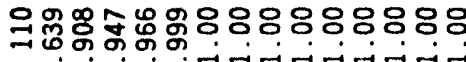

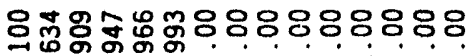

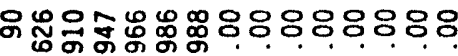

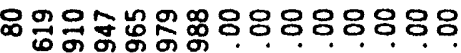

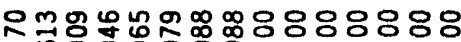

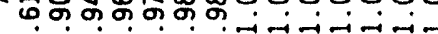

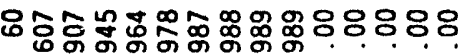

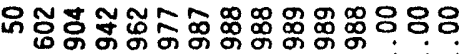

웅

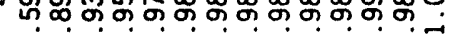

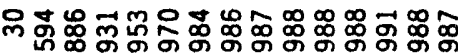

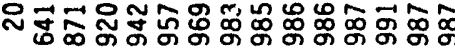

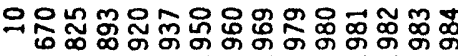

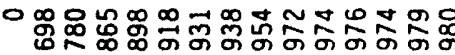

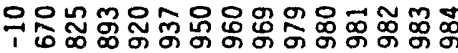

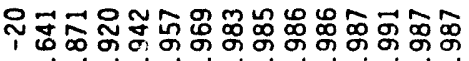

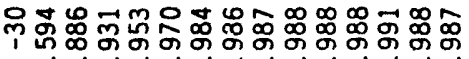

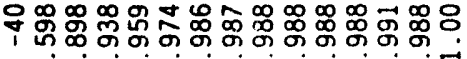

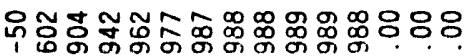

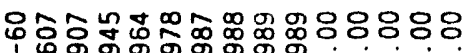

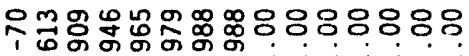

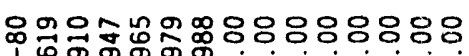
(1)

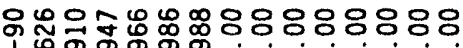

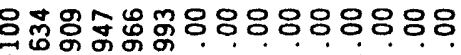

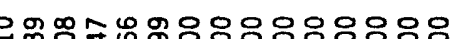
७

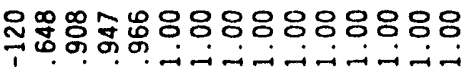

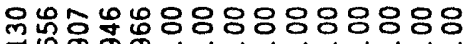
†

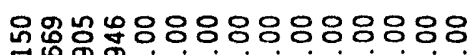




\section{$M=V-50 . I N V$}

MEVP 50 hp inverter

228 Minimum voltage

330 Maximum current

14

$\begin{array}{rrrrrrrrrrrrrrrrrrrrrrrrrr}-110 & -100 & -90 & -80 & -70 & -60 & -50 & -40 & -30 & -20 & -10 & 0 & 10 & 20 & 30 & 40 & 50 & 60 & 70 & 80 & 90 & 100 & 110\end{array}$

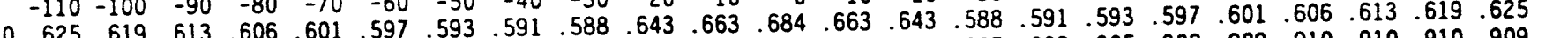

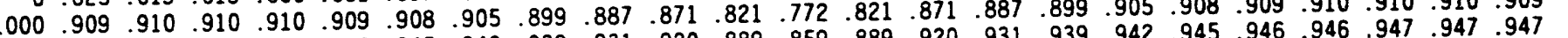

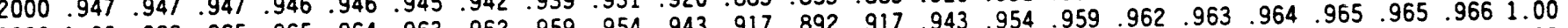

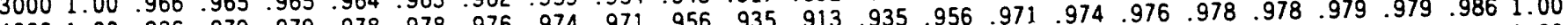

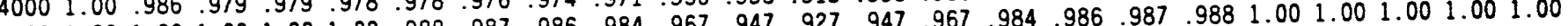
$50001.001 .001 .001 .001 .00 \quad 988.987 .986 .984 .967 .947 .927 .957 .977 .986 .987 .9881 .001 .001 .001 .001 .001 .00$

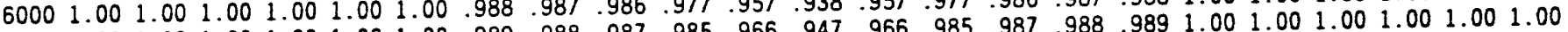

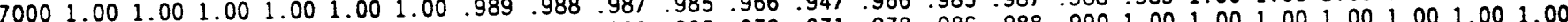

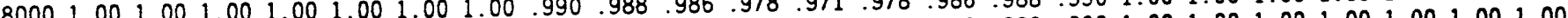

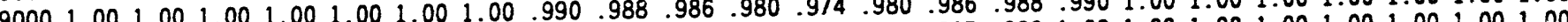

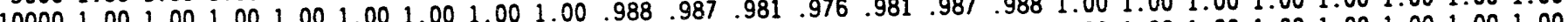

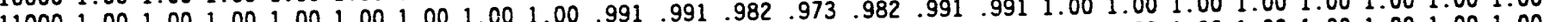

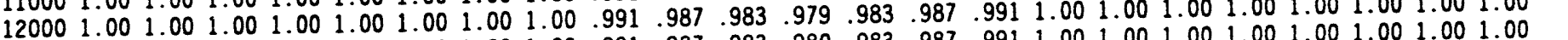

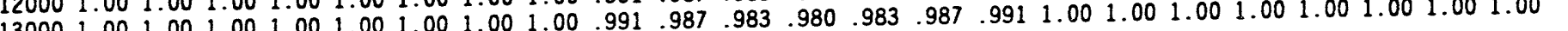

130001.001 .001 .001 .001 .001 .001 .001 .00 .991 .987

Source: Draft MEVP Phase 1 report - Ford Motor Company.

\section{IB-1.INV}

$\begin{gathered}\text { TB-1 Inverter } \\ 120 \\ 400\end{gathered}$
13

Source: Eaton Corporation dydamometer test results. 
APPENDIX $F$

SIMPLEV BATTERY FILES

\section{F-1}




\section{SIMPLEV BATTERY FILES}

\section{ET-205. BTY}

3ET -205

3 cells per module

32.2 module wt $(\mathrm{kg})$

205 Ah capacity

478.8499 Peukert constant

-0.23703 Peukert exponent

$\begin{array}{rrr}5 & \text { "C" } & \text { rating time, } h \\ 0 & 2.105 & -0.00099 \\ 0.1 & 2.089 & -0.00098 \\ 0.2 & 2.074 & -0.00096 \\ 0.3 & 2.055 & -0.00098 \\ 0.4 & 2.033 & -0.001 \\ 0.5 & 2.003 & -0.00103 \\ 0.6 & 1.986 & -0.00111 \\ 0.7 & 1.973 & -0.00121 \\ 0.8 & 1.955 & -0.00134 \\ 0.9 & 1.934 & -0.00155 \\ 1 & 1.909 & -0.00198\end{array}$

Source: Derived from INEL Battery Lab tests. 
6ETX-100.BTY

$6 \mathrm{ETX}-100$

6 cells per module

39.6 module wt $(\mathrm{kg})$

100 Ah capacity

196.1282 Peukert constant

-0.22009 Peukert exponent

5 " $C$ " rating time, $h$
2.147233
$-0.00157$
0.1
2.119762
$-0.00151$
$0.2 \quad 2.092291$
$-0.00146$
$0.3 \quad 2.087724$
$-0.00155$
0.42 .083156
$-0.00163$
$0.5 \quad 2.082427$
$-0.00177$
$0.6 \quad 2.081698$
$-0.00186$
$0.7 \quad 2.078841$
$-0.00202$
$0.8 \quad 2.075985$
$-0.00202$
0.9
2.057079
2.038174
$-0.0022$
$-0.00216$

Source: Derived from INEL Battery Lab tests.

\section{V180.BTY}

$6 V 180$

3 cells per module

31.802 module wt $(\mathrm{kg})$

140 Ah capacity

473.9651 Peukert constant

-0.31438 Peukert exponent

$\begin{array}{rrr}3 & \text { "C" rating time, } h \\ 0 & 2.1434 & -0.00091 \\ 0.1 & 2.1241 & -0.0009 \\ 0.2 & 2.1049 & -0.0009 \\ 0.3 & 2.0694 & -0.00085 \\ 0.4 & 2.0438 & -0.00085 \\ 0.5 & 2.028 & -0.00089 \\ 0.6 & 2.0184 & -0.00098 \\ 0.7 & 2.0088 & -0.00108 \\ 0.8 & 1.9685 & -0.00114 \\ 0.9 & 1.9206 & -0.00144 \\ 1 & 1.8651 & -0.00196\end{array}$

Source: Derived from INEL Battery Lab tests. 


\section{ALC02200,BTY}

\begin{tabular}{|c|c|c|}
\hline $\begin{array}{r}\text { ALCO-220 } \\
3 \\
30.2 \\
115 \\
314.138 \\
-0.21801 \\
3 \\
0 \\
0.1 \\
0.2 \\
0.3 \\
0.4 \\
0.5 \\
0.6 \\
0.7 \\
0.8\end{array}$ & $\begin{array}{l}\text { cells per module } \\
\text { module wt (kg) } \\
\text { Ah capacity } \\
\text { Peukert constant } \\
\text { Peukert exponent } \\
\text { C" rating time, } \\
2.08 \\
2.075 \\
2.07 \\
2.057 \\
2.044 \\
2.022 \\
2.004 \\
1.981 \\
1.949 \\
1.913 \\
1.884\end{array}$ & $\begin{array}{l}t \\
t \\
h \\
-0.0012 \\
-0.0012 \\
-0.00121 \\
-0.00121 \\
-0.00121 \\
-0.00122 \\
-0.00124 \\
-0.00124 \\
-0.00131 \\
-0.00144 \\
-0.00176\end{array}$ \\
\hline
\end{tabular}

Source:

\section{B-11-1.BTY}

PTI B-11 Single module

1 Cells per module - data

277 module weight, $\mathrm{kg}$

155 Ah capacity

155 Peukert constant

0 Peukert exponent

3 C" rating time, $h$

$\begin{array}{rrr}0 & 187.2 & -0.16 \\ 0.1 & 187.2 & -0.16 \\ 0.2 & 187.2 & -0.16 \\ 0.3 & 187.2 & -0.16 \\ 0.4 & 187.2 & -0.16 \\ 0.5 & 187.2 & -0.16 \\ 0.6 & 181.8 & -0.16 \\ 0.7 & 176.4 & -0.16 \\ 0.8 & 171 & -0.16 \\ 0.9 & 165.6 & -0.16 \\ 1 & 160.2 & -0.16\end{array}$




\section{B-11-2,BTY}

PTI B-11 2 parallel modules

1 cells per module

574 module wt $(\mathrm{kg})$

310 Ah capacity

310 Peukert constant

0 Peukert exponent

3 C" rating time, $h$

$\begin{array}{rrr}0 & 187.2 & -0.08 \\ 0.1 & 187.2 & -0.08 \\ 0.2 & 187.2 & -0.08 \\ 0.3 & 187.2 & -0.08 \\ 0.4 & 187.2 & -0.08 \\ 0.5 & 187.2 & -0.08 \\ 0.6 & 181.8 & -0.08 \\ 0.7 & 176.4 & -0.08 \\ 0.8 & 171 & -0.08 \\ 0.9 & 165.6 & -0.08 \\ 1 & 160.2 & -0.08\end{array}$

CSPL.BTY

CSPL Na/S

1 cells per module

696 module wt $(\mathrm{kg})$

300 Ah capacity

300 Peukert constant

0 Peukert exponent

3 C" rating time, $h$

$\begin{array}{lll}0 & 198.9 & -0.1725\end{array}$

$\begin{array}{lll}0.1 & 198.9 & -0.132\end{array}$

$\begin{array}{lll}0.2 & 198.9 & -0.131\end{array}$

$\begin{array}{lll}0.3 & 198.6 & -0.13\end{array}$

$\begin{array}{lll}0.4 & 198.2 & -0.129\end{array}$

$\begin{array}{lll}0.5 & 198 & -0.128\end{array}$

$\begin{array}{lll}0.6 & 197.3 & -0.127\end{array}$

$\begin{array}{lll}0.7 & 195.9 & -0.126\end{array}$

$\begin{array}{lll}0.8 & 192.9 & -0.125\end{array}$

$0.9 \quad 188.3 \quad-0.124$

$1 \quad 183 \quad-0.123$

Source: Derived from ANL tests. 


\section{ED150P.BTY}

ED150P

6 cells per module

42 module wt $(\mathrm{kg})$

135 Ah capacity

329 Peukert constant

-0.23047 Peukert exponent

$\begin{array}{lcr}3 & \text { C" } & \text { rating time, } h \\ 0 & 2.048 & -0.0006 \\ 0.1 & 2.036 & -0.00058 \\ 0.2 & 2.028 & -0.0006 \\ 0.3 & 2.02 & -0.00061 \\ 0.4 & 2.012 & -0.00068 \\ 0.5 & 2.006 & -0.00077 \\ 0.6 & 1.988 & -0.00088 \\ 0.7 & 1.968 & -0.00098 \\ 0.8 & 1.952 & -0.00112 \\ 0.9 & 1.912 & -0.0012 \\ 1 & 1.852 & -0.00138\end{array}$

Source: Derived from INEL Battery Lab tests.

\section{EV5T.BTY}

EV5T

3 cells per module

32.6 module wt $(\mathrm{kg})$

137 Ah capacity

551.0427 Peukert constant

-0.33842 Peukert exponent

5 C" rating time, $h$

$\begin{array}{lll}0 & 2.136 & -0.00144 \\ 0.1 & 2.127 & -0.00149 \\ 0.2 & 2.118 & -0.00153 \\ 0.3 & 2.103 & -0.00151 \\ 0.4 & 2.088 & -0.00151 \\ 0.5 & 2.071 & -0.00153 \\ 0.6 & 2.053 & -0.00151 \\ 0.7 & 2.028 & -0.00152 \\ 0.8 & 2.006 & -0.00162 \\ 0.9 & 1.974 & -0.00176 \\ 1 & 1.942 & -0.00187\end{array}$

Source: Derived from INEL Battery Lab tests. 


\section{NIF170.BTY}

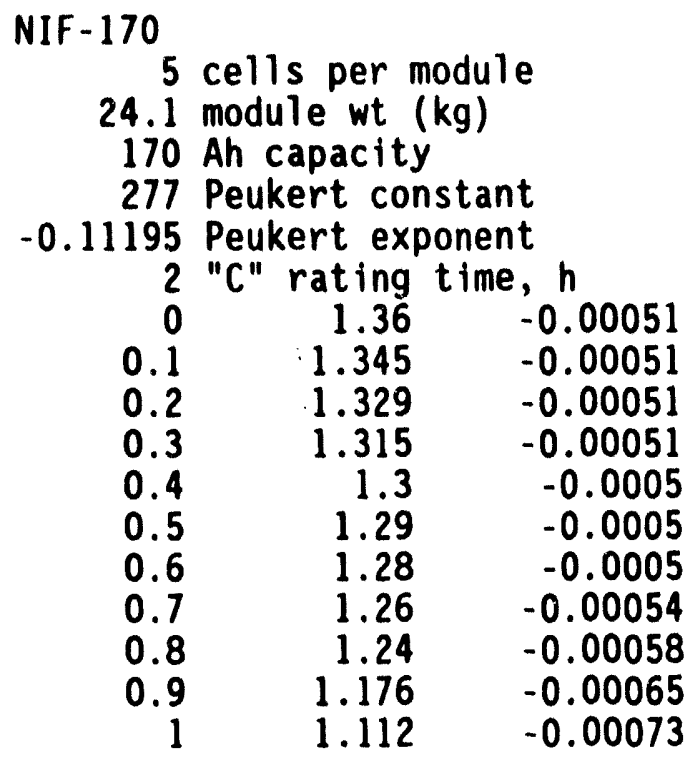

Source: Derived from INEL Battery Lab tests. 

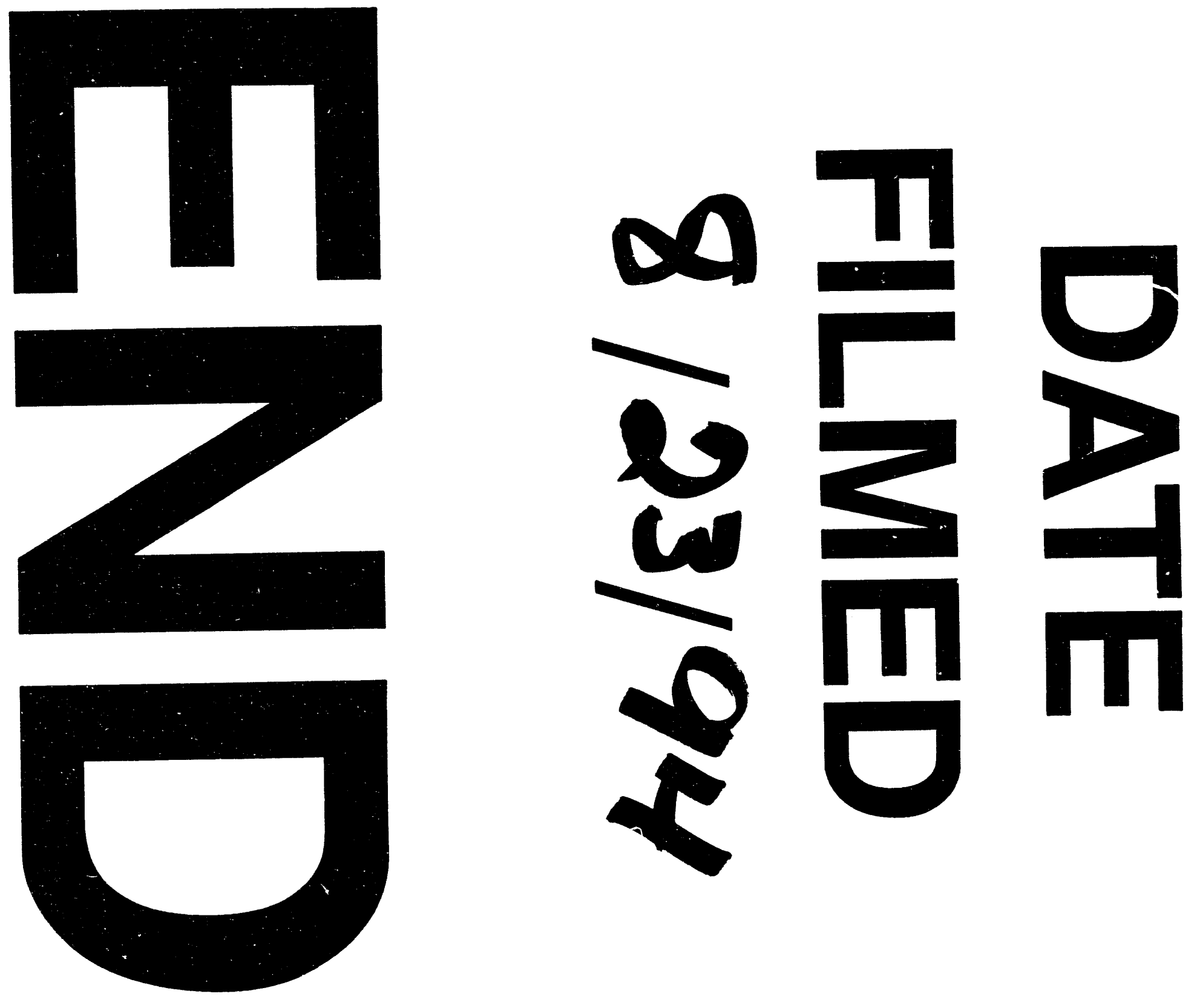
